\title{
Tempting the Chinese Dragon: Political Economy of Chinese Tourism to New Zealand
}

By

Elizabeth Gaspar

A thesis submitted to the Victoria University of Wellington in fulfilment of the requirements for the degree of Master of Arts in International Relations 


\section{Abstract}

This thesis explores the international political economy (IPE) of outbound Chinese tourism within the context of New Zealand. New Zealand as a case study shows the impact of tourism changes on a nation reliant on tourism. It demonstrates the growing impact of China as an international economic and political power. It utilizes a mixed method approach to conduct a document-based and literature-based investigation and concludes Chinese tourism is reshaping the New Zealand political economy. New Zealand marketing strategies have shifted to cater to the Chinese market but could expand to meet these different interests, including culturescapes and collectivism. The economic impact of Chinese tourism has been broadly positive for New Zealand but far more could be done to leverage tourism. New Zealand is an expensive destination and could target high value tourists. This would require more quality offerings and making full use of the linkages between tourism and trade. More can be done to maximise the value added by e-commerce post visitation. The growth of Chinese tourism has uncovered deficiencies in New Zealand and stimulated debates around how to ensure the New Zealand tourism industry is sustainable. New Zealand policymakers and commentators are debating how to shift tourists to the shoulder seasons and the regions and how to maintain sustainable tourism numbers. The rise of Chinese inbound tourism to New Zealand has also uncovered an infrastructure deficit. By examining the overall state of Chinese tourism to New Zealand, this thesis creates a comprehensive assessment of how Chinese outbound tourism is shaping New Zealand's political economy. 


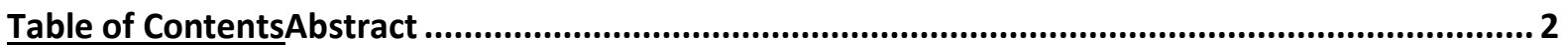

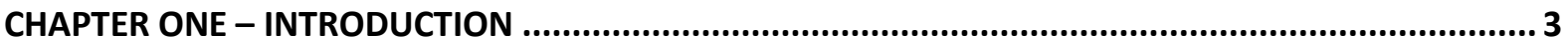

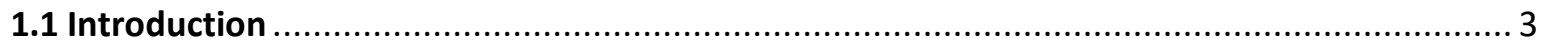

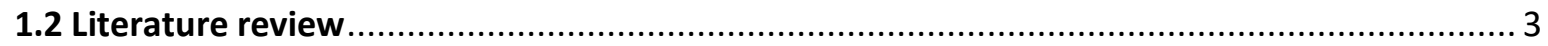

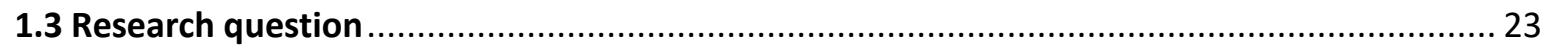

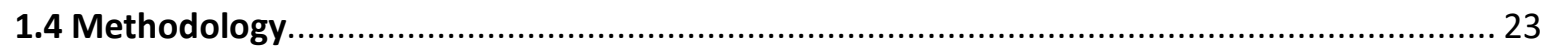

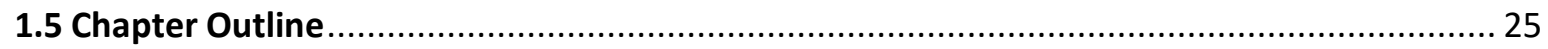

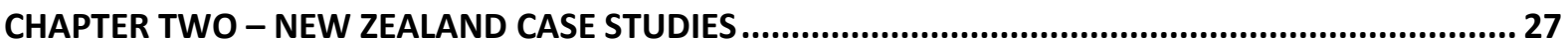

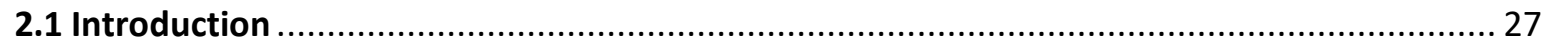

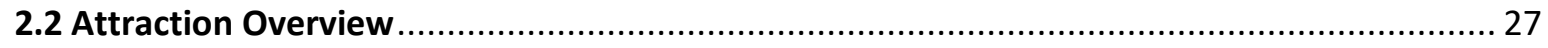

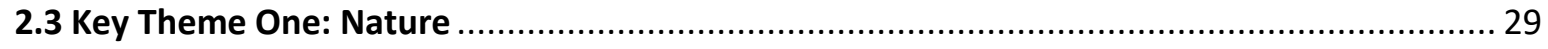

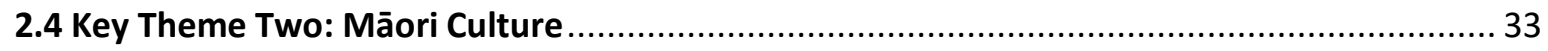

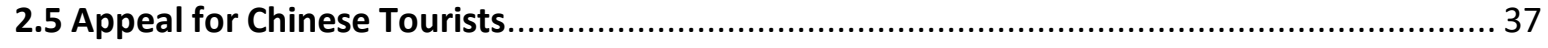

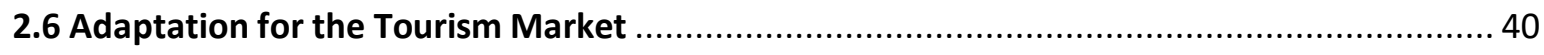

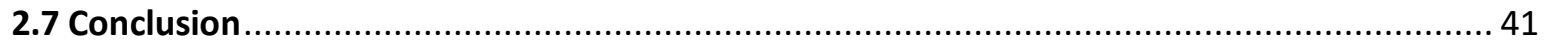

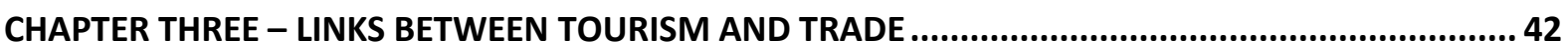

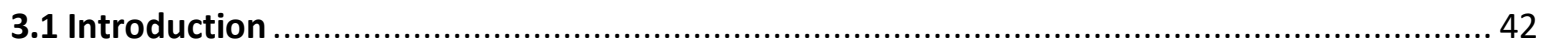

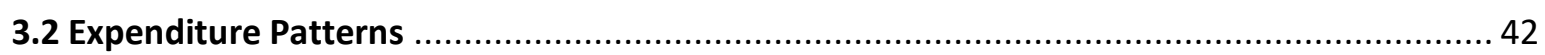

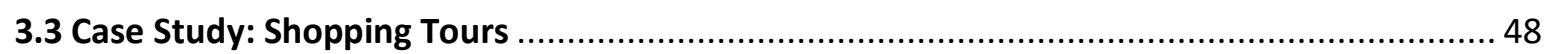

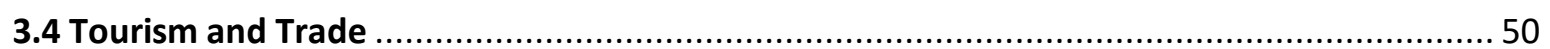

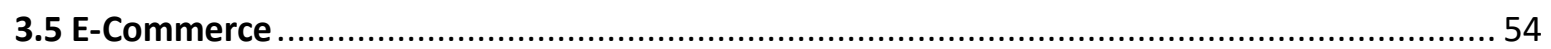

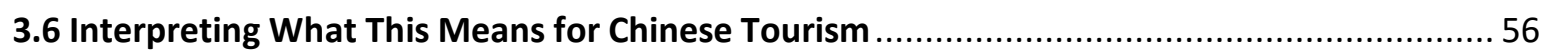

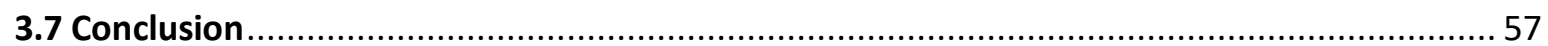

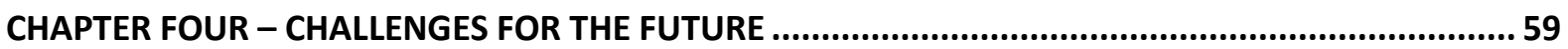

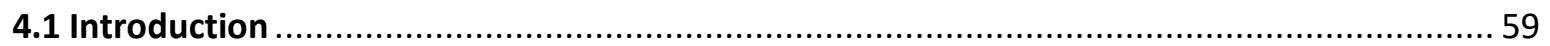

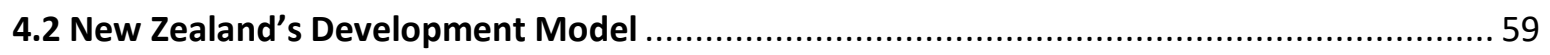

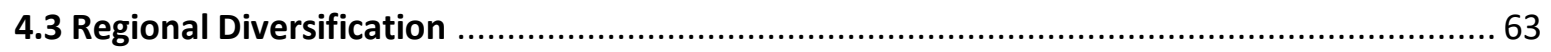

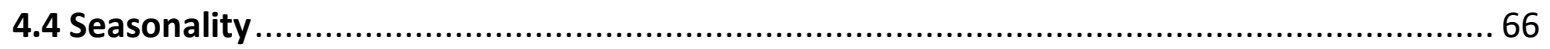

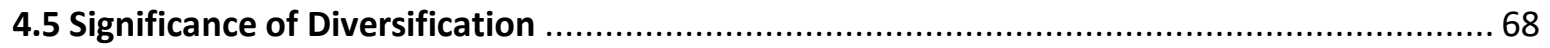

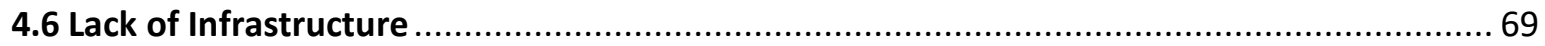

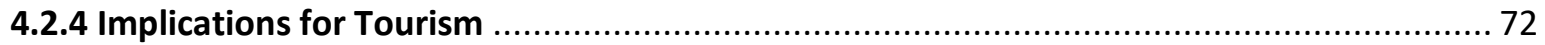

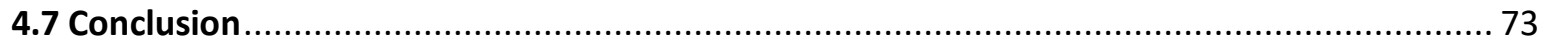

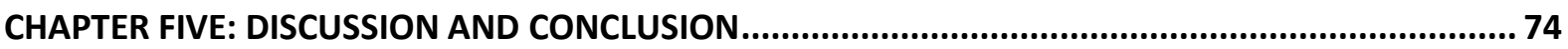

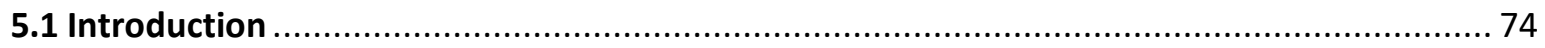

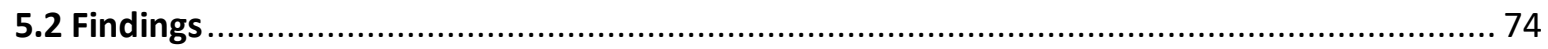

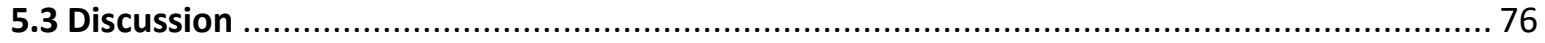


5.3.3 Returning Post COVID-19

84

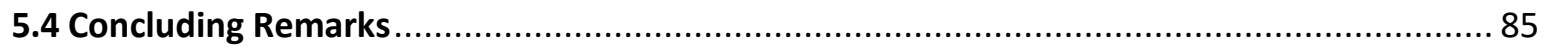

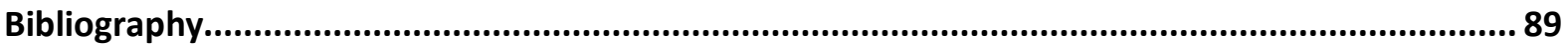




\section{CHAPTER ONE - INTRODUCTION}

\subsection{Introduction}

By examining the overall state of Chinese tourism to New Zealand, this thesis displays how Chinese outbound tourism is shaping New Zealand's political economy. Tourism is an important sector of New Zealand's economy, and attracts many international tourists relative to the country's population size. In 2016, tourism attracted a record 1.8 million holidaymakers while total arrivals reached 3.5 million. ${ }^{1}$ Tourist receipts from international visitors increased $44 \%$ between 2013 and 2018 to over $\$ 14.5$ billion NZD. ${ }^{2}$ Tourism accounts for over $8 \%$ of total employment. ${ }^{3} \mathrm{~A}$ large proportion of this growth can be attributed to the rise in Chinese tourism, which has grown significantly since 2010. In 2010, approximately 105,000 Chinese tourists visited New Zealand, which accounted for $5 \%$ of all international arrivals. This is comparable to the 450,000 who arrived in 2018 , accounting for $12 \%$ of arrivals. ${ }^{4}$ The growth of Chinese tourism has been swift and has contributed an estimated 1.5 billion NZD to New Zealand's economy every year. This massive market is only growing in prominence in Zealand's tourism industry and political economy, and its influence will be examined throughout this research.

\subsection{Literature review}

\subsubsection{International Political Economy}

This thesis places IPE at the centre of the discussion to serve as the base framework for understanding the tourism, political and economic relationship between New Zealand and China. IPE studies issues that arise from or are affected by the interaction of international politics, economics and social systems. ${ }^{5}$ It explores situations that arise from issues such as international trade, international finance, along with the consequences of economic globalization. ${ }^{6}$ The traditional IPE problématique frames the political economy in terms of international trade, international finance, political risk, globalization and hegemony. ${ }^{7}$ Thus, IPE considers all economic factors as important

\footnotetext{
${ }^{1}$ Tourism New Zealand. (2017). Year ends on high for tourism numbers. Retrieved from https://www.tourismnewzealand.com/news/year-ends-on-high-for-tourism-numbers/

${ }^{2}$ Tourism New Zealand. (2018) China, Market information about our Visitors and our Active Considerers. Retrieved from https://www.tourismnewzealand.com/media/3418/china-visitor-information.pdf

${ }^{3}$ Tourism New Zealand. (2019). About the tourism industry. Retrieved from https://www.tourismnewzealand.com/about/about-the-tourism-industry/ ${ }^{4}$ Ibid.

${ }^{5}$ Morton, R. (2014). Political economy experiments: introduction. The Economic Journal, 124(574), F129.

${ }^{6}$ Worth, O. (2013). Polanyi's magnum opus? Assessing the application of the counter-movement in international political economy. The International History Review, 35(4), 906.

${ }^{7}$ Veset, M. (n.d.). What is International Political Economy?. Retrieved from http://www2.ups.edu/ipe/whatis.pdf
} 
causes or consequences for the current international political system. ${ }^{8}$ This thesis relies on the framing of IPE in terms of domestic best interest, alongside soft power linkages to economic advancement. ${ }^{9}$ This suggests stronger economics translate into greater force in international arrangements. ${ }^{10}$ IPE suggests that the development of Chinese tourism will increase China's overall impact on IPE through its economic output, and that this warrants further understanding. ${ }^{11}$ This research questions the role of China's economic growth and the way it has created the potential for global change. This is therefore an examination of secondary influences on political power. Tourism was chosen as a case study to explore China's newfound influence globally and its influence on particular domestic economies in particular.

\subsubsection{Rise of China}

\subsubsection{Rise of China as Significant Economic Figure}

This section highlights the significance of China as a rising global economic power. This is a relatively new development for China. Prior to the initiation of economic reforms and trade liberalization under Deng Xiaoping, policies left the country poor, stagnant, centrally controlled and relatively isolated from the rest of the global economy. ${ }^{12}$ Since opening up to foreign trade and investment in 1979, China has been among the world's fastest-growing economies, with real annual GDP growth averaging 9.5\% up until 2018. This pace was described as "the fastest sustained expansion by a major economy in history. ${ }^{13 "}$ China has become the world's largest economy (on a purchasing power parity basis), manufacturer and merchandise trader. As China's economy has matured, its GDP growth has slowed significantly, from $14.2 \%$ in 2007 to $6.6 \%$ in $2018 .{ }^{14}$ The Chinese Communist Party (CCP) has embraced this slower economic growth, referring to it as the "new normal" and acknowledging the need for China to adjust its economic strategy. This includes more focus on private consumption, services, and innovation to drive economic growth. Overall, the growth of

\footnotetext{
${ }^{8}$ Martin, L. L., \& Frieden, J. (2003). International Political Economy: Global and Domestic Interactions. Political Science: The State of the Discipline, ed. I. Katznelson and HV Milner. New York: WW Norton. 118.

${ }^{9}$ Farrell, H., \& Newman, A. L. (2010). Making global markets: Historical institutionalism in international political economy. Review of International Political Economy, 17(4), 620.

${ }^{10}$ Richmond, O. P. (2017). The paradox of peace and power: Contamination or enablement?. International

Politics, 54(5), 637-658.

${ }^{11}$ Bräutigam, D., \& Xiaoyang, T. (2012). Economic statecraft in China's new overseas special economic zones: soft power, business or resource security?. International Affairs, 88(4), 799-816.

${ }^{12}$ Chang, D. (1988). China under Deng Xiaoping : political and economic reform. Basingstoke: Macmillan.

13 The World Bank. (2019). China Overview. Retrieved from https://www.worldbank.org/en/country/china/overview

${ }^{14}$ Congressional Research Service. (2019) China's Economic Rise: History, Trends, Challenges, and Implications for the United States. Retrieved from https://fas.org/sgp/crs/row/RL33534.pdf
} 
China as an economic figure is gaining increasing significance, which is important because of the role it plays in shaping the international economic system.

\subsubsection{Rise of China as an Important International Political Actor}

China has also grown as an international political figure. Alongside massive economic growth there has been a divergence from 'Keeping a Low Profile' (KLP) to 'Striving for Achievement' (SFA) as China's national strategy. ${ }^{15}$ SFA emphasizes strategic cooperation based on regional and international common interests while KLP based strategic cooperation on improving mutual trust. China is working to show greater initiative in developing strategic cooperation with its neighbours. The focus of SFA is to make more allies, instead of focusing on economic development. China's foreign policy has involved increasing political engagement as this strategy evolves. This can be seen in the Sino-American relationship, where Beijing is 'pushing for constructing a new model of major power... and achieving healthy interactions and win-win cooperation. ${ }^{16 \prime}$ In March 2013, President Xi Jingping attended the BRICS (Brazil, Russia, India, China and South Africa) summit, highlighting an interest in a variety of nations, outside of the traditional Western powers. ${ }^{17}$ China is engaging more in international politics than it was during the KLP period. As one of the largest economic powers in the world today, China has a lot of diplomatic force due to its economic influence, shaping the international political sphere.

\subsubsection{Challenging the Current Global Order}

There are several ways China's challenge to the status quo in international relations can be examined. The first is through soft power. China's overall global soft power currently remains weak. ${ }^{18}$ China's cultural products -art, film, literature, music and design-are still relatively unknown outside of China and do not ye) have the power to set global cultural trends. ${ }^{19}$ Second is diplomacy. Beijing's high-level diplomacy is generally more symbolic than meaningful. ${ }^{20}$ Chinese diplomacy has two major goals: the first being to enhance the CPP's legitimacy among domestic audiences by showing Chinese leaders socializing with the international political elite. The second

\footnotetext{
${ }^{15}$ Yan, X. (2014). From keeping a low profile to striving for achievement. The Chinese Journal of International Politics, 7(2), 166.

16 Ibid. 172.

${ }^{17}$ No Author. (n.d.). BRICS - Brazil, Russia, India, China, South Africa. Retrieved from http://www.itamaraty.gov.br/en/politica-externa/mecanismos-inter-regionais/7505-brics-brazil-russia-indiachina-south-africa

18 Johnston, A. I. (2017). Is Chinese Nationalism Rising? Evidence from Beijing. International Security, $41(3), 40$. ${ }^{19}$ Ibid.

${ }^{20} \mathrm{CaO}, \mathrm{X}$. (2015). Challenges and potential improvements in the policy and regulatory framework for sustainable tourism planning in China: The case of Shanxi Province. Journal of Sustainable Tourism, 23(3), 455476.
} 
aim is to signal to the international community that China has returned as a global power after a period of inaction. ${ }^{21}$ Overall, China does not take the same leadership role in the international political sphere that the United States (US) does. The US still holds the leading position within the international political realm and while China may pose a challenge to the US dominance in Asia (due to the centrality of the Asian economy in China), it will still be a while before China can mount a challenge to the status quo worldwide.

In addition to soft power and diplomacy, China's military presence requires consideration. China's military modernization has been growing steadily for the past twenty-five years. ${ }^{22}$ It now has the world's second-largest military budget (in 2016, China's budget was \$230 billion NZD, compared with $\$ 964$ billion NZD from the US). ${ }^{23}$ Asia's ties to the US has strained over this period due to China's growing influence. ${ }^{24}$ However, China's military forces still possess no conventional power projection capabilities beyond its immediate neighbours. China has just one military base abroad (in Djibouti), no long-range logistics or communications lines and armed ground forces are not equipped for rapid long-range deployment. ${ }^{25}$ Overall, in both military and soft power, China does not yet have the capacities to pose a viable challenge to the US, but it is undeniable that China has gained a lot of influence since 1979, particularly in Asia.

\subsubsection{Debate}

The rise of China has been an important discussion topic among academics for the past few decades following Deng Xiaoping's economic reforms. There is no debate that China has experienced massive economic growth. What is debated, is how this rise has adjusted the way China interacts with the rest of the world and vice versa. There are two sides to this debate; one side argues China is pursuing their own interests and this is changing the way other nations interact with them. In many parts of the world, China's influence takes place through economic channels. Because China is a central point of a majority of Asian supply chains, its influence is even further pronounced. ${ }^{26}$

\footnotetext{
${ }^{21}$ Nicolas, F., \& Buchanan, D. (2016). China and the global economic order: A discreet yet undeniable contestation. China Perspectives, 106(2), 12.

${ }^{22}$ Acharya, A. (2014). Power shift or paradigm shift? China's rise and Asia's emerging security order. International Studies Quarterly, 58(1), 162.

${ }^{23}$ National Priorities Projects. (2016). Military Spending by the United States. Retrieved from https://www.nationalpriorities.org/campaigns/military-spending-united-states/

${ }^{24}$ Nicolas, F., \& Buchanan, D. (2016). China and the global economic order: A discreet yet undeniable contestation. China Perspectives, 106(2), 10.

${ }^{25}$ Aljazeera. (2019). China to increase overseas military bases: Pentagon report. Retrieved from https://www.aljazeera.com/news/2019/05/china-increase-overseas-military-bases-pentagon-report$190503065146243 . \mathrm{html}$

${ }^{26}$ Sznajderska, A. (2019). The role of China in the world economy: evidence from a global VAR model. Applied Economics, 51(15), 1585.
} 
Through controlling the supply flow and supply chain, China has gained increased relevance in the economic sphere, which it can leverage to its advantage. China's influence over economic lines links with its growing influence in the IPE as it influences the economic distribution of the Asian region. Combined with Beijing's military modernization, China's economic power is having serious geopolitical implications as it becomes more assertive. ${ }^{27}$

China is also becoming a more active member of the international political community. In international politics, China has become more involved in discussions regarding non-interference and territorial disputes. ${ }^{28}$ China has presented itself as a leading voice for the developing world and is challenging traditional development leaders in less economically rich countries. ${ }^{29}$ Cooperation between China and less developed nations allows for greater negotiation by poorer governments to secure the best investments, loans, and aid projects for them. ${ }^{30}$ This allows China to shape international discourse and this can influence international and domestic ideas. China's political influence has also grown, with increased involvement in the domestic politics of other nations. Cases of Chinese political interference in Australia and New Zealand were reported during 2017. ${ }^{31}$ Increased ties between China-backed activities and politics is an increasingly prominent issue that needs to considered carefully, as it shapes the IPE and discourse surrounding interference. ${ }^{32}$ Overall, there are a number of strong arguments that support the idea that China is altering the IPE, and that this is having concrete effects on the rest of the world.

In contrast, some argue China's rise has led to few changes in the IPE. The first argument is due to the continued existence of American hegemony. American hegemony continues to exert its influence effectively into the domain of other country's sovereignty, and China is no exception. ${ }^{33}$ Continual pressure from the US and international groups such as the United Nations (UN), and the

\footnotetext{
${ }^{27}$ World Politics Review. (2020). How China's Rise Has Remade Global Politics. Retrieved from https://www.worldpoliticsreview.com/insights/27828/how-china-s-rise-has-remade-global-politics

${ }^{28}$ Zheng, C. (2016). China debates the non-interference principle. The Chinese Journal of International Politics, 9(3), 349-374.

${ }^{29} \mathrm{Gu}$, J., Zhang, C., Vaz, A., \& Mukwereza, L. (2016). Chinese state capitalism? Rethinking the role of the state and business in Chinese development cooperation in Africa. World Development, 81, 24-34.

${ }^{30}$ Scoones, I., Amanor, K., Favareto, A., \& Qi, G. (2016). A new politics of development cooperation? Chinese and Brazilian engagements in African agriculture. World Development, 81, 8.

${ }^{31}$ Walter, L. (2019). Government raises interference concerns with China. Retrieved from https://www.stuff.co.nz/national/politics/114804860/govt-raises-interference-concerns-with-china

32 Corre, P. (2018). China's Rise as a Geoeconomic Influencer: Four European Case Studies. Retrieved from https://carnegieendowment.org/2018/10/15/china-s-rise-as-geoeconomic-influencer-four-european-casestudies-pub-77462

${ }^{33}$ Zhu, T., \& Pearson, M. (2013). Globalization and the role of the state: Reflections on Chinese international and comparative political economy scholarship. Review of International Political Economy, 20(6), 1219.
} 
World Bank have influenced how China conducts itself. From the introduction of elements of democracy to partial liberalisation of the Chinese market, the ongoing Western influence in China is apparent. ${ }^{34}$ This argument is further supported by the lack of power balancing in Asia. Power balancing theory states that when a country rises they will seek to alter the balance of power in its region by asserting some degree of control over its neighbours. ${ }^{35}$ Instead, China's modern strategic priorities involves creating a peaceful foreign policy environment, which is promoting regional economic development and political stability over contestation. ${ }^{36}$

Second is the lack of development in China. Many crucial reforms are needed in China to aid further development. These include greater transparency about the monetary policy strategies, more openness of the capital accounts and less exchange rate and stock market intervention. ${ }^{37}$ These issues make the Chinese market is less efficient than other countries, and even Chinese consumers consider some information unreliable. ${ }^{38}$ The market's inefficiency and underdevelopment hinders the country as China is not operating at its full capacity and there is a degree of reliance on developed economies for quality and consistency. All of this suggests that despite massive economic growth, China still has less influence in the international economy compared with Western nations. Overall, this thesis argues that China warrants increased attention and that China's economic rise has created some changes in behaviour from the international community, though it acknowledges that there is room for continued development.

This thesis contributes to this debate by highlighting the influence of China, and the impact this is having on the New Zealand's political economy. By highlighting the relationship between tourism and the $C C P$, it can be demonstrated how the rise of China and Chinese tourism is influencing the worldwide IPE. Through examining the overall state of Chinese tourism to New Zealand, this research creates a comprehensive assessment of how Chinese outbound tourism is shaping New Zealand's political economy. The political economy of New Zealand is being shaped through China's rise because this growth is causing China to become more engaged with other nations. Some ways

\footnotetext{
${ }^{34}$ Odinye, I. (2012). Western influence on Chinese and Nigerian cultures. OGIRISI: a New Journal of African Studies, 9(1), 108-115.

${ }^{35}$ Nicolas, F., \& Buchanan, D. (2016). China and the global economic order: A discreet yet undeniable contestation. China Perspectives, 106(2), 10-16.

${ }^{36}$ Kastner, S. L. (2008). The Global Implications of China's Rise.

${ }^{37}$ Taylor, J. B. (2016). The role of the Chinese economy in the world economy: A US perspective. China Economic Review, 40, 285.

38 Zhou, K. Z., Su, C., \& Bao, Y. (2002). A paradox of price-quality and market efficiency: a comparative study of the US and China markets. International Journal of Research in marketing, 19(4), 361.
} 
New Zealand is being affected are confined to tourism (such as marketing strategies) while other address national issues, such as infrastructure and online presence.

\subsubsection{Why Tourism?}

The reason why this thesis focuses on tourism as opposed to diplomacy or focusing solely on trading relations is because the way tourism affects the IPE is under-researched. Most of the research focused on China and the IPE tends to gravitate towards international politics, trade, finance and global order. Some works focus on the rise of Sino-capitalism and how China's rise is changing the status quo. ${ }^{39}$ Others are interested in the way New Zealand has responded to China's rise from a business perspective and how companies are attempting to penetrate this emerging market. ${ }^{40}$ There is also interest in exploring how Chinese economic and political policies have changed. ${ }^{41}$ Some works have also demonstrated an interest in the rise of China in the Pacific, but few show an interest in New Zealand in particular. ${ }^{42}$ Most of the work that focuses on Chinese and New Zealand tourism is mainly focused on the perceptions that Chinese tourists have of New Zealand. ${ }^{43}$ Little attention is given to the way tourism impacts economic development in New Zealand. A large quantity of work that focuses on New Zealand tourism addresses either issues with Māori tourism or environmentalism. ${ }^{44}$ This thesis aims to address a gap in the literature by discussing the role that politics has to play in influencing the IPE and the relationship between New Zealand and China.

\subsubsection{Chinese Tourist Gaze}

An influential contributor to tourism theory is John Urry, who suggested a parallel between the tourist gaze and the medical gaze articulated by Michel Foucault. This gaze is 'socially organized and systematized. ${ }^{45 \prime}$ The tourist gaze reflects the power dynamics between tourists and hosts and the relationship between self and 'other'. Urry also argued there are two different forms of the tourist gaze: the 'romantic' and the 'collective. ${ }^{46 \prime}$ The romantic tourist gaze emphasizes a private personal

\footnotetext{
${ }^{39}$ McNally, C. A. (2012). Sino-capitalism: China's reemergence and the international political economy. World politics, 64(4), 741-776.

${ }^{40}$ Chung, H. F. (2003). International standardization strategies: The experiences of Australian and New Zealand firms operating in the greater China markets. Journal of International Marketing, 11(3), 48-82.

${ }^{41}$ Hoadley, S., \& Yang, J. (2007). China's cross-regional FTA initiatives: Towards comprehensive national power. Pacific Affairs, 80(2), 327-348.

${ }^{42}$ Yang, J. (2009). China in the South Pacific: hegemon on the horizon?. The Pacific Review, 22(2), 139-158.

${ }^{43}$ Sun, M., Ryan, C., \& Pan, S. (2015). Using Chinese travel blogs to examine perceived destination image: The case of New Zealand. Journal of Travel Research, 54(4), 543-555.

${ }^{44}$ Hall, C. M., \& Higham, J. (Eds.). (2005). Tourism, recreation and climate change. Channel View Publications.

${ }^{45}$ Tourist gaze. (2009). In S. H. Callahan, The SAGE dictionary of leisure studies. Sage UK. Credo Reference: http://helicon.vuw.ac.nz/login?url=https://search.credoreference.com/content/entry/sageukdicles/tourist ga ze/0?institutionld $=5378$

${ }^{46} \mathrm{Ibid}$.
} 
relationship with the tourism referent object. The collective gaze creates the atmosphere of the tourist location through group opinions and behaviour. The tourist gaze can also be understood as a cognitive construction. Tourist fantasies about a destination and their anticipations are constructed and sustained through a variety of non-tourist technologies, such as film, TV and literature. ${ }^{47}$ In anticipating differences, travellers tend to romanticize what they see and become fascinated by the exotic people, customs and landscapes they encounter. Through the process of 'othering' may be reflective, or could reinforce their pre-existing beliefs. ${ }^{48}$

According to $\mathrm{Li}$, Chinese international tourists have a two-tiered gaze ${ }^{49}$ The first tier is interested in experiencing things that are distinctive from everyday life. Sights considered exotic are unique to vacation travels and thus considered extraordinary. Chinese tourists are also interested in experiencing the local traditions, cuisines and natural landscape. They want to see the major attractions a nation has to offer and they want to view them in an authentic and non-staged manner. When it comes to attractions, Chinese tourist are curious about the world beyond China's borders and want to learn about the Western world. The second tier of the Chinese tourist gaze is a comparative gaze related to their experiences in China. They view everything using a critical rather than patriotic gaze and seek to gain a better understanding about their own nation through experiencing other nations. ${ }^{50}$

\subsubsection{New Zealand - China Relationship}

The rise of China is important to New Zealand for two major reasons. Firstly, because of New Zealand's relationship with China, and secondly because of the value of trading relationships between these two countries. New Zealand and China have a long relationship going back to the 1840s when Chinese immigration to New Zealand began. Official diplomatic contact began in 1912 with trade, missionary and immigration serving as the primary links. ${ }^{51}$ New Zealand's trade relationship with China has nearly tripled over the past decade, with two-way trade rising from $\$ 8.2$ billion in 2007 to $\$ 23$ billion in 2016. Annual exports to China have quadrupled and annual imports from China have also doubled since 2007..$^{52}$

\footnotetext{
${ }^{47}$ Huang, W. J., King, B., \& Suntikul, W. (2017). VFR tourism and the tourist gaze: Overseas migrant perceptions of home. International Journal of Tourism Research, 19(4), 423.

${ }^{48} \mathrm{Ibid}$.

${ }^{49}$ Li, M., Sharpley, R., \& Gammon, S. (2019). Towards an understanding of Chinese tourist photography: Evidence from the UK. Current Issues in Tourism, 22(5), 509.

50 lbid 510.

51 Te Ara. (n.d.). Story: Tourist industry. Retrieved from https://teara.govt.nz/en/tourist-industry/

52 Statistics New Zealand. (2016). Trade with China nearly tripled in past decade. Retrieved from https://www.stats.govt.nz/reports/trade-with-china-nearly-tripled-in-past-decade
} 
The New Zealand-China Free Trade Agreement (FTA) signed in 2008 provided significant development to this trading relationship. ${ }^{53}$ The New Zealand-China FTA was New Zealand's biggest trade deal since the Closer Economic Relations agreement with Australia in 1983. New Zealand supplies more than half of all dairy that China imports alongside a significant amount of the wood, meat, fruit and wool. ${ }^{54}$ By 2016, New Zealand had duty free access on over $97 \%$ of China's tariff lines. New Zealand had a \$3.6 billion NZD goods and services trade surplus with China during 2017. The main contributor to this surplus was the increase in exports of milk powder, butter, and cheese to China - which grew to a value of $\$ 4.1$ billion NZD in $2018 .{ }^{55} \mathrm{New}$ Zealand's exports of services to China were also a large contributor, accounting for $\$ 2.5$ billion NZD. ${ }^{56}$ Travel exports to China fell $\$ 26$ million over the December 2017 year. ${ }^{57}$ China is New Zealand's largest source of international students (a significant source of foreign investment), with over 40,000 Chinese student enrolments in $2017 .{ }^{58}$ All of these statistics highlight the importance of this trading relationship for New Zealand.

\subsubsection{China as Culturally Distinct}

This section discusses the differences between tourism from China and New Zealand's long-standing tourism markets. Fountain suggests that the Western understanding of the world is different from the Chinese one and New Zealand fails to address the Chinese tourist gaze by only focusing on a Western worldview. ${ }^{59}$ Understanding the gaze of Chinese tourists is key to being able to fully cater to their needs. Pearce has criticised most existing research surrounding Chinese tourism trends and perception as Western-centric or drawing from the historical examples of South Korea and Japan. ${ }^{60}$ Mok provides an overview of three characteristics that typically define Chinese tourists. The first characteristic is high power distance. High power distance means that there are established unequal relationships among different people in society. The second characteristic is collective. Collectivism refers to the importance of group relationships while travelling and suggests Chinese tourists are

\footnotetext{
${ }^{53}$ MFAT. (n.d.). China. Retrieved from https://www.mfat.govt.nz/en/countries-and-regions/north-asia/china/

${ }^{54}$ New Zealand China Council. (2019). Statistics. Retrieved from https://nzchinacouncil.org.nz/statistics/ $55 \mathrm{lbid}$.

${ }^{56}$ New Zealand Foreign Affairs and Trade. (n.d.). China. Retrieved from https://www.mfat.govt.nz/en/countries-and-regions/north-asia/china/

${ }^{57}$ New Zealand China Council. (2019). Statistics. Retrieved from https://nzchinacouncil.org.nz/statistics/

${ }^{58}$ Christian, H. (2019). New Zealand-China relationship: What's at stake for trade, tourism, students? Retrieved from https://www.stuff.co.nz/business/110664747/new-zealandchina-relationship-whats-at-stake-for-tradetourism-students

${ }^{59}$ Fountain, J., Espiner, S., \& Xie, X. (2010). A cultural framing of nature: Chinese tourists' motivations for, expectations of, and satisfaction with, their New Zealand tourist experience. Tourism Review International, 14(2-3), 71-83.

${ }^{60}$ Pearce, P. L., Wu, M. Y., \& Osmond, A. (2013). Puzzles in understanding Chinese tourist behaviour: Towards a triple-C gaze. Tourism Recreation Research, 38(2), 146.
} 
less likely to exhibit individualist behaviour. Confucianism stresses the importance of interpersonal relationships. ${ }^{61}$ The third characteristic is medium uncertainty avoidance. ${ }^{62}$ Uncertainty avoidance refers to the likelihood for tourists to engage in risky behaviour, with Chinese tourists unlikely to seek out extreme attractions or go to areas without security.

One reason why the Chinese market is distinct is due to Confucianism. Most relevant to tourism is the Confucian approach to nature (due to New Zealand's nature-based tourism). Confucianism discusses the importance of respect for history, culture and learning, which is present in the Chinese tourists' interest in learning about the literature and history associated with famous landmarks, monuments and landscapes. ${ }^{63}$ Confucianism promotes the unity of human beings and nature ${ }^{64}$ This involves seeking a better understanding of nature while paying attention to spiritual cultivation. ${ }^{65}$ Cultural background shapes experience, which means that Chinese tourists want to see the relationship between people and nature in the form of a culturescape. ${ }^{66}$ The value of nature relates to its cultural significance, not just its natural beauty. ${ }^{67}$ This cultural difference means that tourists have different expectations and desires from New Zealand's other markets. This thesis considers the significance of this difference, and evaluates the effectiveness of New Zealand's tourism strategy when it comes to addressing this cultural difference.

\subsubsection{Linking Politics and Tourism}

The 1971 admission of China to the UN resulted in diplomatic recognition between China and many nations. The less extreme stance of Deng Xiaoping (as determined by the West) further encouraged Western nations that expanded tourism trade with the previously recluse nation was desirable. China saw the expansion of tourism as a logical part of its "normalization" strategy. China elevated the China Travel and Administrative Bureau (CTAB) to ministerial status in 1977 to address tourism and travel issues. ${ }^{68}$

\footnotetext{
${ }^{61}$ Yang, F., \& Tamney, J. (Eds.). (2011). Confucianism and spiritual traditions in modern China and beyond. Brill. 90

${ }^{62}$ Mok, C., \& DeFranco, A. L. (2000). Chinese cultural values: Their implications for travel and tourism marketing. Journal of Travel \& Tourism Marketing, 8(2), 102.

63 Ibid 79.

${ }^{64}$ Tianchen, L. (2003). Confucian ethics and the environment. Culture Mandala, 6(1), 5856.

${ }^{65} \mathrm{He}, \mathrm{C}$. (2018). New Confucianism, science and the future of the environment. European Review, 26(2), 371.

${ }^{66}$ Fountain, J., Espiner, S., \& Xie, X. (2010). A cultural framing of nature: Chinese tourists' motivations for, expectations of, and satisfaction with, their New Zealand tourist experience. Tourism Review International, $14(2-3), 74$

67 Ibid 75.

${ }^{68}$ Richter, L. K. (1983). Political implications of Chinese tourism policy. Annals of tourism Research, 10(3), 401.
} 


\subsubsection{CCP is Dominant in Tourism}

Tourism operations and operators are currently centrally controlled and planned. ${ }^{69}$ Since 1982 , all the liaison work with foreign countries has been handled only by the head office of the CTAB. Offices abroad work to explain China's tourist development policies, promote China's tourist attractions, to carry out market surveys, prepare visas for tourists to China, and find out information as requested by the CCP. ${ }^{70}$ In order to encourage tourism development and increase its contribution to the national economy, the CCP has adopted a "Government-led Tourism Development Strategy" where the government plays a dominant role in tourism development and management. ${ }^{71}$

Another way politics influence tourism is through the acquisition of Approved Destination Status (ADS). The process of obtaining ADS is highly political. Gaining ADS can provide a significant boost to the economy because there is potential for an influx of Chinese tourists. The average annual impact on countries was between $10.1 \%$ and $13.7 \%$ over the initial three-year period following the acquisition of ADS. ${ }^{72}$ Voting records from the UN on global security issues suggests that the more frequently a country votes in alignment with China, the more likely they are to have ADS. Overall, the CCP plays an active and ongoing role in Chinese tourism, as tourism is a political tool. It can be used to promote behaviour with the promise of increased revenue (caused by the influx of high paying tourists), and this can cause countries to adjust their stance on Chinese policy.

\subsubsection{Tourism Enhancing Government Messages}

The Chinese state uses domestic tourism media to achieve hegemony and foster national pride. The state has a dominant role in sustaining ideologies and restricting contrary ideas. This is achieved through controlling education, tourism destinations, travel conditions and media. ${ }^{73}$ Through framing tourism destinations in China within a context of heritage, education and national pride, the CCP is able to control messages presented to domestic Chinese tourists. This is reinforced through state controlled media, which utilizes traditional news presentation techniques such as direct visual addresses and collective language to present propaganda as fact. ${ }^{74}$ However when Chinese tourists

\footnotetext{
${ }^{69}$ Wang, D., \& Ap, J. (2013). Factors affecting tourism policy implementation: A conceptual framework and a case study in China. Tourism Management, 36, 224.

${ }^{70} \mathrm{lbid}$.

${ }^{71} \mathrm{CaO}, \mathrm{X}$. (2015). Challenges and potential improvements in the policy and regulatory framework for sustainable tourism planning in China: The case of Shanxi Province. Journal of Sustainable Tourism, 23(3), 468.

${ }^{72}$ Arita, S., La Croix, S., \& Edmonds, C. (2014). Effect of Approved Destination Status on Mainland Chinese Travel Abroad. Asian Economic Journal, 28(3), 219.

${ }^{73}$ Feng, D. (2013). National voice: A discourse analysis of China central television's news simulcast. Discourse \&amp; Communication, 7(3), 255-273.

${ }^{74} \mathrm{lbid}$.
} 
go abroad, they observe what is different from their everyday experience. This allows them to compare their own lives and standards with those outside of China. Of particular focus to modern Chinese tourists is the ways the CCP has failed in the wake of modernisation. Some of the key ways in which the CCP is criticised is the lack practical skills among Chinese youth, conservation efforts and social pressures. ${ }^{75}$ Overall, the CCP has an active role in controlling China's tourism and has a strong role in shaping the tourist gaze of Chinese international tourists, though Chinese tourists also use their international travels to compare the places they visit to China.

\subsubsection{Expansion of Power}

A further consideration worth noting is the idea that Chinese outbound tourism can be viewed as a form of soft power. Because of the massive power of Chinese international tourists, encouraging or discouraging travel to particular countries can have a significant impact on other nations. An example of this is Japan. Since 2011, Chinese tourism to Japan has either been encouraged and discouraged depending on relationship between Japan and China. In 2011, Japan suffered from an earthquake and tsunami, which had a devastating impact on tourism. China promoted tourism by allowing group tours to return as soon as possible, establishing a system of charter flights and creating a joint venture travel agency. ${ }^{76}$ In 2012, relations between the two nations soured. following a debate over Diaoyu/Senkaku islands.Chinese travel agencies cancelled all organised trips to Japan, resulting in a 70\% deficit of 2012 's estimated tourism profit earnings. ${ }^{77}$ A strong relationship with China is key to marketing efforts, as a negative diplomatic relationship can also lead to a lack of inbound travellers. ${ }^{78}$ This can be seen in New Zealand in June 2019, where visitor arrivals from China totalled 316,069 , down $8.0 \%$ on $2018 .{ }^{79}$ This is due in part to tensions between the two nations. One source of tension is the use of Huawei equipment. The Government Communications Security Bureau decided to exclude Huawei from Spark's 5G network due to security risks. The tourism industry has suffered since the Huawei incident. ${ }^{80}$ Overall, tourism is highlighted as showing a close relationship to politics and this highlights how Chinese tourism can be

\footnotetext{
${ }^{75}$ Yang, F., \& Tamney, J. (Eds.). (2011). Confucianism and spiritual traditions in modern China and beyond. Brill.

${ }^{76}$ Tse, T. (2013). Chinese Outbound Tourism as a Form of Diplomacy. Tourism Planning \& Development, 10(2), 154.

77 Ibid.

${ }^{78}$ Zhu, Y. (2013). Making sense of Canada's public image in China. Journal of American-East Asian Relations, 20(2-3), 284.

79 Tourism New Zealand. (2019). China. Retrieved from https://www.tourismnewzealand.com/marketsstats/markets/china/

${ }^{80}$ Rutherford, H. (2019). Ardern's swift trip to China marks a new political reality in New Zealand. Newshub. Retrieved from https://www.stuff.co.nz/business/111562567/arderns-swift-trip-to-china-marks-a-newpolitical-reality-in-new-zealand
} 
linked to the Chinese national agenda, and how Chinese tourism can have a real impact on the overall success of the CCP.

\subsubsection{Tourism Promoting Political Agenda}

The CCP promotes its agenda and existence, through Red Tourism. Red Tourism, i.e. communist heritage tourism, is an official policy of the CCP with sites distributed widely across the country. ${ }^{81}$ The goal of Red Tourism is to promote national identity and cohesion, and to glorify the party-state through patriotism. According to the National Plan, the central government set up an annual budget of 700 million yuan (\$138 million NZD) in 2005 for Red Tourism..$^{82}$ One of the largest Red Tourism sites is Shaoshan Village; a small village prominent in Mao Zedong's childhood. Shaoshan Village reinforces the ideas of nationalism and promotes modern ideological discourse, through memorialising leaders, ideas and values ${ }^{83}$ One major way in which Red Tourism differs is that these attractions produce a "semiotic loop of representation and reality", which works to associate cultural and historical interest through enshrinement. ${ }^{84}$ Overall, Red Tourism promotes the ideas of the CCP and explicitly tries to encourage loyalty to the Chinese government and promotes the CCP's narrative. $^{85}$

\subsubsection{Control Citizens}

China uses tourism to exert further control over its citizens, controlling where they can go (only being allowed to travel to ADS approved countries), and how they behave overseas. China has blocked millions of travellers from buying plane or train tickets as part of the country's controversial social credit system. The social credit system aims to incentivise "trustworthy" behaviour through penalties as well as rewards. Social credit offences range from not paying individual taxes or fines to taking drugs. Local governments and agencies have been piloting aspects of the system, which will eventually give every Chinese citizen a personalised score ${ }^{86}$ China is also attempting to monitor the

\footnotetext{
${ }^{81}$ Almay. (n.d.). Mao Memorabilia souvenirs in Shaoshan village Hunan province China. Retrieved from https://www.alamy.com/stock-photo-mao-memorabilia-souvenirs-in-shaoshan-village-hunan-province-china59636962.html

82 Wall, G., \& Zhao, N. R. (2017). China's red tourism: communist heritage, politics and identity in a party-state. International Journal of Tourism Cities, 3(3), 306.

83 Ibid.

${ }^{84}$ Hunter, William Cannon. (2013). China's Chairman Mao: A visual analysis of Hunan Province online destination image. Tourism Management, 34, 109.

${ }^{85}$ Zhang, H. Q., Chong, K., \& Ap, J. (1999). An analysis of tourism policy development in modern China. Tourism Management, 20(4), 477.

${ }^{86}$ Kuo, L. (2019). China bans $23 \mathrm{~m}$ from buying travel tickets as part of 'social credit' system. Retrieved from https://www.theguardian.com/world/2019/mar/01/china-bans-23m-discredited-citizens-from-buying-traveltickets-social-credit-system
} 
behaviour of its citizens while they are abroad. The China National Tourism Administration (CNTA) said that provincial and national authorities would be in touch with unruly citizens when they return to China, and the police, customs officers, border control and even bank credit agencies may be contacted. They are hoping the strict measures will encourage Chinese tourists from doing anything inappropriate or illegal while abroad. ${ }^{87}$ Tourism is monitored and movements and behaviours are controlled, highlighting the imposing role of authorities of the Chinese population.

\subsubsection{Tourism}

This section provides an understanding into relevant tourism theory employed in this thesis. A tourist is defined as a traveller taking a trip to a main destination outside his/her usual environment, for less than a year, for any purpose (business, leisure or other personal purpose) other than to be employed in the country or place visited. Tourism refers to the activity of the visitor who is defined as a tourist. ${ }^{88}$ The trips taken by visitors qualify as tourism trips. ${ }^{89}$ Tourists are usually defined in experiential terms, with associated behaviours including "taking photos," "buying souvenirs," "going to famous places" and "staying briefly in one place. ${ }^{90 "}$

\subsubsection{Worldwide Tourism}

Worldwide, the number of international tourist arrivals was 1.32 billion in $2018 .{ }^{91}$ These tourists made a total contribution to the global economy of 8.81 trillion USD (13.29 trillion NZD).${ }^{92}$ Enhanced air transport infrastructure and improved international diplomatic relations all contribute to an industry that promotes, engages and exchanges culture and finances. Between 2015 and 2018, scheduled available seat kilometres increased by nearly $30 \%$ for most countries with high tourism yields. Flying and travel in general has become more affordable thanks to lower global fuel prices, reduced ticket taxes, and an end to the majority of airport charges. At the same time the number of mobile broadband internet subscriptions per 100 people has climbed by more than one-quarter between 2017 and 2019. More nations are positioned to take advantage of the growing popularity

\footnotetext{
${ }^{87}$ CBS. (2019). China hatches plan to keep vacationers in check. Retrieved from https://www.cbsnews.com/news/china-government-keep-records-chinese-tourists-inappropriate-actionsabroad/

${ }^{88} \mathrm{Yu}, \mathrm{X} ., \mathrm{KIm}, \mathrm{N}$. , Chen, C. C., \& Schwartz, Z. (2012). Are you a tourist? Tourism definition from the tourist perspective. Tourism Analysis, 17(4), 446.

89 lbid.

90 Ibid 447.

${ }^{91}$ Roser, M. (2019). Tourism. Our World in Data. Retrieved from https://ourworldindata.org/tourism

92 Statista. (2019). Global travel and tourism industry - Statistics \& Facts. Retrieved from

https://www.statista.com/topics/962/global-tourism/
} 
of online tourism and tourism offerings. New tourism has led to a dramatic change in the tourism industry, where visits are more frequent, and travel is becoming a common leisure activity.

\subsubsection{New Tourism}

Since the 1970s the world has transitioned from a period of 'old' tourism to 'new' tourism. ${ }^{93}$ Gone are the mass, standardized and rigidly packaged travel experiences. In their place is the desire for flexibility, segmentation and more authentic experiences ${ }^{94}$ Of particular importance towards 'new' tourism best practice is the way in which online media is harnessed. Internet usage has become an integral part of everyday life; in 2017, the average person in a developed country spent 23 hours a week on the internet. ${ }^{95}$ Approximately $55 \%$ of the world's population had a stable connection to the internet at the end 2017. ${ }^{96}$ In order to stay globally competitive, it is crucial that countries utilize the internet in their destination marketing campaigns. Destination Management Organisations need to establish a strong online presence as the internet is one of the most important ways in which people get information in the $21^{\text {st }}$ century. ${ }^{97}$ They are able to build trust with future visitors by creating a feeling of authenticity and personalisation, which are key elements of 'new' tourism.

\subsubsection{New Zealand Tourism}

\subsubsection{Background}

New Zealand tourism is a long-standing industry that has existed for over 100 years. The earliest record of annual international tourist numbers to New Zealand occurred in 1903 with 5,233 visitors. International tourism growth was very slow until it took off in the 1960s. This is because New Zealand had little to offer as a tourism destination. At its core, New Zealand remained an agricultural country. ${ }^{98}$ Imported goods were severely restricted and preference was given to agriculture and manufacturing over luxury goods. Regulations against licensed restaurants, Sunday shopping and cinemas limited the country's appeal to visitors - the whole country shut on weekends. The advent of jet passenger planes in the 1960s and jumbo jets in the 1980s revolutionised New Zealand tourism. ${ }^{99}$ Distances shortened, costs fell and more tourists made business viable. New Zealand

\footnotetext{
93 Poon, A. (1994). The 'new tourism' revolution. Tourism Management, 15(2), 91-92.

94 Ibid 91.

${ }^{95}$ Cole, J. (2017). Surveying the Digital Future. The 2017 Digital Future Report. Centre for the Digital Future. 96 Ibid.

${ }^{97}$ Buhalis, D., \& Wagner, R. (2013). E-destinations: Global best practice in tourism technologies and applications. In Information and communication technologies in tourism 2013. Springer, Berlin, Heidelberg. 129

98 Te Ara. (n.d.). Story: Tourist industry. Retrieved from https://teara.govt.nz/en/tourist-industry/ 99 Ibid.
} 


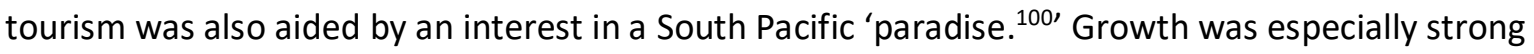
during the 1990s and 2000s, and in the year to March 2009, there were 2.4 million international tourists. In the early 2000s, tourism's annual contribution to the economy was $\$ 18.6$ billion, or $9 \%$ of GDP. ${ }^{101}$

\subsubsection{Statistics}

Tourism is New Zealand's largest export industry in terms of foreign exchange earnings, contributing $21 \%$. In the financial year ending March 2019, total tourism expenditure was $\$ 40.9$ billion NZD, an increase of $4 \%$ ( $\$ 1.6$ billion) from the previous year. Tourism generated a direct contribution to GDP of $\$ 16.2$ billion, or $5.8 \%$ of GDP. The indirect value from industries supporting tourism generated an additional $\$ 11.2$ billion NZD, or 4\% of GDP. Around 230,000 people are directly and another 163,713 indirectly employed in tourism in New Zealand $-14.4 \%$ of the total employment. Tourists generated $\$ 3.8$ billion NZD in GST, with $\$ 1.8$ billion from international tourists. ${ }^{102}$ Currently New Zealand's five largest source countries for international tourists are (1) Australia, (2) China, (3) the US, (4) the United Kingdom (UK) and (5) Germany. Below are the total tourism numbers for these five countries in the year ending October 2019.

Figure One: Tourism to New Zealand (October 2019) by Country

\begin{tabular}{|l|l|l|l|l|l|}
\hline & Australia & China & US & UK & Germany \\
\hline $\begin{array}{l}\text { Year End } \\
\text { (Total) }\end{array}$ & $1,537,215$ & 409,428 & 366,787 & 234,184 & 99,858 \\
\hline $\begin{array}{l}\text { Year End } \\
\text { (Holiday) }\end{array}$ & 605,702 & 305,440 & 240,668 & 101,050 & 73,645 \\
\hline
\end{tabular}

Source: Tourism New Zealand. (2019). Market and Stats. Retrieved from

https://www.tourismnewzealand.com/markets-stats/

\subsubsection{Tourism Strategy}

The New Zealand government has two roles it plays in the tourism sector; steward and actor. ${ }^{103}$ In its steward role, the government acts as an overseer to the tourism industry, and ensures that the

\footnotetext{
100 Ibid.

101 Ibid.

102 Tourism New Zealand. (2019). About the tourism industry. Retrieved from https://www.tourismnewzealand.com/about/about-the-tourism-industry/

${ }_{103}$ Ministry of Business, Innovation and Employment. (n.d.). Aotearoa New Zealand Government Tourism Strategy. Retrieved from https://www.mbie.govt.nz/immigration-and-tourism/tourism/new-zealand-aotearoagovernment-tourism-strategy/
} 
tourism systems are running cohesively by organising the national strategy and national planning. In the actor role, the government acts through its own investments and interventions. They take an active and consultative role in the tourism industry, coordinating its own actions alongside other actors. The government's current overarching goal is to enrich New Zealand through socially and economically sustainable growth. ${ }^{104}$ The government wants value (average spend per visitor) to grow faster than volume, and wants a greater uptake of technology and a more skilled workforce. Tourism aims to generate positive word of mouth and a strong international reputation. Currently, New Zealand is reliant primarily on two markets; Australia and China, for $40 \%$ and $11 \%$ of inbound tourists respectively. Tourism New Zealand (TNZ) hopes to build on the next four largest markets (the US, the UK, Germany and Japan). ${ }^{105}$ There are also hopes to engage with emerging markets (Canada, South Korea, Singapore and India). ${ }^{106}$ There is hope that tourism will protect and enhance New Zealand's natural, cultural and historic heritage, as well as promoting New Zealand's culture abroad. It is also hoped regions and communities will benefit from tourism, leading to inclusive growth. ${ }^{107}$ This includes ensuring whānau, iwi and hapū benefit from tourism by enabling Māori to realise and actualise their economic aspirations in the regions, many of which will be marketed as new 'must see' destinations.

\subsubsection{Mātauranga Māori}

The term mātauranga Māori literally translates to "Māori knowledge" and refers to the period of traditional concepts of knowledge and knowing that Māori ancestors brought with them to New Zealand. ${ }^{108}$ For this reason, mātauranga Māori generally refers to pre-European contact. It can be more broadly defined as 'the knowledge, comprehension, or understanding of everything visible and invisible existing in the universe. ${ }^{109 \prime}$ The survival of the Māori language acts as a cultural and

\footnotetext{
${ }^{104}$ Ryan, C. (n.d.). Delivering on our clean and green image. Bright (Wellington, N.Z.), Bright (Wellington, N.Z.). 19.

105 Tourism New Zealand (2018). Visitor Experience Infographic April 2018. Retrieved from https://www.tourismnewzealand.com/media/3423/visitor-experience-infographic-april-2018.pdf

106 Tourism New Zealand. (2019). Markets \& Stats. Retrieved from https://www.tourismnewzealand.com/markets-stats/

107 Ministry of Business, Innovation and Employment. (n.d.). Aotearoa New Zealand Government Tourism Strategy. Retrieved from https://www.mbie.govt.nz/immigration-and-tourism/tourism/new-zealand-aotearoagovernment-tourism-strategy/

108 Kaai, T. (n.d.). Mātauranga Māori. Auckland University of Technology. Retrieved from https://www.aut.ac.nz/study/study-options/maori-and-indigenous-development/research/researchexpertise/mataurangamaori\#: :text=The\%20term\%20m\%C4\%81tauranga\%20M\%C4\%81ori\%20literally,them\%20to\%20Aotearoa\%2F New\%20Zealand

${ }^{109}$ No Author. (n.d.). WHAT IS MATAURANGA MAORI? Manaaki Whenua Landcare Research. Retrieved from https://www.landcareresearch.co.nz/about/sustainability/voices/matauranga-maori/what-is-matauranga- 
historical marker demonstrating a continuum from pre-contact to the present day in 2020. In a modern setting (post first-contact), mātauranga Māori has evolved in significant ways as Māori encountered new European contexts such as flora and fauna as well as new technology, languages and cultures they had not witnessed before. Māori historically practice collective decision-making at all levels of their society. A consensus (kotahitanga) is reached following discussion among individuals, families and communities. These discussions often involve debate related to social, cultural, spiritual, economic and political dimensions of the issue in question. ${ }^{110}$ There are a number of different factors that are considered important to mātauranga Māori within the context of tourism. The first is ensuring a sustainable environment, which focuses on the environment from a Māori perspective (including reference to mātauranga Māori and other cultural considerations). Another important value is ensuring a high quality of life, by paying attention to Māori wellbeing and health. Third is a sustainable economy through economic development by contributing to regional and local economies and developing authentic Mãori tourism attractions. ${ }^{111}$ Equally important is ensuring engagement with Māori in ensuring accurate cultural recognition, cultural heritage, use of te reo Māori and consideration into Tikanga. The final major point of importance is participation and equity, which can be achieved through building relationships within Māori communities, fostering an environment that allows for the expression of kaitiakitanga (guardianship and protection), Māori comanagement of tourism facilities and enabling and encouraging the practice of tinorangatiratanga ('absolute sovereignty'). ${ }^{112}$

\subsubsection{Growth of Chinese Tourism}

The significant increase in China's political and economic influence has led to a growth in Chinese tourism. Since the 1990s, there has been immense growth in international Chinese tourists worldwide. In 2017, there were 130 million Chinese outbound travellers, which represented a 7\% increase from the previous year. ${ }^{113}$ According to the World Tourism Organization (UNWTO), China became the number one source market in the world in 2012 and during that year spent 161 billion

\footnotetext{
110 lbid.

${ }^{111}$ Hikuroa, D. (2017). Mātauranga Māori-the ūkaipō of knowledge in New Zealand. Journal of the Royal Society of New Zealand, 47(1), 5-10.

112 Smith, L. T., Maxwell, T. K., Puke, H., \& Temara, P. (2016). Indigenous knowledge, methodology and mayhem: What is the role of methodology in producing Indigenous insights? A discussion from mātauranga Māori.

${ }^{113}$ China Travel Guide. (2018). 2018 China Tourism Facts \& Figures. Retrieved from https://www.travelchinaguide.com/tourism/2018statistics/
} 
NZD on international tourism. ${ }^{114}$ This increase in travel can be attributed to the reduced travel restrictions, the growth of the Chinese economy, and Chinas rising middle class. ${ }^{115}$ Massive economic growth between 1978 and 2013 led to the emergence of a new middle class and the development of a higher standard of living. ${ }^{116}$ This has led to the growth of tourism as people now have access to disposable income. Accompanying this economic growth is a relaxation of travel restrictions. In the early 1980s, China allowed its citizens to travel to Hong Kong and Macau to visit family members in tightly controlled group package tours. In the late 1980s, Chinese citizens were permitted to purchase group tours to visit foreign countries with negotiated Approved Destination Status (ADS) agreements. ${ }^{117}$ According to the CNTA, the travel and tourism sector contributed $10.51 \%$ of China's overall GDP in 2015, which is more than the contribution of education, banking, and automobile. ${ }^{118}$ The growth of Chinese tourism has had major impacts on China's international engagement and has provided massive economic contributions to both China and host countries.

\subsubsection{Chinese Tourism to New Zealand}

\subsubsection{Statistics and Trends}

As already mentioned, a large number of Chinese tourists choose to come to New Zealand every year. A few key trends define Chinese inbound tourists to New Zealand. A large number of Chinese tend to travel during the Chinese New Year in February. This means that New Zealand summer is becoming increasingly popular for Chinese visitors. Currently summer accounts for $31 \%$ of all visitation, while the shoulder seasons of spring and autumn account for $23 \%$ and $29 \%$ respectively. ${ }^{119}$ The majority of Chinese visitors stay in hotels $(69 \%)$ and tour buses remain a popular transportation option (61\%). In age, a majority independent professional aged between 25 and 54 (55\% of total visitation). They are likely to be tertiary qualified (73\%) and because of their higher education, they tend to have higher incomes. 79\% have an income of over 180,000 RMB a year (38,000 NZD). Visitors to New Zealand tend to come from a variety of locations including Shanghai, Nanjing, Hangzhou,

\footnotetext{
${ }^{114}$ Chen, C. Y. (2016). The impact of the Chinese tourism market on Taiwan residents' attitudes. Journal of Quality Assurance in Hospitality \& Tourism, 17(1), 1-23. 1.

115 Jainchill, J. (2016). Growth of Chinese tourism the talk of U.S. Travel show.(NEWS). Travel Weekly, 75(26). ${ }^{116}$ Amadeo, K. (2019). China's Economic Growth, Its Causes, Pros, Cons, and Future. The Balance. Retrieved from https://www.thebalance.com/china-s-economic-growth-cause-pros-cons-future-3305478

${ }_{117}$ Arita, S., La Croix, S., \& Edmonds, C. (2014). Effect of Approved Destination Status on Mainland Chinese Travel Abroad. Asian Economic Journal, 28(3), 218.

118 Liu, J., Nijkamp, P., \& Lin, D. (2017). Urban-rural imbalance and tourism-led growth in China. Annals of Tourism Research, 64, 24.

119 Tourism New Zealand. (2019). China. Retrieved from https://www.tourismnewzealand.com/marketsstats/markets/china/
} 
Beijing, Shenyang, Changsha, Chengdu, Xi'an, Wuhan, Guangzhou and Shenzhen. ${ }^{120}$ There are several aspects of New Zealand that Chinese tourists enjoy. ${ }^{121}$ When Chinese tourists come to New Zealand, the most popular activities usually involve nature. Visiting national parks (60\%), observing wildlife (81\%), beach visits (65\%), walking / hiking / tramping (72\%), visiting farms/orchards (65\%) and geothermal park experiences $(60 \%)$ all place nature as the focal point and places the tourists within the landscape. ${ }^{122}$ Several additional options put the Chinese tourist in contact with nature in a more passive way. Some examples of this include trying out hot pools (47\%), scenic tour buses (52\%) and scenic boat trips (49\%). The final point of interest for Chinese tourists is New Zealand culture. This is demonstrated by the popularity of museum and art gallery visits (45\%) as well as Māori cultural experiences $(71 \%) .{ }^{123}$

Fountain's research suggests that New Zealand does not fully cater to the specific needs of the Chinese tourists. ${ }^{124}$ The first way New Zealand is failing to appeal is when tour guides cut costs on food, activities and accommodation in package tours. The second failure is the prioritization of shopping over seeing famous sights, as this is more profitable for tour guides. A third reason is because New Zealand is often seen as an expensive add-on to a trip to Australia; $75 \%$ of Chinese visitors who came to New Zealand in 2014 had already vacationed in Australia. ${ }^{125}$ The final reason why New Zealand is not pleasing the Chinese market is that their needs are not fully recognised. Fountain suggests that the Western gaze of the world is significantly different from the Chinese one and New Zealand is focusing only on a Western worldview. This is done through focusing on untamed nature, with an emphasis on ecological processes. All of these reasons suggest New Zealand does not fully meet the needs of the Chinese tourist, but there are solid foundations for improvement.

\subsubsection{Significance}

Overall, it is apparent that Chinese tourism to New Zealand is of great importance to the future of the New Zealand tourism industry and the economy. Because of the scale of inbound Chinese

\footnotetext{
120 Tourism New Zealand. (n.d.). China Visitor Information. Retrieved from https://www.tourismnewzealand.com/media/3418/china-visitor-information.pdf

${ }^{121}$ Chan, D. (2009). Sustainable tourism in New Zealand: The Chinese visitors' view. 6.

122 Ibid.

123 Ibid.

${ }^{124}$ Fountain, J., Espiner, S., \& Xie, X. (2010). A cultural framing of nature: Chinese tourists' motivations for, expectations of, and satisfaction with, their New Zealand tourist experience. Tourism Review International, 14(2-3), 73.

${ }^{125}$ Che, L. (2014). Understanding motivations to visit New Zealand: A quantitative study amongst young Chinese FITs (Doctoral dissertation, Auckland University of Technology). 13.
} 
tourists to New Zealand, they provide a significant boost to New Zealand's economy. Of the five largest source markets to New Zealand, China is the only country from within Asia, which means culturally China is distinct from New Zealand's other major markets which needs acknowledgement. China has also been a consistently strong tourism market, with large growth over the last decade. Properly understanding and utilizing this market is key to ensure it doesn't stagnate. This is already something that is being seen at the end of 2019 , with numbers declining by $11 \%$ on $2018 .{ }^{126}$ Because the issues with appealing to Chinese tourism have not been addressed, interest in visiting New Zealand is declining. This is even more concerning considering that 2019 was supposed to be the China -New Zealand Year of Tourism. This highlights a number of issues with New Zealand's ability to retain the interest of Chinese tourists. Research undertaken by TNZ shows understanding of the current interests of Chinese tourists while they visit New Zealand. Some academic scholarship, however, suggests that New Zealand is not yet doing enough to account for some of the differences and as a result, New Zealand is leaving Chinese tourists unsatisfied. This thesis will provide an examination of TNZ's interactions with the Chinese tourist as of 2019, noting the issues and the potential movement. By examining the overall state of Chinese tourism to New Zealand, this thesis creates a comprehensive assessment of how Chinese outbound tourism is shaping New Zealand's political economy.

\subsection{Research question}

How is the New Zealand tourism economy responding to the growth in outbound Chinese tourism?

\subsection{Methodology}

This methodology will examine the way in which the New Zealand tourism economy is responding to the influx of Chinese outbound tourism. This thesis is primarily focused on conducting an analysis into the industry response that New Zealand has. The measures that I will use primarily rely on statistics and policy to perform my analysis. Statistics related to tourism and visitation numbers are the main statistics that will be used during this analysis. Statistics will be used to catalogue Chinese tourism behaviours while travelling. This includes travelling trends (including seasons of arrival and travel locations) and purchasing behaviour. This measure of my analysis will be used to provide a qualitative understanding to my research. Two main sources are relied upon to gather this data; TNZ and Statistics New Zealand. TNZ is the main source for gathering information about tourism movements, numbers and activities visited. Statistics New Zealand is used to support and validate

\footnotetext{
${ }^{126}$ Tourism New Zealand. (2019). Markets \& Stats. Retrieved from https://www.tourismnewzealand.com/markets-stats/
} 
the findings presented by TNZ. Statistics New Zealand also offers more data that highlights change over time, whereas TNZ primarily focuses on static at the moment data, and their changes over time are not always easily digestible.

Policy will be useful to determine the way New Zealand is responding to the current growth in Chinese tourism. Official documents released by New Zealand government helps determine the ongoing tourism policy direction. It also show how tourism is shifting in response to Chinese tourism. It highlights the importance of key ideas such as natural environment, conservation and marketing strategies. This helps to determine how effective the New Zealand government is at marketing to Chinese tourists. Secondary documents such as official statements and public consultation references were also accessed to support the claims made by this thesis. Through using policy as my second measure, this thesis is able to forge an understanding of the situation from the perspective of the New Zealand government, which will provide insight into New Zealand's policy perspective. In order to supplement this analysis, chapter 2 provides a case study analysis of four different sites. The case selection criteria uses a most similar case comparison method, where the variable is the level of Māori tourism. In the first case study, Milford Track, there is no Māori cultural tourism. In the second and third case studies, Tongariro National Park and Waitomo Caves, Māori tourism plays a secondary role to natural phenomenon. In the final case study, Rotorua, Māori cultural tourism acts as an equal tourism attraction than the natural attractions. This involves a qualitative analysis relying on a mixture of document-based research, literature research and internet-based research. Of particular relevance is statements and planning documents from the DOC, which provides signals as to what the New Zealand government considers important in relation to these sites and the future of natural attraction in New Zealand's tourism plan.

From a theoretical perspective, the theory of IPE will be utilized, as the base framework for understanding the tourism, political and economic relationship between New Zealand and China. Through framing this thesis using an IPE model, active consideration into the role of economics in shaping international relations. As already established within the literature review, Chinese outbound tourism can be linked to individual nations' relationship with China. Therefore international relations and their role in shaping the economy is very important to understanding what influences Chinese outbound tourism. A secondary theory utilized is public policy systems theory. Systems theory describes public policy as the response of the political system to demands from its social, cultural, international and economic environment. Political institutions make authoritative allocations which are responsible for uniting society. The utilization of a systems 
approach assumes mutual causation exists between public policy and the state of the political environment. ${ }^{127}$

The thesis then concludes by discussing what more can be done to improve New Zealand's tourism industry in respect to Chinese outbound tourism. Through looking at the information provided in the previous sections, areas where the New Zealand response to Chinese tourism is lacking become apparent. This section will examine literature and/or scholarship and the previously mentioned statistics and polices. Through the implementation of literature/scholarship, this thesis draws on information from both the tourism and international relations fields. This helps the research to fit in with both the themes of tourism and IPE. Literature was also used as a means providing frameworks for the discussion and it enables the collection of research and data that already exists. The literature research also enables a focused discussion around the ideas of China, New Zealand, tourism and IPE and utilizing other research enables this thesis to fit in with existing literature as well as identifying any gaps in current literature.

\subsection{Chapter Outline}

This thesis is divided into three chapters. The first chapter provides a series of case studies that analyse how New Zealand attractions cater to Chinese tourists. This chapter focuses on four different sites from around the country to create a cohesive idea of how effectively New Zealand tourism attractions market to the Chinese tourist gaze. In this chapter, there is a focus on naturebased attractions, because this is what TNZ thinks Chinese tourists are most interested in seeing when they come to New Zealand. ${ }^{128}$ They are also the types of attractions that are most prominently advertised by TNZ, particularly through the focus of $100 \%$ Pure New Zealand. ${ }^{129}$ The sites analysed are Tongariro National Park, Milford Track, Waitomo and Rotorua. This review involves a literature review and document-based research. This chapter shows that there are two key ideas related to New Zealand tourism; nature-based tourism and cultural tourism. New Zealand places a lot of focus on nature in tourism, with a particular focus on untamed nature. This is not always fully appealing to Chinese tourists, who are more interested in the ideas of culture merging with nature to create a culturescape. Culture-based tourism in New Zealand is most prominent through Māori tourism. Māori tourism in New Zealand is significant as it is provides a means for tourism and also enhances nature with a culturescape.

\footnotetext{
127 Anyebe, A. A. (2018). An Overview of Approaches to the Study of Public Policy. e-Bangi, 15(1).

128 Tourism New Zealand. (2018) China Market Snapshot. Retrieved from https://www.tourismnewzealand.com/media/2590/china-market-snapshot.pdf

129 100\% Pure New Zealand. (n.d.). Good Morning World. Retrieved from https://www.newzealand.com/int/
} 
The second chapter provides a breakdown of shopping patterns made by Chinese tourists in New Zealand. In order to do this, this section relies on a statistical analysis. There was also a comparative analysis of the statistics to determine their significance. The significance of these findings are then discussed. Following this examination, this chapter concludes with an examination of Chinese ecommerce. By establishing the ways tourism links to trade through a literature review and case study of agritourism and wine tourism this section highlights the importance of developing New Zealand's online presence with regard to e-commerce. This reflects the changing nature of commerce and trade, but it also highlights how New Zealand needs to change to respond to Chinese outbound tourism. This chapter demonstrates the economic impact of Chinese tourism in New Zealand. This economic effect is not only bound to tourist spending within the country. Through the initiation of e-commerce, spending continues economic growth once tourists return home. Strong links between tourism and trade continue to develop the New Zealand economy through the growth of revenue generated by tourism. In the e-commerce sector, New Zealand underperforms through its limited presence and sole focus on agricultural produce. Creating a strong brand and developing both tourism and online shopping capabilities would help to more effectively market to Chinese tourists and would make New Zealand more memorable.

The final chapter provides a breakdown of future challenges that the New Zealand tourism industry faces in attracting sustainable growth. A statistical and literature examination New Zealand's tourism industry provides an understanding into the challenges that the sector faces in terms of developing growth in new areas. There is also an examination into the availability of the necessary facilities to encourage growth, based off international reports. This incorporates an international comparison to judge New Zealand alongside the rest of the world. This chapter finishes with a document-based discussion related to the goals set out by New Zealand tourism. This discussion draws on literature to reinforce the ideas presented and discussed. This chapters shows Chinese outbound tourism is changing the New Zealand political economy by highlighting the necessary changes the tourism industry needs to make. Chinese tourism has uncovered major deficiencies in New Zealand's political economy and that the New Zealand government and tourist providers are working to try to resolve these, some more successfully than others. New Zealand currently has a one dimensional tourism model with insufficient diversification among regional and seasonal tourism. There are many issues that need to be addressed to protect New Zealand's tourism industry. 


\section{CHAPTER TWO - NEW ZEALAND CASE STUDIES}

\subsection{Introduction}

Chinese tourism is changing New Zealand's political economy. This can be seen in recent movements in the types of tourism offerings and marketing strategies. New Zealand tourist attractions generally place nature at the forefront. A focus on untamed nature is the major marketing attraction for New Zealand. Untamed nature like this is not always the most effective way at appealing to Chinese tourists on its own, because of their interest in culture. Confucian ideology highlights the important relationship between people and nature, and therefore many Chinese tourists are interested in the way that culture interacts with nature. Because of this New Zealand is not maximising its potential as tourism destination in the eyes of Chinese tourists. Māori culture fills in this gap effectively, highlighting New Zealand's unique culture and history. Highlighting Māori tourism proves a meaningful way to appeal to Chinese tourists, though so far Rotorua is one of the only tourism sites in New Zealand that has been able to successfully merge natural features and Mãori culture into one location. More needs to be done to cater to the Chinese tourism market if New Zealand wants to continue to profit from this market. Currently, Chinese tourism runs the risk of stagnating due to their needs not being fully met, and this has major ramifications for New Zealand's economy.

\subsection{Attraction Overview}

\subsubsection{Milford Track}

Milford Track is one of New Zealand's most popular walks, with approximately 14,000 people completing it each year. ${ }^{130}$ Milford Track is a one-way track covering $53.5 \mathrm{~km}$ and takes four days to complete. ${ }^{131} 40$ independent walkers are permitted to start the track each day. This is to prevent overcrowding, damage to the environment and to preserve the feeling of solitude while walking. This solitude is due to the lack of people, infrastructure and technology on the Track. Most people walk the Milford Track during the Great Walks season (October-April). Outside of the Great Walks season, it is recommended that people not walk the Track. This is due to two major reasons; lack of facilities and risk. ${ }^{132}$ The Department of Conservation (DOC) does not manage or monitor hazards during winter. The Milford Track has complex terrain, resulting in frequent avalanches and floods.

\footnotetext{
${ }^{130}$ No Author (n.d.). Milford Track. Retrieved from https://milfordtrack.net/milford-blog/

${ }^{131}$ No Author. (2018). Plan and Prepare; Milford Track. Department of Conservation. Retrieved from https://www.doc.govt.nz/globalassets/documents/parks-and-recreation/tracks-and-walks/southland/milfordtrack-brochure.pdf

${ }^{132}$ No Author. (n.d.). Milford Track winter tramping. Department of Conservation. Retrieved from https://www.doc.govt.nz/globalassets/documents/parks-and-recreation/tracks-and-walks/southland/milfordtrack-winter-tramping.pdf
} 
Many of bridges are removed over winter to avoid these damages and this serves to make the Track even more dangerous. The lack of facilities and risk disincentivize travel outside the Great Walks season

\subsubsection{Tongariro National Park}

Tongariro National Park is a UNESCO dual heritage site in culture and nature, covers 79,000 ha and contains three volcanoes; Mt. Ngauruhoe, Mt. Tongariro and Mt. Ruapehu. ${ }^{133}$ Tongariro was gifted to the British Crown in 1887, before being officially opened as a national park in 1893 (the world's fourth national park). ${ }^{134}$ Tongariro National Park has a number of different attractions. There are 16 different walking tracks available, requiring a variety of skill levels. ${ }^{135}$ The Ruapehu region is home to two cycleways; Timber Trail and Mountains to Sea. Snow also features during winter months; Mt Ruapehu's Whakapapa and Turoa offer snow sports, making the site a valuable tourist attraction in winter (New Zealand's lowest tourism season). Mt Ruapehu offers learners' facilities, terrain parks for snowboarders and free-ski tracks for all abilities. There is also a huge variety of flora and fauna in and around the alpine zone of Tongariro National Park. ${ }^{136}$

\subsubsection{Waitomo Caves}

Waitomo Caves consists of three major limestone caves: Waitomo, Puakuri and Aranui. Limestone occurs when shells, which accumulated on the sea floor, are buried and compacted to create thick layers of material. The caves are decorated with both stalactites and stalagmites. The main attraction in the caves are the New Zealand Glowworm. When visiting the caves tourists mainly float on rafts and led by a professional tour guide. The caves serve as the focal tourist attraction in Waitomo Village, but other attractions have emerged nearby. A major attraction is walking tracks; 19 start within a $10 \mathrm{~km}$ radius of Waitomo Village. ${ }^{137}$ In 2010, the Waitomo Glowworm Caves Visitor Centre was created to educate visitors about the caves and associated environmental issues. ${ }^{138}$ In

\footnotetext{
${ }^{133}$ Tongariro National Park Villages. (n.d.). Retrieved from https://www.nationalpark.co.nz/

${ }^{134}$ Department of Conservation. (n.d.). About Tongariro National Park. Retrieved from https://www.doc.govt.nz/parks-and-recreation/places-to-go/central-north-island/places/tongariro-nationalpark/about-tongariro-national-park/

135 Department of Conservation. (n.d.). Walks in and around Tongariro National Park. Retrieved from https://www.doc.govt.nz/globalassets/documents/parks-and-recreation/tracks-and-walks/tongarirotaupo/tongariro-national-park-walks.pdf

136 Department of Conservation. (n.d.). Flora and Fauna. Retrieved from https://www.doc.govt.nz/parks-andrecreation/places-to-go/central-north-island/places/tongariro-national-park/about-tongariro-nationalpark/flora-and-fauna/

137 Department of Conservation. (n.d.). Waitomo and King Country Tracks. Retrieved from http://www.waitomo.govt.nz/PageFiles/597/waitomo-kingcountry-walks\%5B1\%5D.pdf?epslanguage=en-NZ 138 THL. (2010). Waitomo Glowworm Caves Visitor Centre rises from the ashes. Retrieved from https://www.explorecentralnorthislandnz.com/wp-content/uploads/2012/02/Waitomo Glowworms.pdf
} 
addition, there is the Waitomo Museum of Caves that houses a large range of fossils, crystal formations and skeletons. Finally, there is the Waitomo Caves Discovery Centre, which houses the only speleological museum in New Zealand. ${ }^{139}$

\subsubsection{Rotorua}

Rotorua is a town in New Zealand's North Island, with two major attractions. The first is the geysers, which are formed when water underground is heated, and rises to the surface. ${ }^{140}$ The geysers at Rotorua are important internationally because of their rarity, with only a few geyser basins in the world today. ${ }^{141}$ At Rotorua, eight geysers remain active, compared with over 60 prior to human interference. Water extraction has resulted in this massive destruction of geysers. Current government oversight sees $90 \%$ of well withdrawal reinjected, with monitoring to ensure wells are not drowned. ${ }^{142}$ The second attraction is New Zealand Māori Arts and Crafts Institute (NZMACI). Sir Apirana Ngata created NZMACl in 1926, believing material culture was key to Māori cultural preservation. There are three National schools at NZMACl, each with their own specialisation. One is the Wood Carving School (Te Wānanga Whakairo Rākau). ${ }^{143}$ Second is the Stone and Bone Carving School (Te Takapū o Rotowhio). ${ }^{144}$ The third school is the Weaving School (Te Rito). ${ }^{145}$ There is also a Pre-European Māori village and Marae that holds Māori cultural performances, rounding out the Māori cultural experience.

\subsection{Key Theme One: Nature}

The idea of nature tourism is very important to New Zealand tourism and many campaigns have been devoted to highlighting its importance. The Chinese tourist gaze is interested in the relationship that nature has with humanity; whether that be through infrastructure, technology or culture (to name a few options). ${ }^{146}$ Confucianism discusses the importance of respect for history, culture and learning, which is present in the Chinese tourists' interest in learning about the literature

\footnotetext{
${ }^{139}$ Arrell, R. (n.d.). Waitomo Caves, N.Z.: Waitomo Caves Museum Society.

140 Stewart, C. (2006). Story: Hot springs, mud pools and geysers. Te Ara. Retrieved from https://teara.govt.nz/en/hot-springs-mud-pools-and-geysers

${ }^{141}$ Barrick, K. A. (2007). Geyser decline and extinction in New Zealand-energy development impacts and implications for environmental management. Environmental Management, 39(6), 784.

142 Ibid 786-802.

${ }^{143}$ No Author. (n.d.). About Te Wānanga Whakairo. Retrieved from https://www.nzmaci.com/schools/tewananga-whakairo-rakau-o-aotearoa/

${ }^{144}$ No Author. (n.d.). About Te Takapū. Retrieved from https://www.nzmaci.com/schools/te-takapu-orotowhio/

145 No Author. (n.d.). About Te Rito. Te Puia. Retrieved from https://www.nzmaci.com/schools/te-rito/

146 Tianchen, L. (2003). Confucian ethics and the environment. Culture Mandala, 6(1), 5856.
} 
and history associated with famous landmarks, monuments and landscapes. ${ }^{147}$ This relates to seeking a better understanding of nature while paying attention to spiritual cultivation. ${ }^{148}$ This section examines the presentation of nature within New Zealand tourism and how it relates to the Chinese gaze.

\subsubsection{Milford Track}

The Milford Track highlights the relationship between conservation and profits, with Milford Track supporting conservation over financial success. The Milford Track showcases preservation and unaltered natural landscape. Only 40 people can start the Milford Track each day, which helps protect the environment. Choosing to limit the number of people who start the Track also frames the relationship between nature and man as something that should work together. ${ }^{149}$ There is less congestion and crowding on the Track and this places less pressure on the natural ecosystem. Sustaining low numbers on the Track means it does not get overcrowded allows people to experience the feeling of being alone. The walking track offers, "complete immersion in the landscapes of southern New Zealand. ${ }^{150 \prime \prime}$ It relates strongly to the third goal in New Zealand's tourism development plan, with a focus on environmental sustainability over immediate economic benefits. It also suggests a rejection of high volume and shows a preference for travellers who value eco-tourism. Milford Track boasts flora and fauna that are unique to the region and New Zealand, which serves to elevate the ideas of experiencing nature. ${ }^{151}$

Milford Track has an international reputation for being one of the best walking tracks, which could be leveraged to create a strong economic growth pole. ${ }^{152}$ This would lead to a growth in macroeconomics, as the development of the Milford Track to facilitate more walkers would also lead to the growth of the surrounding area with the growth of facilities to support more tourists, and then to encourage purchases and extended stay in the area. This is not sustainable, as infrastructure would need to develop to maintain the growing number of tourists. ${ }^{153}$ Milford Track highlights the emphasis of nature in New Zealand, and represents an ongoing resistance to development, if it will

\footnotetext{
147 Ibid.

$148 \mathrm{He}, \mathrm{C}$. (2018). New Confucianism, science and the future of the environment. European Review, $26(2), 371$.

149 Tianchen, L. (2003). Confucian ethics and the environment. Culture Mandala, 6(1), 5856.

150 Milford Track. (2017). Milford Track Diary - One Tramper's Experience of the Milford Track. Retrieved from https://milfordtrack.net/milford-track-diary-one-trampers-experience-milford-track/

${ }^{151}$ Destination Fiordland. (n.d.). Flora and Fauna. Retrieved from https://www.fiordland.org.nz/aboutfiordland/flora-and-fauna/

152 Becken, S. (2005). The role of tourist icons for sustainable tourism. Journal of Vacation Marketing, $11(1), 24$.

153 Mandić, A., Mrnjavac, \&., \& Kordić, L. (2018). TOURISM INFRASTRUCTURE, RECREATIONAL FACILITIES AND

TOURISM DEVELOPMENT. Tourism and Hospitality Management, 24(1), 48.
} 
cause degradation to the environment. Overall, the Milford Track highlights a close relationship between people and nature and suggests the importance of wild nature in New Zealand tourism. It suggests an adherence to environmentalism and eco-tourism, over immediate profits and encouraging free and independent travellers (FIT), as FITs are the most likely to walk the Track .

\subsubsection{Tongariro National Park}

Tongariro National Park highlights the other side of the conservation debate that Milford Track brings up, showing a system where environmental integrity is competes with profits and tourism. Tongariro National Park places the wonders of nature as a key feature of the Park's experience. All of the different attractions studied in this thesis have a basis in nature and highlight the natural flora and fauna in the region. The unique lifeforms and plant life in the Park are marketed as a spectacle. ${ }^{154}$ This makes it apparent that the natural attractions are the major attraction, with Tongariro National Park as a nature-based World Heritage Site. According to DOC, Tongariro National Park is managed with the ultimate goal of protecting the environment and its inhabitants. This is not only due to environmental concerns, but also because of the spiritual importance on the land for Māori. ${ }^{155}$

At the same time, the Park attempts to make a profit and allows for recreational sports like cycling and skiing to occur, which means the environmental integrity of Tongariro National Park is compromised. ${ }^{156}$ The focus on environmental sustainability us not as prominent here as it is on the Milford Track. This has become especially prominent since the park was granted World Heritage Status. The argument for the utilization of the Park is financially strong; skiing on Ruapehu is worth over 26 million NZD annually. This area is very popular, with over 125,000 tourists every year. ${ }^{157}$ Removing skiing in order to protect the environment would have a devastating impact on the regional and national economy. The infrastructure to support tourism has serious impacts on the environment. ${ }^{158}$ The debate between profits and conservation is apparent when looking at Tongariro

\footnotetext{
${ }^{154}$ Department of Conservation. (n.d.). Flora and Fauna. Retrieved from https://www.doc.govt.nz/parks-andrecreation/places-to-go/central-north-island/places/tongariro-national-park/about-tongariro-nationalpark/flora-and-fauna/

${ }^{155}$ Carr, A. (2004). Mountain places, cultural spaces: The interpretation of culturally significant landscapes. Journal of Sustainable Tourism, 12(5), 433.

${ }^{156}$ Groot, R. (2003). The Tongariro National Park: Are We Loving it to Death? New Zealand Journal of Geography, 115(1), 3.

${ }^{157}$ Hampton, L. (2017). Tongariro Crossing struggling to cope with hordes of tourists. Retrieved from https://www.newshub.co.nz/home/new-zealand/2017/02/tongariro-crossing-struggling-to-cope-with-hordesof-tourists.html

158 Ibid 8.
} 
National Park, and the huge profit potential of a world-renowned site is hard to ignore. While conservation efforts exist, it is far less prominent and effective than on the Milford Track.

\subsubsection{Waitomo Caves}

The Waitomo Caves place a lot of emphasis on the human-nature relationship, and works to promote education to encourage environmentally conscious actions. During guided talks, tourists are educated about the caves and environmental concerns are brought to their attention. They are encouraged to think critically about the environment and to adopt more environmental practices. The Troll Cave (found within the Museum of Caves) is an example of how the conservation message is emphasized. Designed for children, the Troll Cave provides an interactive story with a conservation message. The tourism strategy of environmental protection is key here, and there is a focus on education (particularly about biodiversity and the natural heritage of New Zealand). The reason why the Waitomo Caves focuses on human environmental responsibility is the impact that humans have had on the ecosystems within the caves. In 1979, the caves had to close for a year because an increase in moisture and temperature (caused by high tourism numbers) led to a decline in glowworm health, representing the extent of human damage to the planet. ${ }^{159}$ The ongoing human movement and development within the caves poses a serious threat to the longevity of the caves. Overall, the impacts felt by human interference within the caves is significant and a strong environmentally conscious image indicates a serious attempt to mitigate the damage done by humans within the caves and the surrounding environment. Education of the environment and conservation is a key element of the tourism experience in New Zealand.

\subsubsection{Rotorua}

Rotorua demonstrates how human activity has damaged the environment in the past and shows the risk that New Zealand's natural environment is facing. Previous human activity in Rotorua has already led to the extinction of a number of different geysers in Rotorua. In the Rotorua area, there were originally an estimated 65 geyser basins. Of those 65, 27 are now extinct, 22 were flooded by humans, eight are dormant and eight remain active. ${ }^{160}$ The active ones face threats caused by human activity. DOC outlines the ways the activities of humans are putting geysers at risk. ${ }^{161}$

\footnotetext{
${ }^{159}$ Van Beynen, P. E., \& Bialkowska-Jelinska, E. (2012). Human disturbance of the Waitomo catchment, New Zealand. Journal of environmental management, 108, 130-140.

${ }^{160}$ Barrick, K. A. (2007). Geyser decline and extinction in New Zealand-energy development impacts and implications for environmental management. Environmental Management, 39(6), 789.

${ }^{161}$ Department of Conservation. (2006). Geothermal systems. Retrieved from https://www.doc.govt.nz/Documents/about-doc/concessions-and-permits/conservationrevealed/geothermal-systems-lowres.pdf
} 
Extraction of fluids and energy has affected and reduced the extent of geothermal features and vegetation. Urban and industrial developments adjoining the geothermal fields have already destroyed much of the geyser's associated scrublands. The introduction of exotic plants (primarily pines, bamboo, and acacias) damages native ecosystems and the natural character of geothermal areas. $^{162}$

The highlighting of conservation and eco-tourism is also evident here, through education and a focus on the ecological processes that have created the geysers, mud pools and hot springs. Through educating about how industrialisation has led to the destruction of so many natural phenomenon in the area, DOC aims to encourage social responsibility and promote environmentally conscious movements. However, some locals are concerned about the prohibition of using well water, and the costs of acquiring water (and energy) elsewhere. The relationship between people and nature pits economic profits/advantages against securing the planet for future generations, which is something that has been observed at several locations around New Zealand. The message of eco-tourism and conservation is prominent here, through utilizing rarely occurring natural spectacles.

\subsection{Key Theme Two: Māori Culture}

Cultural interactions in tourism are important to Chinese tourism because of ideas rooted in Confucianism. The interest in cultural tourism relates to a number of ideas discussed in Confucianism. This includes respect for history, exposure to foreign cultures, horizon broadening and gaining knowledge. ${ }^{163}$ The Chinese gaze in relation to culture encourages understanding other cultures and that cultural appreciation is key to personal development. This section examines the role of Māori tourism in New Zealand, as it is one of the most prominent examples of cultural tourism in the country. Their cultural distinctiveness enables Māori tourism to create unique, original and authentic tourism offerings that align to their abilities and competencies, while controlling the dissemination of their culture. ${ }^{164}$

\section{Maori Values in New Zealand Tourism}

Mãori culture within New Zealand tourism because of its uniqueness to the nation. It has been crucial for more than 150 years by offering a 'point of difference' from other destinations, as the

\footnotetext{
162 Burns, B., Ward, R., \& Downs, J. (2013). Trampling Impacts on Thermotolerant Vegetation of Geothermal Areas in New Zealand. Environmental Management, 52(6), 1463-1473.

$163 \mathrm{Hsu}$, C. H., \& Huang, S. S. (2016). Reconfiguring Chinese cultural values and their tourism implications. Tourism Management, 54, 235-236.

164 Puriri, A., \& Mclntosh, A. (2019). A cultural framework for Māori tourism: values and processes of a Whānau tourism business development. Journal of the Royal Society of New Zealand, 49(sup1), 91.
} 
culture cannot be found anywhere else in the world. However, their identity as tourist 'attractions' rather than tourism 'managers' has tended to stereotype the Māori image and fix Māori culture in a temporal zone of 'traditionalized. ${ }^{165}$ ' Because of their lack of involvement in the tourism management until recently, many of New Zealand's offshore tourism marketing campaigns present a stereotypical and homogenous representation of 'Māori culture. ${ }^{166}$ ' In the last two decades the Māori population have taken a more active role in managing Māori tourism. Through adjusting existing power structures, indigenous peoples re-define their cultural production and products. ${ }^{167}$ This has led to the integration of Māori values within the New Zealand tourism industry. Puriri identifies a number of Māori values that are present within New Zealand's tourism structure ${ }^{168}$;

- Wairuatanga - state of being spiritual

- Whānaungatanga - relationship/kinships

- Ngā Matatini Māori - Māori diversity

- Kaitiakitanga - guardianship of the land

- Manaakitanga - warm hospitality

- Tino Rangatiratanga - self-determination

- Kotahitanga - unity and solidarity

- Tuhono - principle alignment

- Purotu - principle of transparency

- Puawaitanga - principle of best outcomes

Given that Māori refers to themselves as tangata whenua or "people of the land" the social, economic and political upheavals and changes caused by tourism affect the Māori population to a serious degree. ${ }^{169}$ It is important to examine the incorporation of the Māori people and their values in New Zealand tourism as it is a major factor in driving people to visit New Zealand.

\footnotetext{
${ }^{165}$ Amoamo, M., \& Thompson, A. (2010). (re) Imaging Māori tourism: Representation and cultural hybridity in postcolonial New Zealand. Tourist Studies, 10(1), 41.

${ }^{166}$ Amoamo, M., \& Thompson, A. (2010). (re) Imaging Māori tourism: Representation and cultural hybridity in postcolonial New Zealand. Tourist Studies, 10(1), 36.

${ }^{167}$ Amoamo, M., \& Thompson, A. (2010). (re) Imaging Māori tourism: Representation and cultural hybridity in postcolonial New Zealand. Tourist Studies, 10(1), 37.

168 Puriri, A., \& McIntosh, A. (2019). A cultural framework for Māori tourism: values and processes of a Whānau tourism business development. Journal of the Royal Society of New Zealand, 49(sup1), 91.

${ }^{169}$ Amoamo, M., Ruckstuhl, K., \& Ruwhiu, D. (2018). Balancing indigenous values through diverse economies: A case study of Māori ecotourism. Tourism Planning \& Development, 15(5), 481.
} 


\subsubsection{Milford Track}

Milford has no serious Māori elements, but rather it solely focuses on nature. There is no discourse in literature about the role of Māori at this location.

\subsubsection{Tongariro National Park}

The historical relationship between European settlers and indigenous Māori is important to the ongoing cultural discourse at Tongariro National Park, and it demonstrates ongoing tensions related to the use of the land in the area. Tongariro originally gifted by Horonuku te Heuheu Tukino IV and Ngāti Tuwharetoa in 1893 as a means of protecting the mountains. ${ }^{170}$ This act has seen the authority of Ngāti Tuwharetoa greatly reduced as their involvement, guardianship and protection of their taonga (treasured heritage) was limited. ${ }^{171}$ In 1882, when the first European documents were written about the area, the Māori connections were absent and recreational needs came to the forefront. ${ }^{172}$ This is how skiing, climbing and hiking first came to the region. The destination image at today is still aligned with those early European ideas. ${ }^{173}$

Zeppel talks about the emergence of conflicts between indigenous and recreational thoughts regarding Tongariro National Park. ${ }^{174}$ This relates to the use of equipment in the area as well as the introduction of machinery, people and/or animals that alter the ecosystem. This disregards the spiritual importance of the area in Māori mythology. This creates a clash of value systems between Māori and tourists. Recreational users are concerned primary about their own enjoyment. Indigenous groups are concerned about how the degradation of the land affects their identity, as their identity is related to the land. They are also concerned over their rights to be involved in the deliberation process regarding Tongariro National Park. At Tongariro National Park there is a clear conflict over the cultural values and there is tension related to the relationship between Māori and the New Zealand government. While Māori cultural growth is discussed at length in New Zealand's tourism strategies, this is not realized at Tongariro National Park. There is the presence of Māori heritage at a superficial level (where their historical presence and mythology are lightly referenced)

\footnotetext{
${ }^{170}$ Cahn, R., \& Cahn, P. L. (1989). Reorganizing conservation efforts in New Zealand. Environment: Science and Policy for Sustainable Development, 31(3), 36.

${ }^{171}$ Zeppel, H. (2010). Managing cultural values in sustainable tourism: Conflicts in protected areas. Tourism and Hospitality Research, 10(2), 95.

172 Walliss, J. (2014). Transformative Landscapes: Postcolonial Representations of Uluru-Kata Tjuta and Tongariro National Parks. Space and Culture, 17(3), 281.

173 Baird, M. (2013). "The breath of the mountain is my heart": Indigenous cultural landscapes and the politics of heritage. International Journal of Heritage Studies, 19(4), 336.

${ }^{174}$ Zeppel, H. (2010). Managing cultural values in sustainable tourism: Conflicts in protected areas. Tourism and Hospitality Research, 10(2), 93-115.
} 
but actual engagement is not present. In order to more effectively utilize Māori culture at this site, acknowledge of Māori history and more involvement of the Māori community is crucial.

\subsubsection{Waitomo Caves}

The heritage of Māori at Waitomo Caves is largely ignored, but rather there is a focus on natural processes. The ownership of the Waitomo Caves has been returned to the descendants of the original owner (Tane Tinorau) in 1989, following almost a century of government administration. ${ }^{175}$ This has allowed a degree of Māori involvement and influence in the area. This is supported by DOC, who mention Māori's ongoing role in the future of the Waitomo Caves. Prior to European colonisation, Māori used caves as shelter and burial sites, which means that caves are regarded as sacred (tapu). Ruakuri is the site of a Māori cultural story that predates the settling of the area. ${ }^{176}$ Māori legend speaks about a hunter who came across the cave 500 years ago, and was attacked by a pack of wild dogs. ${ }^{177}$ The original entrance to Ruakuri was used for burials, and it was not until 2005 that a new entrance was made so tourists would not step on these burial grounds. Comparatively, it is very easy to find information about how limestone or cave decorations are made. There is also a lot of attention on the life cycle of the glowworm, as the main attraction of the caves. Overall, the Visitor Centre takes a more scientific as opposed to a sociological approach, and the history of Māori involvement at Waitomo Caves have largely been ignored. ${ }^{178}$ At Waitomo, Māori involvement exists, but their cultural presence and heritage are almost completely ignored, which does not fall in line with TNZ's goal of enhancing New Zealand's cultural tourism.

\subsubsection{Rotorua}

Rotorua has one of the best realised examples of Māori tourism in New Zealand. Māori culture in Rotorua's tourism industry has a largely performative role, from their performances in the village, at dances/singing events and even through the production of Māori crafts at NZMACl. Tahana suggests tourists expect to see an unspoiled, idealistic and traditional presentation during indigenous tourism. ${ }^{179}$ This subverts Māori culture and reduces it to a spectacle. Uniformity ensures the experience is similar for all tourists around the nation. This uniformity undermines historical

\footnotetext{
175 Pavlovich, K. (2003). The evolution and transformation of a tourism destination network: the Waitomo Caves, New Zealand. Tourism Management, 24(2), 203-216.

176 THL. (2010). Waitomo Glowworm Caves Visitor Centre rises from the ashes. Retrieved from https://www.explorecentralnorthislandnz.com/wp-content/uploads/2012/02/Waitomo Glowworms.pdf/

177 No Author. (n.d.). Waitomo Caves Discovery Centre. Retrieved from https://www.waitomocaves.com/

178 Ibid.

179 Tahana, N., \& Oppermann, M. (1998). Māori cultural performances and tourism. Tourism Recreation Research, 23(1), 23.
} 
differences and further serves to commercialise Māori culture, however, it does enable cultural expression. Some critics have noted the fact that NZMACl, while it has protected Māori arts from extinction, now resembles a construction line and is primarily geared towards selling art to tourists. ${ }^{180}$ At the same time, Māori culture is largely controlled and operated by Māori people, so they have a significant degree of autonomy and self-determination. This is one of the best examples of Māori involvement in tourism in the country, and it also allows for regional development as Rotorua has grown as one of regional New Zealand's most well-known tourism locations (even following the destruction of the Pink and White Terraces). Overall, Māori's relationship with tourism in Rotorua is based solely on the tourists' expectations of Mãori life, and the desire to demonstrate the pre-colonial life of Māori. This places the Māori way of life as an exotic other that reinforces the traditional Western colonial narrative.

\subsection{Appeal for Chinese Tourists}

\subsubsection{Iconic Status}

These four case studies provide a lot of useful information about appealing to Chinese tourists. First is the renown of attractions. Locations with an iconic status are appealing to Chinese tourists. These attractions are located away from the central hubs of Auckland and Otago that Chinese tourists usually visit. Hsu mentions that Chinese tourists prefer to visit the most popular destinations when they travel. ${ }^{181}$ The Milford Track is internationally recognised and Tongariro National Park is a UNESCO heritage site, which means both are must-see attractions in New Zealand. This means Chinese tourists are likely to consider travelling to visit these attractions despite the time as distance costs. ${ }^{182}$ Tongariro National Park was also a filming location for both the Lord of the Rings and Hobbit trilogies, an internationally recognised franchise. With a combined have a box office value of over 8.7 billion NZD, they have become a key marketing element for New Zealand tourism (valued at \$33 million NZD a year). ${ }^{183}$ Rotorua also has an established Chinese tourism industry, with Chinese tourists spending $\$ 43$ million NZD in the town last year. As long as positive word of mouth continues, Chinese tourism will continue to develop in Rotorua.

\footnotetext{
${ }^{180}$ Foley, D. (2011). From traditional carving to plastic Tiki: Māori struggles to balance commerce and culture within the global tourism marketplace, 1860-2010. Journal of Tourism History, 3(2), 182.

${ }^{181} \mathrm{Hsu}, \mathrm{C}$. H., \& Song, H. (2012). Projected images of major Chinese outbound destinations. Asia Pacific Journal of Tourism Research, 17(5), 584.

182 Jin, X. C., \& Sparks, B. (2017). Barriers to offering special interest tour products to the Chinese outbound group market. Tourism Management, 59, 212.

183 Li, S., Li, H., Song, H., Lundberg, C., \& Shen, S. (2017). The economic impact of on-screen tourism: The case of The Lord of the Rings and the Hobbit. Tourism Management, 60, 178.
} 


\subsubsection{Natural Scenery}

Scenery appreciation is another major selling point for Chinese tourists. Chinese tourists want to get in touch with nature, and $70 \%$ of Chinese tourists cite nature as a key reason for travelling to New Zealand in the first place. ${ }^{184}$ Immersion in nature is offered at Milford Track, Tongariro National Park and Waitomo, which fulfils the interest that Chinese tourists have. ${ }^{185}$ While Chinese tourists are interested in nature, they prefer to have it enhanced with stories and culture. This is something New Zealand often lacks. Chinese tourists, while they care about the environment, also want a certain standard of living when they travel. Chinese travellers want comfort while they are travelling and do not want to live in harsh conditions, but would rather engage in activities that relate to the ideas of indulgence and quality of life. ${ }^{186}$ Sites such as Milford Track is unable to provide these accommodations, because of environmental movements and concerns. This is not appealing to Chinese tourists. There needs to be a merging of culture, development and landscape in order to create the ideal tourism situation to appeal to the largest portion of Chinese tourists.

\subsubsection{Environmental Sustainability}

Chinese tourists want to enhance the natural world with more technology and human influence, as long as it is done in a sustainable way. In Confucianism, infrastructural phenomenon and natural phenomenon should work in harmony and nature is there to help humanity develop. Confucianism considers that all things in nature were the material foundation upon which human beings lived; hence, people should take a conservative approach to nature. ${ }^{187}$ Modernity has led to the exploitation of natural resources and degradation of the natural environment. The Waitomo Caves, Rotorua and the Milford Track emphasise conservation and protecting the environment. China has felt first-hand the effects of environmental degradation. Haze and smog are both very real occurrences in China that have serious economic and health-based consequences. ${ }^{188}$ This means that Chinese tourists have a strong appreciation for conservation efforts. DOC and the New Zealand government are concerned about environmentalism and conservation and this is the message

\footnotetext{
${ }^{184}$ Tourism New Zealand. (2018). China Market Snapshot. Retrieved from https://www.tourismnewzealand.com/media/2590/china-market-snapshot.pdf

${ }^{185} \mathrm{Kim}, \mathrm{H} .$, \& Stepchenkova, S. (2015). Effect of tourist photographs on attitudes towards destination: Manifest and latent content. Tourism Management, 37.

${ }^{186} \mathrm{Hsu}, \mathrm{C}$. H., \& Huang, S. S. (2016). Reconfiguring Chinese cultural values and their tourism implications. Tourism Management, 54, 237.

${ }^{187}$ Christensen, J. (2014). Building an Environmental Ethics from the Confucian Concepts of Zhengming and Datong. Asian Philosophy, 24(3), 1-15.

188 Peng, J., \& Xiao, H. (2018). How does smog influence domestic tourism in China? A case study of Beijing. Asia Pacific Journal of Tourism Research, 23(12), 1115-1128.
} 
presented to all tourists. Chinese tourists generally agree with the ideas of conservation and the responsibility to protect the environment.

\subsubsection{Challenges and Risk}

Challenges and risk are not appealing to Chinese tourists. According to Mok, Chinese tourists can be described as risk averse. ${ }^{189}$ Chinese tourists who come to New Zealand prefer pamper themselves and relax (54\% and 53\% respectively). ${ }^{190}$ There are several news articles that detail the risks associated with walking on the Milford Track, and those that have died attempting it. ${ }^{191}$ These risks could hinder Chinese tourists from experiencing the Track. Adventure sports are also not appealing to the Chinese audience. While some areas like Tongariro National Park offer safer options (such as beginner skiing), there are less opportunities for Chinese tourists. Their risk adverse nature means that they will not participate in the more adventurous activities at Waitomo or Tongariro National Park; for example black water rafting, wild caving or abseiling. ${ }^{192}$ However, they will very much enjoy the safer activities such as the guided tour and the boat rides, so marketing these options will help to develop Chinese tourism.

\subsubsection{Māori Culture}

The presence of Māori at key tourism locations in New Zealand acts as a special drawcard for Chinese tourists. Māori influence serves a dual purpose; to give New Zealand a feeling of uniqueness, and to construct a culturescape. Chinese tourists are not as interested in ecological processes as Western tourists are, so cultural history serves to draw in Chinese tourists. According to TNZ, experiencing Māori culture and/or activities is a popular element of visiting New Zealand (71\% experienced a Māori-related event). ${ }^{193}$ If Tongariro National Park or Waitomo Caves utilized the Māori culture, myths or history, it would elevate the scenery for Chinese tourists. ${ }^{194} \mathrm{NZMACl}$ is also a prominent attraction that appeals to Chinese tourists, with $45 \%$ of Chinese tourists visiting museums

\footnotetext{
${ }^{189}$ Mok, C., \& DeFranco, A. L. (2000). Chinese cultural values: Their implications for travel and tourism marketing. Journal of Travel \& Tourism Marketing, 8(2), 111.

${ }^{190}$ Tourism New Zealand. (2018). China Market Snapshot. Retrieved from https://www.tourismnewzealand.com/media/2590/china-market-snapshot.pdf

191 One News. (2015). Walker dies on Milford Track. Retrieved from https://www.tvnz.co.nz/one-news/newzealand/walker-dies-on-milford-track-6249499

${ }^{192}$ No Author. (n.d.). Waitomo Caves Discovery Centre. Retrieved from https://www.waitomocaves.com/

193 Tourism New Zealand. (2018) China Market Snapshot. Retrieved from https://www.tourismnewzealand.com/media/2590/china-market-snapshot.pdf

${ }^{194}$ Fountain, J., Espiner, S., \& Xie, X. (2010). A cultural framing of nature: Chinese tourists' motivations for, expectations of, and satisfaction with, their New Zealand tourist experience. Tourism Review International, $14(2-3), 79$.
} 
or art galleries. ${ }^{195}$ Visiting NZMACI provides Chinese tourists with an opportunity to discover how some souvenirs are made and it provides them with a chance to shop for authentic goods. This is appealing to Chinese tourists, because Chinese tourists are one of the world's biggest shoppers who place a high value on authentic goods. This is because they will serve to strengthen relationships between those who give and those who receive. The prominent nature of Māori culture and its commodification is a major draw feature for Chinese tourists and is one of the major driving forces for Rotorua's Chinese tourism market.

\subsection{Adaptation for the Tourism Market}

This chapter has established that there are some issues in attracting tourism, which is due in part to the traditional Western marketing model utilized within New Zealand since the onset of tourism. Alongside the rise of Chinese outbound tourism, New Zealand has begun to take steps to adjust its offerings and marketing strategies. The first involves better understanding the Chinese market, as cultural distinctions are not usually accounted for. This was highlighted in New Zealand-Aotearoa Government Tourism Strategy, where there was acknowledgement to better understand markets outside of New Zealand's traditional ones (the US, UK and Australia). Visitor analysis, insights and forecasting by the Ministry of Business, Innovation and Employment (MBIE), TNZ and DOC are key to better understanding inbound markets. ${ }^{196}$ New Zealand Story (NZ Story) has also addressed marketing issues and argues New Zealand needs to more carefully market to Chinese tourists. NZ Story points out that much of New Zealand's marketing is too one dimensional for the Chinese market, and images need to be both appealing and need to highlight that they are from New Zealand. An example used suggests moving away from a plate of food to a dining scene with nature in the background, highlighting community and the culture of farm-to-table in New Zealand. ${ }^{197}$

TNZ also wants to showcase the country's nature, culture and history in world-class, authentic and safe experiences, reflecting a shift to high quality and an integration of culture and nature in the tourism experience. ${ }^{198} \mathrm{NZ}$ Story also supports advertising and implementing the integration of

\footnotetext{
195 Tourism New Zealand. (2018). China Market Snapshot. Retrieved from https://www.tourismnewzealand.com/media/2590/china-market-snapshot.pdf

196 Ministry of Business, Innovation and Employment. (2019). New Zealand-Aotearoa Government Tourism Strategy. Retrieved from https://www.mbie.govt.nz/dmsdocument/5482-2019-new-zealand-aotearoagovernment-tourism-strategy-pdf

197 NZ Story. (n.d.). Creative Imagery Tips. Retrieved from https://toolkit.nzstory.govt.nz/assets/264335?tags=creative\%20imagery\%20tips

198 Ministry of Business, Innovation and Employment. (2019). New Zealand-Aotearoa Government Tourism Strategy. Retrieved from https://www.mbie.govt.nz/dmsdocument/5482-2019-new-zealand-aotearoagovernment-tourism-strategy-pdf
} 
technology and nature, through suggesting the traditional marketing model of 'open spaces' is no longer enough. They argue China is already well versed in New Zealand nature, so now it is important to showcase industry, development and progress. This is not only to highlight the Chinese tourists' experience with nature, but also to challenge the perception of New Zealand as a solely agricultural nature. ${ }^{199}$ There is also interest in the interactions Chinese tourists have with New Zealanders. Over the course of the China - New Zealand Year of Tourism, there were a number of document produced by TNZ. They highlight some minor variations in behaviour concerning Chinese tourists, for example group size and inter-group relationships. ${ }^{200}$ Chinese outbound tourism to New Zealand is shaping the political economy by challenging the offerings and marketing available. It is adjusting the tourism economy and promoting a greater uptake of technological and cultural facilities around the nation. These adaptations are still in their infancy, but they represent a move in national direction through the adjustments of offerings and marketing in New Zealand.

\subsection{Conclusion}

Currently, Chinese tourism runs the risk of stagnating due to their needs not being fully met, and this has major ramifications for New Zealand's economy. This examination highlights that New Zealand's largest tourist attractions place a major focus on the natural elements of New Zealand. Alongside these natural attractions, Māori tourism sometimes acts as a secondary feature to provide history and interest in the natural phenomenon. This nature focus does not always meet all of the needs of the Chinese audience, who are more interested in culturescapes that combine cultural understanding with nature appreciation. Māori culture fills in this gap effectively, highlighting New Zealand's unique culture and historical past. More New Zealand attractions need to adopt Rotorua's practices and highlight Māori culture to Chinese inbound tourists. These attractions highlight a couple of issues with TNZ's current strategies. These strategies reference the increase involvement by the Māori population, but issues with representation and Māori discourse poses a problem to legitimate Māori involvement. Tourism in New Zealand attempts to balance profit and sustainability. New Zealand stresses environmental responsibility and has a history of environmental activism. ${ }^{201}$ The rise of Chinese tourism to New Zealand has challenged the traditional way of understanding nature based tourism through encouraging a more technologically adapt process and considering a different narrative from the traditional Western one that New Zealand has traditionally relied on.

\footnotetext{
199 NZ Story. (2018). CHINA PERCEPTIONS RESEARCH PRESENTATION. Retrieved from https://toolkit.nzstory.govt.nz/assets/243584?tags=Perception\%20Research

${ }^{200}$ China - New Zealand Year of Tourism. (2019). Catering to Chinese visitors. Retrieved form https://www.cnzyot.govt.nz/assets/PDF-resources/c002499002/Catering-to-Chinese-visitors.pdf ${ }^{201}$ Downes, D. (2000). The New Zealand environmental movement and the politics of inclusion. Australian Journal of Political Science, 35(3), 474.
} 


\section{CHAPTER THREE - LINKS BETWEEN TOURISM AND TRADE}

\subsection{Introduction}

The economic impact of Chinese tourism has been broadly positive for New Zealand but more could be done to leverage international tourism, because the economic effect of tourism is not only bound to tourist spending within the country. Through the initiation of e-commerce, spending continues economic growth once tourists return home. Strong links between tourism and trade continue to develop the New Zealand economy through the growth of revenue generated by tourism. There are risks to the current system however. New Zealand runs the risk of developing a negative reputation among Chinese tourists due to two reasons; (1) high costs and (2) the negative practices associated with shopping tours. In the e-commerce sector, New Zealand underperforms through its limited presence and sole focus on agricultural produce. Creating a strong brand and developing both tourism and online shopping capabilities would help to more effectively market to Chinese tourists and would make New Zealand more memorable. This would help to protect the nation's economic interests and strengthen the economic earnings from a successful tourism relationship with China.

\subsection{Expenditure Patterns}

\subsubsection{Overall Spend}

This section examines Chinese expenditure patterns around the world. This thesis has collected information from six countries (New Zealand, Australia, Canada, US, Japan and Thailand) and examined how much Chinese tourists are spending on average, and how much they are spending per day. These six countries cover a wide base of nations that are linked to New Zealand and Chinese tourism. Japan and Thailand are the most popular destinations for Chinese tourists. The US is the most popular English-speaking destination. Australia is a close neighbour and tourism competitor. Canada promotes the same ideas of eco-tourism and promotes nature-based tourism. On average Chinese consumers spend a large amount of money per day when they visit New Zealand compared with other nations ( $\$ 500 N Z D$ a day). ${ }^{202}$ This can be compared to the $\$ 300$ NZD they spend around the rest of the world. This section will provide a breakdown of common spending patterns to determine why Chinese tourists are spending so much in New Zealand. All numbers noted in the figures below are recorded in New Zealand dollars (NZD).

\footnotetext{
${ }^{202}$ Travel China Guide. (2018). 2017 China Tourism Facts \& Figures. Retrieved from https://www.travelchinaguide.com/tourism/2017statistics/
} 
Figure Two: Average Shopping Spend in Different Countries

\begin{tabular}{|l|l|l|l|}
\hline Destination & $\begin{array}{l}\text { Length of Stay } \\
\text { (Days) }\end{array}$ & Total Spend (NZD) & Spend Per Day \\
\hline New Zealand & 9 & $4,901.00$ & 544.55 \\
\hline Australia & 32 & $5,437.97$ & 169.93 \\
\hline Canada & 30 & $3,243.71$ & 108.12 \\
\hline US & 18 & $10,474.45$ & 581.13 \\
\hline Japan & 6 & $1,536.06$ & 256.01 \\
\hline Thailand & 8 & $2,331.31$ & 288.56 \\
\hline World Average & 10 & $2,994.14$ & 299.41 \\
\hline
\end{tabular}

Source: Tourism New Zealand. (2019). Markets \& Stats. Retrieved from

https://www.tourismnewzealand.com/markets-stats/

Spending per day when visiting New Zealand is not only higher than visiting countries closer to China (such as Japan and Thailand) but also significantly more than neighbouring Australia. When observing New Zealand, the high are obvious. High costs are detrimental to destination competitiveness, especially when nearby locations are much less expensive. Statistics several expenses that Chinese tourists are likely to incur while they are visiting New Zealand have been analysed below; these include the average price of a hotel, average food prices and transportation costs.

\subsubsection{Hotel Prices}

Figure Three: Average Hotel Price

\begin{tabular}{|l|l|}
\hline Country & Average Price (NZD) \\
\hline New Zealand & $\$ 207$ \\
\hline Australia & $\$ 173.55$ \\
\hline Canada & $\$ 129.69$ \\
\hline US & $\$ 201.61$ \\
\hline Japan & $\$ 72.29$ \\
\hline Thailand & $\$ 50.67$ \\
\hline
\end{tabular}

Source: Numbeo. (2019). Price by Country (NZD). Retrieved from https://www.numbeo.com/cost-ofliving/prices by country.jsp?displayCurrency=NZD\&itemld=8 
An examination of the average price of a hotel suggests that, of the countries surveyed, New Zealand is an expensive place to stay. Overall, the average price for a hotel is the most expensive among the six sampled countries, though not significantly more expensive than the US. ${ }^{203}$ Japan and Thailand are the cheapest options, and are significantly cheaper than New Zealand (34\% and $24 \%$ respectively). Canada and Australia make up the middle of this study and there is still a large disparity between them and New Zealand. In terms of percentages, an Australian hotel costs $83 \%$ of a New Zealand one, while Canadian hotels are 62\%. Overall, an examination of the average hotel prices demonstrates how expensive New Zealand hotels are compared with the rest of the world.

\subsubsection{Food Prices}

Figure Four: Average Food Prices

\begin{tabular}{|l|l|l|l|l|l|}
\hline Country & Banana (kg) & Big Mac & Milk (1) & $\begin{array}{l}\text { Domestic } \\
\text { Beer (0.5I) }\end{array}$ & Water (1.5I) \\
\hline New Zealand & $\$ 2.93$ & $\$ 7.00$ & $\$ 2.68$ & $\$ 4.42$ & $\$ 1.80$ \\
\hline Australia & $\$ 3.66$ & $\$ 7.31$ & $\$ 1.61$ & $\$ 5.15$ & $\$ 2.34$ \\
\hline Canada & $\$ 1.85$ & $\$ 8.25$ & $\$ 2.76$ & $\$ 3.18$ & $\$ 2.68$ \\
\hline US & $\$ 1.99$ & $\$ 8.25$ & $\$ 1.73$ & $\$ 3.28$ & $\$ 2.76$ \\
\hline Japan & $\$ 1.62$ & $\$ 5.29$ & $\$ 2.69$ & $\$ 3.82$ & $\$ 1.82$ \\
\hline Thailand & $\$ 3.81$ & $\$ 5.76$ & $\$ 2.67$ & $\$ 2.85$ & $\$ 0.83$ \\
\hline
\end{tabular}

Source: Numbeo. (2019). Price by Country (NZD). Retrieved from https://www.numbeo.com/cost-ofliving/prices by country.jsp?displayCurrency=NZD\&itemld=8

Figure Five: Average Restaurant Prices

\begin{tabular}{|l|l|l|l|l|l|}
\hline Country & $\begin{array}{l}\text { Regular } \\
\text { Cappuccino }\end{array}$ & $\begin{array}{l}\text { Inexpensive } \\
\text { Meal for 1 }\end{array}$ & $\begin{array}{l}\text { Mid-Range } \\
\text { Meal for 2 }\end{array}$ & $\begin{array}{l}\text { Imported } \\
\text { Beer (0.33I) }\end{array}$ & Coke/Pepsi \\
\hline New Zealand & $\$ 4.52$ & $\$ 20.00$ & $\$ 85.00$ & $\$ 9.00$ & $\$ 3.15$ \\
\hline Australia & $\$ 4.66$ & $\$ 21.34$ & $\$ 85.36$ & $\$ 8.54$ & $\$ 3.51$ \\
\hline Canada & $\$ 4.89$ & $\$ 18.90$ & $\$ 76.81$ & $\$ 8.27$ & $\$ 2.51$ \\
\hline USA & $\$ 6.37$ & $\$ 23.34$ & $\$ 77.80$ & $\$ 9.34$ & $\$ 2.81$ \\
\hline Japan & $\$ 5.70$ & $\$ 12.66$ & $\$ 58.22$ & $\$ 7.28$ & $\$ 1.98$ \\
\hline Thailand & $\$ 3.08$ & $\$ 3.05$ & $\$ 33.00$ & $\$ 5.59$ & $\$ 0.97$ \\
\hline
\end{tabular}

203 Bradley, G. (2019). Hotels.com figures show prices on the move - are you paying too much?. NZ Herald. Retrieved from https://www.nzherald.co.nz/business/news/article.cfm?c id=3\&objectid=12229598 
Source: Numbeo. (2019). Price by Country (NZD). Retrieved from https://www.numbeo.com/cost-ofliving/prices by country.jsp?displayCurrency=NZD\&itemld=8

Looking into the average food prices of products can say a lot about the ongoing costs of staying in a country. The average cost of dining out is an important consideration for tourists, as they generally eat at establishments rather than cooking (particularly on short term stays). A useful examination is the cost of a Big Mac burger from McDonalds. ${ }^{204}$ First coined in 1986, the Big Mac Index is used by economists to discuss purchasing power parity. In this examination there are three price points. The New Zealand falls in the middle price point, which average near the \$7NZD mark. When it eating at other restaurants, New Zealand is an expensive choice. In terms of low and mid-range meals, New Zealand is among the most expensive options. These high costs can be off-putting, and they create expectations of quality not always met. In terms of alcohol, New Zealand is also one of the more expensive destinations, being the second most expensive in both domestic and imported beer. It is worth noting the high taxation rate for liquor in New Zealand; $10 \%$ for beer, $15 \%$ for wine and $38 \%$ for spirits. ${ }^{205}$ Overall, the cost of food is high and this plays a large part in explaining the high cost of visiting New Zealand, and reflects the high cost of living in New Zealand. In many cases, the only more expensive option is the US, and this means that places that are closer (such as Japan and Thailand) or less expensive (such as Canada or Australia) will be more popular choices for visitation.

\subsubsection{Transport Costs}

\section{Figure Six: Average Transportation Prices}

\begin{tabular}{|l|l|l|l|}
\hline Country & Gasoline (I) & $\begin{array}{l}\text { Ticket One } \\
\text { Way (Local) }\end{array}$ & Taxi (km) \\
\hline New Zealand & $\$ 2.19$ & $\$ 3.40$ & $\$ 2.95$ \\
\hline Australia & $\$ 1.55$ & $\$ 4.48$ & $\$ 2.13$ \\
\hline Canada & $\$ 1.48$ & $\$ 3.60$ & $\$ 2.22$ \\
\hline US & $\$ 1.14$ & $\$ 3.50$ & $\$ 2.66$ \\
\hline Japan & $\$ 2.09$ & $\$ 3.06$ & $\$ 6.04$ \\
\hline Thailand & $\$ 1.53$ & $\$ 1.37$ & $\$ 0.51$ \\
\hline
\end{tabular}

\footnotetext{
${ }^{204}$ No Author. (n.d.) Big Mac Index - Prices Around The World. Retrieved from https://www.worldatlas.com/articles/the-world-s-most-expensive-countries-measured-by-the-big-macindex.html 205 Alcohol Healthwatch. (2009). INFORMATION SHEET: TAX ON ALCOHOL. Retrieved from http://www.ahw.org.nz/Portals/5/Resources/Fact\%20Sheet/Info\%20Sheet\%20Alcohol\%20and\%20Tax\%20Fina \%2009.pdf
} 
Source: Numbeo. (2019). Price by Country (NZD). Retrieved from https://www.numbeo.com/cost-ofliving/prices by country.jsp?displayCurrency=NZD\&itemld=8

The cost of transport is crucial to understanding the level of overall expenditure made by tourists, because tourists will travel around a destination once they arrive, and it is often an underrepresented expense when it comes to holiday travel. Examining the cost of gasoline provides an insight overall transportation costs within a nation and highlights how expensive it would be to use a car should tourists want to be self-driving. The cost of gasoline in New Zealand is higher than the rest of the world, with only Japan coming close. In terms of local ticket prices, New Zealand is similar in price to Canada and the US, while being slightly cheaper. Looking at the cost of a taxi per kilometre, New Zealand is slightly more expensive than the other Western countries that have been examined, but comes nowhere near to the cost of Japanese taxis.

\subsubsection{Recreational Shopping Trends}

This section examines recreational shopping trends of Chinese tourists while they are abroad. Lin suggests that Chinese shopping trends are worldwide, which makes it easy to predict what Chinese tourists will be interested in buying. ${ }^{206}$ Tsujimoto provides a breakdown of the types of purchases Chinese tourists make in Japan. ${ }^{207}$ Cosmetics were the most popular item with $78 \%$ of Chinese tourists purchasing some. Second was medicines/health products, with a $76 \%$ purchase rate. The third most popular purchases are food products, with $67 \%$ buying confectionaries and $57 \%$ buying other food products. Western clothing, bags and shoes were another popular purchase at $47 \%$. The fifth most popular purchase was Japanese items, with $24 \%$ divided among traditional clothing, manga and crafts. These shopping trends similar to what Chinese tourists purchase in the rest of the world, with Zhu finding similar results in Europe. ${ }^{208}$ The main difference was the items reminiscent of the nation that they visited. In Europe, tourists tended to buy items related to local sports teams, or food that was distinctive to the area. There was a specific focus here on chocolate, perfume and wine that were easily recognizable as having come from Europe. In the case of New Zealand, Chinese tourists' most popular purchases are Māori crafts, milk powder, health food products such as honey

\footnotetext{
${ }^{206}$ Lin, L. (2017). Food souvenirs as gifts: tourist perspectives and their motivational basis in Chinese culture. Journal of Tourism and Cultural Change, 15(5), 439-454.

207 Tsujimoto, N. (2017). The purchasing behaviour of Chinese tourists at popular visiting areas in Japan. Journal of Global Tourism Research, 2(2). 99.

${ }^{208}$ Zhu, D., Xu, H., \& Jiang, L. (2016). Behind buying: The Chinese gaze on European commodities. Asia Pacific Journal of Tourism Research, 21(3), 301.
} 
and New Zealand wine. ${ }^{209}$ Market research conducted by TNZ shows an understanding of these trends and advertising campaigns have been launched to target Chinese tourists. ${ }^{210}$ Chinese shopping trends are relatively predictable and this makes marketing easier, as long as there is an understanding of what products Chinese tourists perceive as distinctive to New Zealand.

\subsubsection{Quality Expectations}

It is also worth noting the high level of quality expected by Chinese tourists. As the Chinese tourist industry has become more experienced, and this has resulted in some Chinese tourists moving from traditional mass tourism and becoming more closely associated with new tourism. Partially selfguided and high-end package tours are on the rise as mature travellers demand a customized travel experience. ${ }^{211}$ This new rise has become associated with characteristics not traditionally associated with the Chinese market; designing unique travel experiences, immersion in local culture and an emphasis on quality. This tourist is typically middle-aged with a high income. Most notably, they are willing to exceed budget if their expectations are surpassed. ${ }^{212}$ They are willing to pay more for quality as they prefer to stay in three stars or higher. This means they expect access to facilities and a certain hygiene standard. ${ }^{213}$ They also want single use toiletries. Within New Zealand, there is acknowledgment of the high standard that Chinese tourists expect. This has seen the rise of high cost travel itineraries for those who can afford it. ${ }^{214}$ All of this demonstrates the high level of quality that Chinese tourists are interested in, and this highlights the need for quality experiences for when the Chinese market come to visit New Zealand.

\subsubsection{Summary of Expenses}

Overall, this data highlights how expensive New Zealand is as a place to visit. Jensen argues that, while New Zealanders have high living standards, they also have high living costs, which is in alignment with the findings of this thesis' cost expenditure analysis. ${ }^{215}$ High living costs can serve to

\footnotetext{
209 Ryan, C., Minghui, S., \& Xiaoyu, Z. (2013). Chinese Tourists and Souvenir Shopping in New Zealand. The China-New Zealand Tourism Research Centre Department of Tourism and Hospitality Management. The University of Waikato Management School.

210 Ibid.

${ }^{211}$ Mckinsey and Company. (2018). Chinese tourists: Dispelling the myths. Retrieved from https://www.mckinsey.com/ /media/McKinsey/Industries/Travel\%20Transport\%20and\%20Logistics/Our\%20I nsights/Huanying\%20to\%20the\%20new\%20Chinese\%20traveler/Chinese-tourists-Dispelling-the-myths.ashx 212 Ibid.

213 Li, X. R., Lai, C., Harrill, R., Kline, S., \& Wang, L. (2011). When east meets west: An exploratory study on Chinese outbound tourists' travel expectations. Tourism Management, 32(4), 745.

214 Johnson, A. (2004). Tourists tempted by a touch of class. Dominion Post (Wellington, N.Z.).

215 Jensen, J., Krishnan, V., Spittal, M., \& Sathiyandra, S. (2003). New Zealand living standards: their measurement and variation, with an application to policy. Social Policy Journal of New Zealand, 72-97.
} 
drive away potential tourists, and this is especially important among Chinese tourists due to the geographical distance between the two nations. Even among Western nations, New Zealand is an expensive place to visit and its remote geographic location disincentives travel. Travel within the Asia region would logically be more appealing to Chinese tourists due to the decrease in both cost and travel time. Therefore, New Zealand needs to make sure it is worth the long travel required to get to New Zealand from China. In order for New Zealand to be a competitive destination, it needs to highlight the overall quality of the New Zealand tourism experience. This is even more prominent when considering that neighbouring Australia is noticeably cheaper. Considering the high costs of visiting New Zealand as a tourist, shifting to high value tourists makes sense from a marketing perspective. Highlighting value for money and less expensive options (while retaining quality) is essential to maintaining Chinese interest and visitation.

\subsection{Case Study: Shopping Tours}

\subsubsection{Shopping Tours}

Shopping by Chinese tourists while they travel abroad is worth discussing because of the emergence of unethical shopping tours. This is particularly problematic in light of zero dollar tours. Zero dollar tours refer to tour packages where tourists are attracted by low prices. The companies then rely on purchases (and subsequent commissions) in order to break even. Travel companies will negotiate accommodation/meals/events/activities at discounted rates on the promise that they will bring increased revenue from exposure to Chinese tourists. This relates strongly with the ideas of vertical integration, which refers to a situation where one vendor/group control a number of different components of the supply chain and/or experience. ${ }^{216}$ This serves a dual purpose, with consistency on one hand and controlling the user's experiences on the other.

King identifies a further three practices that impact on the overall satisfaction of Chinese tourists when these zero dollar tours occur. ${ }^{217}$ First is uncompetitive shopping arrangements, where secret or excessive commissions result in tourists paying more than a product's value. Second is charging for normally free services. Thirdly, there is a low level of quality in the overall tour, hotel quality and products available. ${ }^{218}$ March suggests some reasons why the Chinese market has been targeted for

\footnotetext{
${ }^{216}$ Turk, M. (2015). Vertical Integration. Computing in Science \& Engineering, 17(1), 64. https://doi.org/10.1109/MCSE.2015.27

217 King, B., Dwyer, L., \& Prideaux, B. (2006). An evaluation of unethical business practices in Australia's China inbound tourism market. International Journal of Tourism Research, 8(2), 127.

218 Tan, L. (2018). \$10 to visit Mission Bay: China tourists get fleeced instead of a bargain from rogue tour operators. NZ Herald. Retrieved from https://www.nzherald.co.nz/nz/news/article.cfm?c id=1\&objectid=12095049
} 
this type of malpractice around the world. ${ }^{219}$ The first is that they are (comparatively) a less mature market, therefore they are perceived as being easier to defraud and predict. Secondly, they tend to have less access to information while they travel. Overall, the presence of zero-dollar shopping tours poses a real threat to the tourism experience

\subsubsection{Illegal Practices}

Outside of the zero-dollar tours, there are a number of problems. The first problem is the issue of enforcing tourism laws, with many tour guides stating that regulation is difficult to enforce. There are a number of cases in the last year, where tourism operators act illegally. The first is the ongoing investigation in the Abel Tasman National Park, where two companies allegedly hosted illegal guided walks. ${ }^{220}$ These companies lacked the proper permits and filmed in prohibited areas. A similar incident occurred in Fiordland, where tour guides led unlicensed tours while claiming they were legal. ${ }^{221} \mathrm{~A}$ third example relates to the tour bus crash on State Highway 5 , in Ngātira, west of Rotorua. A man without the proper permit was driving the bus, carrying 27 Chinese nationals. ${ }^{222}$ This is one of numerous cases in the last five years. ${ }^{223}$ Often utilizing false or borrowed licenses, it is not uncommon to see charges being laid against tour operators for failing to operate within the confines of New Zealand law. A second major issue with New Zealand is the lack of Wi-Fi. Many Chinese tourists use the internet to gain information about New Zealand as well as the products and attractions that they are being taken to. It creates an opportunity to price check themselves. Overall, the mistreatment of Chinese tourists is an ongoing issue that needs addressing in New Zealand. Quality of experience is crucial to ensuring positive word of mouth and repeat visitation.

\subsubsection{Implications}

The implications of these negative practices will result in a negative reputation at the destinations where these zero dollar tours are occurring. The customer dissatisfaction at malpractice leads them

\footnotetext{
${ }^{219}$ March, R. (2008). Towards a Conceptualization of Unethical Marketing Practices in Tourism: a Case - Study of Australia's Inbound Chinese Travel Market. Journal of Travel \& Tourism Marketing, 24(4), 288.

${ }^{220} \mathrm{Gee}, \mathrm{S}$. (2019). DOC investigating illegal guides operating in Abel Tasman National Park. Stuff. Retrieved from https://www.stuff.co.nz/environment/114687072/doc-investigating-illegal-guides-operating-in-abeltasman-national-park

${ }^{221}$ Kelly, R. (2019). DOC catches hundreds of illegal walking and tour guides operating in Fiordland. Stuff. Retrieved from https://www.stuff.co.nz/business/114058023/doc-catches-hundreds-of-illegal-walking-andtour-guides-operating-in-fiordland

222 Tan, L. (2018). Local Chinese tour businesses wage war against unlicensed operators. NZ Herald. Retrieved from https://www.nzherald.co.nz/nz/news/article.cfm?c id=1\&objectid=12093802

${ }^{223}$ Clarkson, D. (2016). Chinese tour drivers had no licences, police allege. Stuff. Retrieved from https://www.stuff.co.nz/national/crime/84044806/chinese-tour-drivers-had-no-licences-police-allege
} 
to share negative word of mouth. ${ }^{224}$ It has also created a situation where Chinese tourists have become distrustful of tour guides. ${ }^{225}$ It leads to the perception of low quality of New Zealand, which disincentives travel. This results in a loss of business and profits, which causes harm to not only the local area, but to New Zealand's economy as a whole. Following zero-dollar tours, the CCP stated that any guides that mistreated Chinese tourists would lose their Approved Tour Guide Status. New Zealand has made several changes to increase the quality of tours within the country. Initiatives such as the Premier Kiwi Partnership Programme and the New Zealand Chinese Tour Guides Association were enacted to ensure the growth of quality tours. ${ }^{226}$ TNZ created and launched the ADS Code of Conduct in 2007. ${ }^{227}$ This code of conduct addressed many issues highlighted in zero-dollar tours including duty of care, organised shopping, accommodation and meals. It also covered other issues addressing quality concerns including cancellations, restrictions on itineraries and the expected qualifications and skills of the tour guides themselves. The Travel Agents' Association New Zealand (TAANZ) created their Code of Ethics and Practice to monitor and self-regulate the tourism industry. ${ }^{228}$ However, New Zealand tour guides did not support these decisions; instead, many felt it was a threat on their profits and integrity. ${ }^{229}$ Many did not want TNZ to become more involved in how they run their tours and they question how easily the government will be able to enforce the new laws. ${ }^{230}$ New Zealand needs to continue to manage its shopping tours to ensure that these practices do not continue as they harm the nation's competitive destination image.

\subsection{Tourism and Trade}

\subsubsection{Wine Tourism}

This next section explores the links between tourism and trade. The first example of a strong link between tourism and trade is wine tourism, which is a key example of an avenue of tourism that has

\footnotetext{
${ }^{224}$ Wang, Y., Weaver, D. B., \& Kwek, A. (2016). Beyond the mass tourism stereotype: Power and empowerment in Chinese tour packages. Journal of Travel Research, 55(6), 734.

${ }^{225}$ Ryan, C., Minghui, S., \& Xiaoyu, Z. (2013). Chinese Tourists and Souvenir Shopping in New Zealand. The China-New Zealand Tourism Research Centre Department of Tourism and Hospitality Management The University of Waikato Management School. 31.

226 Ibid.

${ }^{227}$ Tourism New Zealand. (2019). Approved Destination Status. Retrieved from https://www.tourismnewzealand.com/tools-for-your-business/china-market-development/approveddestination-status/

${ }^{228}$ TAANZ. (n.d.). TAANZ Code of Ethics \& Practice. Retrieved from https://taanz.org.nz/ ${ }^{229}$ Ryan, C., Minghui, S., \& Xiaoyu, Z. (2013). Chinese Tourists and Souvenir Shopping in New Zealand. The China-New Zealand Tourism Research Centre Department of Tourism and Hospitality Management The University of Waikato Management School. 28.

${ }^{230}$ No Author. (2013). Thailand/China: China's new policy of regulating outbound zero-dollar tours will benefit Thai tourism industry in the long term. Asia News Monitor. Retrieved from http://search.proquest.com/docview/1438690090/
} 
a strong potential to be linked to trade. Wine tourism, refers to tourism that includes the tasting or purchase of wine, often at or near the source. ${ }^{231}$ Wine tourism also links with the idea of indulgence and pampering, which is another popular reason for Chinese tourists to visit New Zealand, with 54\% wanting to come to New Zealand for this reason. ${ }^{232}$ Relaxation is an important priority for Chinese tourists when they come to visit New Zealand (53\% come for relaxation). ${ }^{233}$ Fountain's research suggests that wine tourism is even more appealing to Chinese tourists because it fills in many of the desires of the average Chinese tourists who come to New Zealand. $62 \%$ of Chinese tourists to New Zealand come to experience the local food and/or wine, $42 \%$ come to visit a vineyard, $67 \%$ want to visit scenic landmarks and $56 \%$ want to shop for gifts and souvenirs. ${ }^{234}$ All of these interests can be fulfilled at a vineyard, which means they are equipped at catering to the interests of Chinese tourists.

Wine tourism is important to the seller as it provides both short term and long-term benefits. ${ }^{235}$ The short-term benefits include immediate sales without having to pay a third party seller, increasing profits for the seller. The long-term advantages include the ongoing retail benefits from gaining new customers, as well as the growth of an international market. There is strong interest in buying wine from New Zealand vineyards, mostly as gifts for family members back home. ${ }^{236}$ The practice of purchasing wine is a way to encourage international trade once the tourists leave New Zealand. Wine tourism provides the opportunity to develop international networks and a worldwide clientele for New Zealand's wine industry. ${ }^{237}$ This idea is increasingly important because since 2010 the world has seen an increase in the internationalization and globalisation of wine. Currently, one of the biggest problems for New Zealand vineyards is that Chinese tourists are relatively uninformed about New Zealand wines, with $75 \%$ of overseas visitors to New Zealand feeling that they do not know a lot about wines. ${ }^{238}$ Fountain suggests many Chinese tourists are relatively inexperienced with grape

\footnotetext{
${ }^{231}$ Alonso, A. D., Fraser, R. A., \& Cohen, D. A. (2008). Exploring wine tourism in New Zealand: the visitors' points of views. Tourism Analysis, 13(2), 171-180.

232 Ibid.

233 Tourism New Zealand. (2019). China. Retrieved from https://www.tourismnewzealand.com/media/3418/china-visitor-information.pdf

${ }^{234}$ Fountain, J. (2018). The Wine Tourism Experience in New Zealand: An Investigation of Chinese Visitors' Interest and Engagement. Tourism Review International, 22(1), 75.

${ }^{235}$ Baird, T., Hall, C. M., \& Castka, P. (2018). New Zealand winegrowers attitudes and behaviours towards wine tourism and sustainable winegrowing. Sustainability, 10(3), 797.

${ }^{236}$ Fountain, J. (2018). The Wine Tourism Experience in New Zealand: An Investigation of Chinese Visitors' Interest and Engagement. Tourism Review International, 22(1), 76.

${ }^{237}$ Baird, T., Hall, C. M., \& Castka, P. (2018). New Zealand winegrowers attitudes and behaviours towards wine tourism and sustainable winegrowing. Sustainability, 10(3), 797.

238 Alonso, A. D. (2009). Are travellers interested in wine tourism in New Zealand?. International Journal of Culture, Tourism and Hospitality Research, 3(1), 17.
} 
wine, but instead are more used to rice, lychee and Asian plum as the basis of their wines. ${ }^{239}$ However, many tourists are happy with their experience, so more broadly advertising New Zealand wines would be a helpful step to overcoming this issue.

\subsubsection{Agritourism}

Agritourism is another key example of tourism that has the potential to highlight the link between tourism and trade. Agritourism involves any agriculturally based operation or activity that brings visitors to a farm or ranch. ${ }^{240}$ Agritourism provides owners with a supplemental source of income, and provides a chance them to utilize existing resources to highlight both their production and lifestyle. They provide the opportunities to diversify the farmer's economy, which also helps provide financial stability. ${ }^{241}$ In addition to the obvious economic benefits of agritourism, there are also societal benefits, for example maintaining rural lifestyle and the preservation of local customs and unique culture. ${ }^{242}$ The setting of agritourism can also draw tourists into the rural environment. About $70 \%$ of Chinese tourists want to visit New Zealand to get in touch with nature, and nature features several popular activities for Chinese tourists such as seeing wildlife (81\%), second is walking in nature $(71 \%)$ and fourth is visiting parks $(60 \%) .{ }^{243}$

Agritourism can also help to develop trade relationships. Dairy and agricultural products are valuable in the relationship between New Zealand and China. Agriculture is a major industry in New Zealand, contributing approximately $\$ 10.6$ billion NZD to the country's GDP. Total agricultural exports brought in over $\$ 28$ billion NZD as at year ending June 2016. This includes over $\$ 12.1$ billion NZD from dairy, $\$ 6.77$ billion NZD from meat and $\$ 759$ million NZD from raw wool. ${ }^{244}$ This emphasises the importance and interest that the international market has in New Zealand dairy and agricultural products, and suggests that agritourism could be used as a way to enhance the trade. Cultivating agritourism can be used as a means to demonstrate the quality of New Zealand products and will help to incentivize purchasing these products now and again in the future. Agritourism creates a

\footnotetext{
239 Ibid.

240 Phillip, S., Hunter, C., \& Blackstock, K. (2010). A typology for defining agritourism. Tourism Management, 31(6), 754-758.

${ }^{241}$ Choo, H., \& Petrick, J. F. (2014). Social interactions and intentions to revisit for agritourism service encounters. Tourism Management, 40, 372.

242 Tew, C., \& Barbieri, C. (2012). The perceived benefits of agritourism: The provider's perspective. Tourism Management, 33(1), 216.

243 Ibid.

${ }^{244}$ No Author. (2018). Agriculture. Environment Guide. Retrieved from

http://www.environmentguide.org.nz/activities/agriculture/
} 
positive brand association for New Zealand and its agricultural products. This will help to ensure the long-term financial success of New Zealand agricultural goods in China.

\subsubsection{Significance}

The links between tourism and trade are significant because of added revenue value to the New Zealand economy. New Zealand tourism generated \$15.9 billion NZD, or 6.1\% of GDP directly and the indirect value added an additional $\$ 11.1$ billion NZD, or $4.3 \% .{ }^{245}$ Tourism provides an important means of promoting international trade and it does a good job at promoting the New Zealand brand. According to Khan, tourism encourages international trade because of tourists' behaviour. ${ }^{246}$ Tourists purchase food, transportation, accommodation, products and services while abroad. These purchases stimulate the domestic economy, which provide revenue to develop infrastructure and facilitates. Many products required to facilitate tourism also need to be imported which further helps to grow international trade. ${ }^{247}$ Growth in international trade between two nations can also stimulate tourism arrivals, because of a growth in interest in both the products from a country, business and interest in the country itself. ${ }^{248}$ An open tourism environment will help to enhance positive trading relationships between two nations. Because of the relations-based system of governance, an advance of tourism relationships can improve political relations. ${ }^{249}$ If tourists enjoy their purchases while abroad, this can help to incentivise them to continue purchasing these types of products once they return to their home nation, which boosts New Zealand's economic success. The relationship between tourism and trade is ongoing and can have a long-term impact on both tourists and the destination economy, even after they leave their tourist destination. Through these linkages between tourism and trade, the New Zealand political economy benefits to a large degree from Chinese outbound tourism.

\footnotetext{
245 Tourism New Zealand. (2019). About the Tourism New Zealand. Retrieved from https://www.tourismnewzealand.com/about/about-the-tourismindustry/\#targetText=Data\%20and\%20statistics\&targetText=Total\%20tourism\%20expenditure\%20was\%20\%2 439.1,billion)\%20from\%20the\%20previous\%20year.\&targetText=216\%2C012\%20people\%20were\%20directly\% 20employed, percent\%20from\%20the\%20previous\%20year.

${ }^{246}$ Fry, D., Saayman, A., \& Saayman, M. (2010). The relationship between tourism and trade in South Africa. South African Journal of Economics, 78(3), 289.

${ }^{247}$ Ibid.

${ }^{248}$ Katircioglu, S. (2009). Tourism, trade and growth: the case of Cyprus. Applied Economics, 41(21), 2747.

${ }^{249}$ Lejárraga, I., \& Walkenhorst, P. (2013). Economic policy, tourism trade and productive diversification. International Economics, 135, 8.
} 


\subsection{E-Commerce}

\subsubsection{Popular Websites}

This section explores the state of the Chinese e-commerce market as of 2019. The Alibaba Group has a significant amount of influence on the Chinese e-commerce market. Recently online Chinese ecommerce has seen a move from customer-to-customer (C2C) and towards business-to-customer (B2C). This has prompted several changes in the way e-commerce has been conducted in recent year. In 2015, B2C accounted for $51.6 \%$ of market shares. ${ }^{250}$ In 2018, B2C accounted for $62 \%$ of all online transactions in China and was worth 7.5 trillion RMB (16.5 billion NZD). ${ }^{251}$ Two major Chinese companies control a large amount of B2C transactions. The largest is Tmall, which accounts for $59.5 \%$ of all B2C sales. ${ }^{252}$ The second largest is JD, which accounts for $25.8 \% .{ }^{253}$ Tmall is owned by the Alibaba group, which also has a strong amount of control in C2C and business-to-business (B2B) transactions. Alibaba also has control over the $\mathrm{C} 2 \mathrm{C}$ spending through its sub-company Taobao, which accounts for $75 \%$ of online $\mathrm{C} 2 \mathrm{C}$ sales in China. ${ }^{254}$ Overall, it is apparent that the Alibaba Group has a large share of the internal purchases made by non-governmental groups within China; Alibaba Group held $58 \%$ of all sales shares in China during $2018 .{ }^{255}$ This monopoly on e-commerce sets an important backdrop for this discussion, as it highlights a lack of diversity in offerings.

\subsubsection{High Spenders}

In 2017 the average amount spent online per capita in China was 13,450 RMB (2,964 NZD), which suggests that online shopping has become a fundamental part of the Chinese experience for those who choose to participate. Based on the 24 trillion RMB gross merchandise volume (GMV) in 2017, that would suggest that each of the 800 million netizens within China are spending on average 30,000 RMB a year on online shopping (6,615 NZD). ${ }^{256}$ This makes the Chinese online market extremely lucrative and if New Zealand was able to capitalise on this, there is a potential for

\footnotetext{
${ }^{250}$ Kwak, J., Zhang, Y., \& Yu, J. (2019). Legitimacy building and e-commerce platform development in China: The experience of Alibaba. Technological Forecasting and Social Change, 139, 118.

${ }^{251}$ Statista. (2019). E Commerce in China. Retrieved from https://www.statista.com/study/11567/ecommerce-in-china-statista-dossier/

252 No Author. (2019). Tmall. Retrieved from https://www.tmall.com/

${ }^{253}$ No Author. (2019). JD. Retrieved from https://www.jd.com/2017

${ }^{254}$ No Author. (2011). An internet with Chinese characteristics; Chinese internet companies. The Economist, 400(8744), 71-72

${ }^{255}$ Kwok, S. (2018). Alibaba tops e-commerce market share while facing fresh competition in China. Retrieved from https://www.marketing-interactive.com/alibaba-tops-e-commerce-market-share-while-facing-freshcompetition-in-china/

${ }^{256}$ Statista. (2019). E Commerce in China. Retrieved from https://www.statista.com/study/11567/ecommerce-in-china-statista-dossier/
} 
economic growth which would to increase New Zealand's reputation and visibility to the Chinese market.

\section{$\underline{\text { 3.5.4 Trust Fraud }}$}

A major problem in Chinese e-commerce relates to online trust. Because the internet and online shopping is a new phenomenon in China, there are still concerns about the security of online shopping and online payment methods. ${ }^{257}$ Trust fraud is a major issue on Chinese websites. High ratings on Chinese websites are crucial for success, because reputable sellers are rewarded with special discounts, brand deals and exposure for products; all of which create opportunities for future sales. ${ }^{258}$ Fraudulent reviews are estimated to account from anywhere between $9 \%$ and $47 \%$ of all transactions. ${ }^{259}$ New Zealand already has a quality assurance programme. FernMark is a label for New Zealand companies to signal their country of origin and highlight that they have passed quality control standards. ${ }^{260}$ FernMark is also trademarked in China, so the label is protected. Utilizing FernMark will help to make New Zealand products more competitive and will help to tackle issues related to trust fraud. Most of the provisions for New Zealand to succeed in the Chinese ecommerce world already exist, but New Zealand companies have yet to capitalise on this opportunity. FernMark has created a quality assurance programme that highlights the best products that New Zealand has to offer. However, the opportunities for growth made possible by innovations such as FernMark have yet to be utilized to their full potential, particularly in B2C transactions.

\subsubsection{New Zealand Brands in Chinese E-Commerce}

When it comes to New Zealand products, there is not a strong presence in the Chinese online market. New Zealand has a number of different stores that specialise in selling New Zealand goods, including http://www.buynzmarket.org.nz/.261 Many 'iconic' New Zealand brands (such as Marmite, Speights and Whitakers) do not have their own online stores; however many of these products can be purchased at other third party websites such as https://www.mightyape.co.nz/. ${ }^{262}$

\footnotetext{
${ }^{257}$ Chen, Y., Yan, X., \& Fan, W. (2015). Examining the effects of decomposed perceived risk on consumer's online shopping behavior: A field study in China. Inzineriné Ekonomika, 26(3), 322.

${ }^{258}$ Zhang, Y., Bian, J., \& Zhu, W. (2013). Trust fraud: A crucial challenge for China's e-commerce market. Electronic Commerce Research and Applications, 12(5), 299-308.

259 Ibid.

${ }^{260}$ Fernmark. (n.d.). Promoting Provenance To Grow Export Success. Retrieved form https://www.fernmark.nzstory.govt.nz/info

${ }^{261}$ No Author. (2019). BuyNZ Online Market. Retrieved from http://www.buynzmarket.org.nz/

262 No Author. (2019). Mightyape. Retrieved from https://www.mightyape.co.nz/
} 
On Chinese e-commerce websites, there is only a small selection of New Zealand products available, and several products appear to be Chinese in origin. Few of these sellers have any ties to New Zealand companies. Many of these products also do not have any English on the packaging, but rather are written in mandarin, which decreases the likelihood these are authentic New Zealand products. Companies like Qingmei (卿妹) use the New Zealand flag, the silver fern and the words

"New Zealand." Numerous lamb products are advertised under the New Zealand search function, but all these products were grown, killed and packaged in Mainland China. There are also instances where companies such as Jiao Chu (娇楚) advertise their products as being from New Zealand, when it is a Chinese company. Some companies such as Anchor and Westgold do have an established presence on Chinese e-commerce websites, but this is largely confined to the dairy sector, a sector that is already well regarded in China. These findings suggests that there is some interest in authentic products from New Zealand. If New Zealand invested in the Chinese e-commerce scene there is the potential for New Zealand to make a lot of money. Ways in which this could occur would be through establishing an online presence in major Chinese e-commerce markets and/or marketing New Zealand goods through a reputable third-party seller in China. The dominance of JD, Tmall and Taobao when it comes to Chinese ecommerce means that New Zealand sellers will need to advertise and market on these sites if they want to be competitive. If New Zealand were to involve itself in Chinese ecommerce, a comprehensive strategy would be needed to effectively market on these websites; however, as of writing none exists.

\subsection{Interpreting What This Means for Chinese Tourism}

This chapter highlights the relationship between tourism and New Zealand's overall international trade performance. Spending data demonstrates how expensive New Zealand is as a place to visit, even among Western nations. Travel within the Asia region would logically be more appealing to Chinese tourists due to the decrease in both cost and travel time. Therefore, New Zealand needs to make sure it is worth the long travel required to get to New Zealand from China. Highlighting value for money and less expensive options (while retaining quality) is essential to maintaining Chinese interest and visitation. The links between tourism and trade are significant because of added revenue value to the New Zealand economy. New Zealand tourism generated \$15.9 billion NZD, or $6.1 \%$ of GDP directly and the indirect value added an additional $\$ 11.1$ billion NZD, or $4.3 \% .{ }^{263}$

\footnotetext{
${ }^{263}$ Tourism New Zealand. (2019). About the Tourism New Zealand. Retrieved from https://www.tourismnewzealand.com/about/about-the-tourismindustry/\#targetText=Data\%20and\%20statistics\&targetText=Total\%20tourism\%20expenditure\%20was\%20\%2 439.1,billion)\%20from\%20the\%20previous\%20year.\&targetText=216\%2C012\%20people\%20were\%20directly\% 20employed,percent\%20from\%20the\%20previous\%20year.
} 
Tourists' purchases stimulate the domestic economy, which provide revenue to develop infrastructure and facilitates. ${ }^{264}$ Growth in international trade between two nations can also stimulate tourism arrivals, because of a growth in interest in both the products from a country, business and interest in the country itself. ${ }^{265} \mathrm{E}$-commerce research suggests there is some interest in authentic products from New Zealand. Ways for New Zealand invested in Chinese e-commerce include establishing an online presence in major Chinese e-commerce markets and/or marketing New Zealand goods through a reputable third-party seller in China. The dominance of JD, Tmall and Taobao when it comes to Chinese ecommerce means that New Zealand sellers will need to advertise and market on these sites if they want to be competitive. The relationship between tourism and trade is ongoing and can have a long-term impact on both tourists and the destination economy, even after they leave their tourist destination. Through these linkages between tourism and trade, the New Zealand political economy benefits to a large degree from Chinese outbound tourism. Overall, the three sections examined in this chapter highlight the relationship between tourism and trade and how it could be utilized more in the case of Chinese international tourists. Through a comprehensive strategy, boosting and developing tourism with China would lead to an increase in international trade with the nation and a booming of New Zealand's overall economy.

\section{$\underline{3.7 \text { Conclusion }}$}

This chapter examined the relationship between tourism and trade. Chinese tourism has created new political and economic opportunities and challenges for New Zealand. Through the development of stronger diplomatic ties, the growth of business tourism, to strengthening trade relationships to develop facilities, there are many benefits to taking advantage of the strong links between tourism and trade. Through the initiation of e-commerce, spending continues economic growth once tourists return home. The economic impact of Chinese tourism has been broadly positive for New Zealand but more could be done to leverage tourism. There are risks to the current system however. New Zealand runs the risk of developing a negative reputation among Chinese tourists due to two reasons; (1) high costs and (2) the negative practices associated with shopping tours. High costs means high spending tourists should be targeted to maximise yield while shopping tours need to be dealt with through legislation. In the e-commerce sector, New Zealand underperforms through its limited presence and sole focus on agricultural produce. E-commerce allows New Zealand to capitalize on tourism positivity and helps to grow New Zealand's international

\footnotetext{
${ }^{264}$ Fry, D., Saayman, A., \& Saayman, M. (2010). The relationship between tourism and trade in South Africa. South African Journal of Economics, 78(3), 289.

${ }^{265}$ Katircioglu, S. (2009). Tourism, trade and growth: the case of Cyprus. Applied Economics, 41(21), 2747.
} 
presence. Creating a strong brand and developing both tourism and online shopping capabilities would help to more effectively market to Chinese tourists and would make New Zealand memorable. This would help to protect the nation's economic interests and strengthen the economic earnings from a successful tourism relationship with China. 


\section{CHAPTER FOUR - CHALLENGES FOR THE FUTURE}

\subsection{Introduction}

Chinese outbound tourism is changing the New Zealand political economy through highlighting the necessary changes the tourism industry needs to make. Chinese tourism has uncovered major deficiencies in New Zealand's political economy that the New Zealand government and tourism providers are working to resolve, some more successfully than others. New Zealand currently has a one dimensional tourism model with insufficient diversification among regional and seasonal tourism. New Zealand also faces an infrastructure deficit, which hinders the nation's ability to carry out important changes. It has also continued to assist in the rise of the eco-tourism model that New Zealand has been working to establish, through promoting a move towards high value over high volume. This has been accompanied with renewed concerns over environmental sustainability and interest in promoting niche markets. Overall, Chinese outbound is changing the focus of the New Zealand tourism industry and is influencing discourse surrounding infrastructure and the environment.

\subsection{New Zealand's Development Model}

\subsubsection{Volume to Value}

New Zealand is moving to a new model of tourism development to address volume and environmental concerns. Three major changes define this. The first shift in New Zealand's tourism model is moving away from high volume tourism to high value tourism. High volume tourism poses a number of real threats to New Zealand's tourism as high visitor numbers place pressure on New Zealand's tourism facilities and cause damage to the environment. A shift to attracting high value tourism hopes to increase spend per visitor, bringing about the greatest economic benefits with the lowest impact on the environment. It is important to recognise that a balance between volume and value is needed, otherwise there will be negative consequences. Relying too much on high value tourism can contribute to economic downturn. ${ }^{266}$ The high cost to appeal to rich tourists can offset many gains from the high value tourists, and a less open system means that revenue and growth would remain stunted. On the other hand, an overreliance on mass tourism leads to a decline in tourism numbers because of a lack of differentiation and thus less return visits. Therefore maintaining a proper balance is essential. ${ }^{267}$

\footnotetext{
266 Magole, L. I., \& Magole, L. (2011). Revisiting Botswana's high-value, low-volume tourism. Tourism Analysis, 16(2), 207.

267 Ozturk, A. B., \& Van Niekerk, M. (2014). Volume or value: A policy decision for Turkey' s tourism industry. Journal of Destination Marketing \& Management, 3(4), 193.
} 
This is also relevant to New Zealand, due to the high tourism costs. Chapter three identified the high costs of visiting New Zealand as a tourist, and therefore shifting to high value tourists makes sense from a marketing perspective. TNZ has outlined several strategies to move from volume to value. ${ }^{268}$ The first way is to lift the yield from existing markets, which can be done through developing new airline partnerships from high value source locations (the number from China has increased dramatically over the last two decades). Currently, New Zealand lacks internationally recognizable brands so it needs to work on partnerships with larger international companies to create effective campaigns. ${ }^{269}$ The second strategy is through the introduction of business events, which has seen more conferences held in New Zealand. The third suggestion is through cultivating relationships with international influencers such as Huang Lei (a Chinese actor, director, singer, screenwriter, and model). Utilizing high-profile figures in China helps to highlight cross-cultural understanding and interest. A successful example of this is with actress Yao Chen's wedding in Queenstown has been reported more than 2.4 million times on various Chinese news sites and portals. ${ }^{270}$ The fourth strategy is the creation of special interest segments and the initiation of marketing these segments. ${ }^{271}$ According to MBIE's forecasts, Chinese tourists remain in New Zealand for 19 days and spend \$348 NZD (outside of accommodation) a day on average. ${ }^{272}$ Spending $\$ 4,091$ NZD on average, they are New Zealand's second highest spenders per person. Overall, a shift to high value tourism will help to encourage growth and drive high spending and luxury tourism, where Chinese tourists are a well-established market.

\subsubsection{Increase FIT Travel}

The second shift is moving away from mass tourism and instead focusing on FITs. Research suggests that Chinese FITs are likely to spend significantly more than package tourists (as much as 33\%). ${ }^{273}$ This higher spend means that FITs represent an important sector for encouraging the move to high

\footnotetext{
268 Tourism New Zealand (2017). Four Year Strategic Plan.

${ }^{269}$ Boase, J. P. (2000). Beyond government? The appeal of public-private partnerships. Canadian Public Administration, 43(1), 75-92.

270 Tan L. (2012) Chinese star's wedding boon for tourism. Retrieved from https://www.nzherald.co.nz/nz/news/article.cfm?c id=1\&objectid=10848887

${ }^{271}$ Ministry of Business, Innovation and Employment

(MBIE). (2018). New Zealand Tourism Forecasts 2018 - 2024. Retrieved from https://www.mbie.govt.nz/assets/5c05b7bfce/nz-tourism-forecasts-2018-2024-report.pdf

272 Tourism New Zealand. (2019). China. Retrieved from https://www.tourismnewzealand.com/media/3418/china-visitor-information.pdf

273 The Nordics. (2018). Chinese Market Segment: High Spending FITs May 2018 Opportunities and Challenges for Nordic Destinations. Retrieved from

http://www.tourismstat.gl/resources/reports/en/r23/Chinese Market_Opportunities and Challenges 07082 018.pdf
} 
value tourism. Tourism Queensland has identified several key trends related to expectations that Chinese FITs generally have. ${ }^{274}$ FITs like uniqueness and high quality service and details. FITs usually visit a larger number of locations within a single country, meaning they are more likely to consolidate their spending in a small number of countries. The last major trend is that FITs are more likely to travel to niche regional destinations within a nation, which helps to develop regional tourism. A problem is that only 4\% of arrivals in 2018 were aged between 18 and 24 (the age most likely to be FITs). In order to increase the number of FITs, New Zealand will need to create more campaigns designed specifically to target a younger demographic. In order to effectively market to Chinese youth, a concentrated online presence will be necessary, as many FITs rely on the internet as a central means of collecting information. ${ }^{275}$ Changes like functional Chinese websites, utilization of Chinese search engines, advertising on popular Chinese sites and localization for the Chinese market are commonly suggested to encourage travel and spending by Chinese FITs. ${ }^{276} \mathrm{New}$ Zealand will also need to invest in marketing the niche and/or regional areas of New Zealand. This will help the nation to offer something unique, which will act as a major selling point. ${ }^{277}$ The search for uniqueness is something that New Zealand can capitalise on to effectively market to this rising demographic within Chinese travel. ${ }^{278}$ An increase in FITs will likely correlate to an increase in high value spending, which will help with the move from volume to value.

\subsubsection{Environmental and Economic Sustainability}

The third shift in New Zealand's tourism model is towards a more balanced environmental and economic system. Tourism development often acts as a double-edged swords, where economic growth comes at the cost of degradation to the environment. The production of infrastructure can lead to pollution, destruction of natural features and biodiversity loss. It is important to balance development with conservation. Tang highlights the importance of managing economic and environmental sustainability. ${ }^{279}$ This is particularly relevant to New Zealand because of the emphasis that New Zealand places on the natural environment, through the prominence of ' $100 \%$ Pure New

\footnotetext{
274 Tourism Queensland. (2013). Meeting the expectations of your Chinese visitors and making them feel welcome. Retrieved from https://cdnteq.queensland.com/ /media/15c4dcb13eb643f0b1eb0931a9cb3eae.ashx?la=enau\&vs $=1 \& d=20140515 T 115458$

275 Zheng, T. (2018). A study of Chinese Free Independent travellers' motivations and their preferred accommodation types in New Zealand (Doctoral dissertation, Auckland University of Technology). 11. 276 Tourism New Zealand (2017). Four Year Strategic Plan.

277 Trivett, V. (2013). Rise of the Chinese Independent Traveller. Retrieved from https://skift.com/wpcontent/uploads/2013/09/skift-chinese-traveler.pdf

278 Ibid.

${ }^{279}$ Tang, Z. (2015). An integrated approach to evaluating the coupling coordination between tourism and the environment. Tourism Management, 46, 11-19.
} 
Zealand. ${ }^{280 \prime}$ Nature features are a key element of New Zealand's tourism scene, as was demonstrated in chapter two, therefore protection of the natural environment is key to the ongoing viability of tourism in New Zealand.

The overall goal of the New Zealand government is to move towards a "clean, green, carbon neutral New Zealand" though Gossling argues that most approaches to carbon neutrality not realistic. ${ }^{281}$ New Zealand has chosen to focus on energy efficiency strategies. These include developing renewable energy including biofuels, the construction of energy-efficient buildings, financial incentives for solar and water heating as opposed to fossil fuels, waste emission reductions, afforestation and the introduction of an emissions trading scheme. ${ }^{282}$ New Zealand wants to strengthen conservation efforts and integrate nature and conservation into its long-term tourism plan. ${ }^{283}$ The creation of environmentally friendly tourism attractions can act as a way to promote environmental awareness, which is one of the main goals of New Zealand's tourism strategy. ${ }^{284} \mathrm{New}$ Zealand is also able to capitalise on the emerging eco-tourism model, which has been gaining popularity since the turn of the century. ${ }^{285}$ Since from 2005 to 2009 , eco-tourism saw a $29 \%$ increase overnight stays, and they feed well into sports tourism (46\%), food tourism (15\%) and cultural tourism (12\%). ${ }^{286}$ Nature and culture based tourism are New Zealand's biggest types of tourism marketing, while sports and food tourism are rising in prominence as part of TNZ's movement to attracting high value tourists. Overall, New Zealand's tourism marketing aims to encourage ecotourism and seeks to encourage sustainable development. At the same time, by encouraging high value tourism, New Zealand to retain economically sustainable tourism.

\footnotetext{
280 Ministry of Business, Innovation and Employment (MBIE). (2019). New Zealand-Aotearoa Government Tourism Strategy Summary of consultation submissions. Retrieved from https://www.mbie.govt.nz/dmsdocument/5483-new-zealand-aotearoa-government-tourism-strategysummary-of-consultation-submissions

${ }^{281}$ Gössling, S. (2009). Carbon neutral destinations: A conceptual analysis. Journal of Sustainable Tourism, $17(1), 33$.

${ }^{282}$ No Author. (2016). Renewable energy resources. EECA. Retrieved from https://www.eeca.govt.nz/energyuse-in-new-zealand/renewable-energy-resources/

${ }^{283}$ Mihalič, T. (2000). Environmental management of a tourist destination: A factor of tourism competitiveness. Tourism management, 21(1), 65.

${ }^{284}$ Department of Conservation. (2017). Aotearoa New Zealand Government Strategy: Summary. Retrieved from https://www.mbie.govt.nz/dmsdocument/1492-aotearoa-new-zealand-government-tourism-strategysummary-draft-pdf

285 Ioppolo, G., Saija, G., \& Salomone, R. (2013). From coastal management to environmental management: The sustainable eco-tourism program for the mid-western coast of Sardinia (Italy). Land Use Policy, $31,461$. 286 Ibid 467.
} 


\subsection{Regional Diversification}

\subsubsection{Define}

According to Sánchez-Zamora, regional diversification is tied strongly with the ideas of place, space and territory. ${ }^{287}$ However, territory is a relatively loose-term that encompasses both material and symbolic ideals of the area, so it refers to ideas outside of the physical values of the land. ${ }^{288}$ Five main types of capital are used when discussing the effectiveness of a regional location. These are economic, social, cultural, environmental and human capital. Place-related variables, such as exposure to environmental problems and economic and cultural connections and natural conditions play a significant role in shaping the concerns of the community. ${ }^{289}$ Social and economic changes occurring within the communities can influence how residents view their environment and can lead to dynamic changes. ${ }^{290}$ These changes, unique to the regional location, spur development in a unique direction. Within the context of tourism, this leads to the creation of niche/distinguishable attractions to incentivize visitation and help develop the economy. ${ }^{291}$

\subsubsection{Statistics}

Figure Seven: Top Five Tourist Locations (\% Overnight Stay) (2018)

\begin{tabular}{|c|c|c|c|c|c|c|}
\hline $\begin{array}{l}\text { Top } 5 \\
\text { Tourist } \\
\text { Locations }\end{array}$ & Australia ${ }^{292}$ & China $^{293}$ & US $^{294}$ & $U^{295}$ & Germany ${ }^{296}$ & Japan $^{297}$ \\
\hline $1^{\text {st }}$ & $\begin{array}{l}\text { Otago } \\
\text { (51\%) }\end{array}$ & $\begin{array}{l}\text { Auckland } \\
(68 \%)\end{array}$ & $\begin{array}{l}\text { Auckland } \\
(68 \%)\end{array}$ & $\begin{array}{l}\text { Auckland } \\
(76 \%)\end{array}$ & $\begin{array}{l}\text { Auckland } \\
\text { (79\%) }\end{array}$ & $\begin{array}{l}\text { Auckland } \\
\text { (68\%) }\end{array}$ \\
\hline
\end{tabular}

\footnotetext{
287 Sánchez-Zamora, P., Gallardo-Cobos, R., \& Ceña-Delgado, F. (2014). Rural areas face the economic crisis: Analyzing the determinants of successful territorial dynamics. Journal of Rural Studies, 35, 12. 288 Ibid 13.

${ }^{289}$ Safford, T. G., \& Hamilton, L. C. (2012). Demographic change and shifting views about marine resources and the coastal environment in Downeast Maine. Population and Environment, 33(4), 285.

290 Ibid.

${ }^{291}$ Yang, Y., \& Fik, T. (2014). Spatial effects in regional tourism growth. Annals of Tourism Research, 46, 146.

292 Tourism New Zealand. (n.d.). Australia. Retrieved from https://www.tourismnewzealand.com/media/3417/australia-visitor-information.pdf

293 Tourism New Zealand. (2018) China, Market information about our Visitors and our Active Considerers. Retrieved from https://www.tourismnewzealand.com/media/3418/china-visitor-information.pdf

294 Tourism New Zealand. (2018). United States of America. Retrieved from https://www.tourismnewzealand.com/media/3422/usa-visitor-information.pdf

295 Tourism New Zealand. (2018). United Kingdom FY18 H2. Retrieved from https://www.tourismnewzealand.com/media/3647/uk-insights-h2-fy18.pdf 296 Tourism New Zealand. (2018). Germany FY18 H2. Retrieved from https://www.tourismnewzealand.com/media/3645/germany-insights-h2-fy18.pdf 297 Tourism New Zealand. (n.d.). Japan. Retrieved from https://www.tourismnewzealand.com/media/3420/japan-visitor-information.pdf
} 


\begin{tabular}{|l|l|l|l|l|l|l|}
\hline $\mathbf{2}^{\text {nd }}$ & $\begin{array}{l}\text { Auckland } \\
(43 \%)\end{array}$ & $\begin{array}{l}\text { Otago } \\
(42 \%)\end{array}$ & $\begin{array}{l}\text { Otago } \\
(56 \%)\end{array}$ & $\begin{array}{l}\text { Otago } \\
(67 \%)\end{array}$ & $\begin{array}{l}\text { Canterbury } \\
(74 \%)\end{array}$ & $\begin{array}{l}\text { Otago } \\
(50 \%)\end{array}$ \\
\hline $\mathbf{3}^{\text {rd }}$ & $\begin{array}{l}\text { Canterbury } \\
(34 \%)\end{array}$ & $\begin{array}{l}\text { Bay of } \\
\text { Plenty } \\
(38 \%)\end{array}$ & $\begin{array}{l}\text { Canterbury } \\
(38 \%)\end{array}$ & $\begin{array}{l}\text { Canterbury } \\
(63 \%)\end{array}$ & $\begin{array}{l}\text { Otago } \\
(72 \%)\end{array}$ & $\begin{array}{l}\text { Canterbury } \\
(38 \%)\end{array}$ \\
\hline $\mathbf{4}^{\text {th }}$ & $\begin{array}{l}\text { Waikato } \\
(21 \%)\end{array}$ & $\begin{array}{l}\text { Canterbury } \\
(31 \%)\end{array}$ & $\begin{array}{l}\text { Bay of } \\
\text { Plenty } \\
(38 \%)\end{array}$ & $\begin{array}{l}\text { Bay of } \\
\text { Plenty } \\
(59 \%)\end{array}$ & $\begin{array}{l}\text { Waikato } \\
(71 \%)\end{array}$ & $\begin{array}{l}\text { Bay of } \\
\text { Plenty } \\
(20 \%)\end{array}$ \\
\hline $\mathbf{5}^{\text {th }}$ & $\begin{array}{l}\text { Bay of } \\
\text { Plenty } \\
(21 \%)\end{array}$ & $\begin{array}{l}\text { Waikato } \\
(19 \%)\end{array}$ & $\begin{array}{l}\text { Waikato } \\
(29 \%)\end{array}$ & $\begin{array}{l}\text { West Coast } \\
(52 \%)\end{array}$ & $\begin{array}{l}\text { Bay of } \\
\text { Plenty } \\
(66 \%)\end{array}$ & $\begin{array}{l}\text { Waikato } \\
(11 \%)\end{array}$ \\
\hline
\end{tabular}

Source: Tourism New Zealand. (2019). Markets \& Stats. Retrieved from

https://www.tourismnewzealand.com/markets-stats/

Auckland is the main destination across all six nationality's travel itineraries, with $67 \%$ of all travellers on average choosing to spend at least one night in Auckland. The five most popular destinations across all six national groups are similar with Auckland, Otago, Canterbury, Waikato and the Bay of Plenty recurring across multiple countries. The only difference to this trend is the UK, where the West Coast is more popular than Waikato. Overall, these statistics suggest that New Zealand does not have an effective regional tourism model, as there is a lack of regional diversification beyond a few locations.

\section{$\underline{4.3 .3 \text { Issues }}$}

New Zealand struggles when it comes to obtaining regional diversification for international visitors. All six of these groups tend to travel to the same regions, though minor variations exist. ${ }^{298}$ Regional tourism development is important because it helps to strengthen the economic performance of the region, can encourage tourists to stay longer (thus spending more) and can create positive economic and social outcomes for people living in regional communities. ${ }^{299}$ These include a reduction of poverty, increased living standards, preservation and expression of cultural identity and heritage, the development of recreational facilities and parks, increased job opportunities and increased

\footnotetext{
298 Tourism New Zealand. (2019). Markets \& Stats. Retrieved from https://www.tourismnewzealand.com/markets-stats/

${ }^{299}$ Hwang, D., Stewart, W. P., \& Ko, D. W. (2012). Community behaviour and sustainable rural tourism development. Journal of Travel research, 51(3), 328-341.
} 
education opportunities. ${ }^{300}$ There can also be a reversal of youth-oriented out-migration towards major cities if there are more career opportunities. ${ }^{301}$ There are a number of possible strategies to increase regional tourism. First is utilization of the internet. User-generated content (UGC) allows tourists to review their experiences and highlight the niche locations that they visit to friends/family. UGC is increasingly a viable source for gaining authentic information because is perceived to be unbiased as opposed to government websites. ${ }^{302}$

A second option for the development of regional tourism is the creation of events-based tourism in order to highlight unique elements of regional destinations. ${ }^{303}$ One example is the Marlborough Wine Region in Picton. Often there is a lack of entrepreneurial skills in many regional areas and scholars suggest a top-down effort led by central government is needed for effective development. ${ }^{304}$ The tourism industry in rural areas can lack financial and social capital that is needed alongside that expertise; therefore, both governmental and non-governmental actors play an important role in planning and helping these regional areas to develop into successful regional tourist locations. ${ }^{305}$

Another possible option would be to reduce the distance or time-cost between different tourist destinations. One major issue is the large distance between different destinations, which acts as a major hindrance to visiting regional locations. ${ }^{306}$ Distance is off-putting because there are two obstacles that need to be overcome; economic costs and time costs. Reducing these costs will incentivise travel. While all of the other systems are necessary to develop tourism capabilities are growing around the country, distance mitigation is still needed. ${ }^{307}$ Overall, international tourism in New Zealand is largely confined to a small number of major areas, and this does not fully capitalize on tourism spending and experience. New Zealand should try to diversify its tourism image to extend

\footnotetext{
${ }^{300}$ Harun, R., Chiciudean, G. O., Sirwan, K., Arion, F. H., \& Muresan, I. C. (2018). Attitudes and perceptions of the local community towards sustainable tourism development in Kurdistan regional government, Iraq. Sustainability, 10(9), 2991.

${ }^{301}$ Miller, E., Van Megen, K., \& Buys, L. (2012). Diversification for sustainable development in rural and regional Australia: How local community leaders conceptualise the impacts and opportunities from agriculture, tourism and mining. Rural Society, 22(1), 10.

302 Usui, R., Wei, X., \& Funck, C. (2018). The power of social media in regional tourism development: a case study from Ōkunoshima Island in Hiroshima, Japan. Current Issues in Tourism, 21(18), 2055.

${ }^{303}$ Ezeuduji, I. O. (2015). Strategic event-based rural tourism development for sub-Saharan Africa. Current Issues in Tourism, 18(3), 214.

304 Ibid.

305 Valente, F., Dredge, D., \& Lohmann, G. (2015). Leadership and governance in regional tourism. Journal of Destination Marketing \& Management, 4(2), 127.

${ }^{306}$ Wang, X., Huang, S., Zou, T., \& Yan, H. (2012). Effects of the high speed rail network on China's regional tourism development. Tourism Management Perspectives, 1, 35.

${ }^{307}$ Fagence, M. (1996). Regional tourism cooperation. Annals of Tourism Research, 3(23), 718-719.
} 
beyond these centres. To do this quality infrastructure and tourism facilities are needed to entice tourists away from urban centres.

\section{$\underline{4.4 \text { Seasonality }}$}

\subsubsection{Define}

Seasonality can occur in two major ways, (1) natural and (2) institutional. ${ }^{308}$ Natural seasonality is a direct result of the regular variations in the weather and climate. It also produces less visible changes such as temperature adjustments and humidity. Natural seasonality changes in accordance with the earth's movement around the sun, and therefore is easily predictable. Institutional seasonality, by contrast, is the result of human decisions and is the outcome of a variety of religious, cultural, social and ethnic factors. ${ }^{309}$

\subsubsection{Statistics}

Figure Eight: Seasonal Distribution of Inbound International Tourists to New Zealand (2017)

\begin{tabular}{|l|l|l|l|l|l|l|}
\hline Season & Australia $^{\mathbf{3 1 0}}$ & China $^{\mathbf{3 1 1}}$ & $\mathbf{U S}^{\mathbf{3 1 2}}$ & UK $^{\mathbf{3 1 3}}$ & Germany $^{\mathbf{3 1 4}}$ & Japan $^{315}$ \\
\hline Summer & $32 \%$ & $31 \%$ & $41 \%$ & $44 \%$ & $49 \%$ & $32 \%$ \\
\hline Autumn & $22 \%$ & $29 \%$ & $25 \%$ & $18 \%$ & $20 \%$ & $22 \%$ \\
\hline Winter & $24 \%$ & $17 \%$ & $11 \%$ & $20 \%$ & $6 \%$ & $20 \%$ \\
\hline Spring & $23 \%$ & $23 \%$ & $23 \%$ & $18 \%$ & $25 \%$ & $25 \%$ \\
\hline
\end{tabular}

Source: Tourism New Zealand. (2019). Markets \& Stats. Retrieved from

https://www.tourismnewzealand.com/markets-stats/

\footnotetext{
${ }^{308}$ Baum, T., \& Lundtorp, S. (Eds.). (2001). Seasonality in tourism. Elsevier. 1.

${ }^{309}$ Cuccia, T., \& Rizzo, I. (2011). Tourism seasonality in cultural destinations: Empirical evidence from Sicily. Tourism Management, 32(3), 589-595.

${ }^{310}$ Tourism New Zealand. (n.d.). Australia. Retrieved from https://www.tourismnewzealand.com/media/3417/australia-visitor-information.pdf

${ }^{311}$ Tourism New Zealand. (2018) China, Market information about our Visitors and our Active Considerers. Retrieved from https://www.tourismnewzealand.com/media/3418/china-visitor-information.pdf

312 Tourism New Zealand. (2018). United States of America. Retrieved from

https://www.tourismnewzealand.com/media/3422/usa-visitor-information.pdf

313 Tourism New Zealand. (2018). United Kingdom. Retrieved from https://www.tourismnewzealand.com/media/3421/united-kingdom-visitor-information.pdf

${ }^{314}$ Tourism New Zealand. (2018). Germany. Retrieved from https://www.tourismnewzealand.com/media/3419/germany-visitor-information.pdf

315 Tourism New Zealand. (n.d.). Japan. Retrieved from

https://www.tourismnewzealand.com/media/3420/iapan-visitor-information.pdf
} 


\section{$\underline{4.4 .3 \text { Issues }}$}

Dips in tourism over a prolonged period (such as a season) can pose many challenges for the local community. Low tourist numbers outside of peak season mean empty accommodation sites, businesses operating at a loss throughout the rest of the year (where profits during peak season cannot mitigate overall loss), underutilized capabilities/facilities year round and long periods of unemployment. The seasonal nature of tourism in New Zealand often means that employers can struggle to fill jobs; this was noticeable in Queenstown last year where the city struggled to find enough seasonal workers to fill all roles over summer. ${ }^{316}$ Insecure job prospects due to the low season in winter also means that most tourism workers tend to only remain in the sector short-term, and thus the sector often faces a lack of qualified and experienced staff. High numbers of tourism also presents their own challenges. ${ }^{317}$ Tourism puts a strain on much of the infrastructure in a location (for example public transport and water facilities) and this places them in conflict with the local population. ${ }^{318}$

Chinese tourism to New Zealand follows the single-peak model of tourism, which has consistently strong performance with a single distinctive high point (around the Chinese New Year). ${ }^{319}$ Concentration around the Chinese New Year and National Day Golden Weeks mean that a significant amount of Chinese tourism to New Zealand occurs during the summer. Spring and autumn act as shoulder seasons to this peak, attracting $23 \%$ and $29 \%$ of tourists respectively. Winter, by contrast, only attracts $17 \%$ of Chinese tourists. This is a common issue in New Zealand tourism with several other countries experiencing dips around the same time. The table above highlighted the seasonal distribution of New Zealand's six largest tourism markets. New Zealand can enhance itself and its regional seasonality.

Promoting shoulder and off-season tourism would help distribute the flow of tourist numbers. ${ }^{320}$ Two examples are through sports and cultural tourism. In terms of sports tourism, New Zealand currently has a ski and snow sports campaign that was launched in 2017 with the tagline of

\footnotetext{
${ }^{316}$ Jamieson, D. (2018). Queenstown short hundreds of workers during busiest time of year. Stuff. Retrieved from https://www.stuff.co.nz/business/industries/109420375/queenstown-short-hundreds-of-workersduring-busiest-time-of-year? $r m=m$

${ }^{317}$ Vargas-Sánchez, A., Porras-Bueno, N., \& de los Ángeles Plaza-Mejía, M. (2014). Residents' attitude to tourism and seasonality. Journal of Travel Research, 53(5), 581-596.

${ }^{318}$ Cropp, A. (2017). Tourism: a brilliant career or a job for dummies? Stuff. Retrieved from https://www.stuff.co.nz/business/93595748/tourism-a-brilliant-career-or-a-job-for-dummies?rm=m ${ }^{319}$ Chen, T., \& Pearce, P. L. (2012). Research note: Seasonality patterns in Asian tourism. Tourism Economics, 18(5), 1109-1110.

${ }^{320}$ Baum, T., \& Lundtorp, S. (Eds.). (2001). Seasonality in tourism. Elsevier. 3.
} 
"naturally diverse winter wonderland. ${ }^{321 "}$ Currently, ski tourism is largely restricted to the Australian market (64\%) so efforts need to be made to diversify this special interest tourism. ${ }^{322}$ Cultural tourism would be a suggested avenue to expand New Zealand's appeal year round. Through highlighting New Zealand's unique Māori heritage and culture, this would not only serve as a way to attract tourists year round, but would also act as a means to highlight the uniqueness of New Zealand. Since 2017, increasing efforts have been made by TNZ to increase the influence of Te reo Māori in tourism projects and it has largely been met with positive feedback from international tourists. ${ }^{323}$ Overall, New Zealand has made some positive steps to combat its seasonality problems and is working towards attracting tourists year round, however, it needs to continue and form a cohesive plan to attract more tourists (particularly in winter).

\subsection{Significance of Diversification}

The previous sections have demonstrated that New Zealand has a serious problem when it comes to diversification. Both of these analyses demonstrate that the majority of international inbound tourists to New Zealand (not just Chinese) do not venture far outside of the central hubs of Auckland and Otago, and even if they do, primarily go to Canterbury, the Bay of Plenty and Waikato. There are also problems with attracting tourists to visit outside of summer. Even though some improvements have been made to encourage shoulder season visits in autumn and spring, these have only been partially successful. Diversification will help to draw in more numbers and secure increased tourism prosperity. ${ }^{324} \mathrm{~A}$ mix of diverse attractions year round will help to create a more competitive destination image at the international level.

So far, New Zealand has made some efforts to provide a variety of more niche activities in regional areas. ${ }^{325}$ These can be grouped into five categories; (1) sports, (2) music, (3) food, (4) beer and (5) arts and culture. Sports tourism is fairly diverse in terms of both regional and seasonal distribution, with events held all around the country all around the year. There is also a wide variety of sports, though many of these are more adventurous sports, which will not necessarily be appealing to the Chinese market. Marathons, mountain biking, and the Coast-to-Coast all encompass a degree of risk. As already discussed, the Chinese market is generally described as risk averse so this will not be

\footnotetext{
${ }^{321}$ Tourism New Zealand. (2017). Special Interest. Retrieved from https://www.tourismnewzealand.com/markets-stats/sectors/special-interest/skiing/ 322 Ibid.

${ }^{323}$ Cropp, A. (2018). Tourism is embracing Te reo and visitors love it. Retrieved from https://www.stuff.co.nz/business/106907095/tourism-is-embracing-te-reo-and-visitors-love-it 324 Cave, J., \& Dredge, D. (2018). Reworking tourism: Diverse economies in a changing world. 325 100\% Pure New Zealand. (n.d.). Events. Retrieved from https://www.newzealand.com/int/events/
} 
effective marketing for this market. In music events, there is good regional diversification, but poor seasonal diversification. Many are held in summer, which is already peak tourism season. A lack of high quality infrastructure is not appealing for the Chinese market. Many music festivals target youths, and few Chinese tourists fit this age bracket. Several events aim to display the New Zealand food and beverage industry. There is a fair degree of seasonal and regional diversification, though it can be challenging to find information on these events. Within arts and culture, there is a range of activities, including an air show, fashion shows and art festivals. There is some regional diversification, though most are in or near major centres and most are held in summer or the shoulder seasons. Overall, New Zealand has a range of niche tourism events that could drive up visitation. However, a lack of marketing makes these events are underutilized as a tourism marketing device. More visibility could help move these events from a means of attracting domestic tourism to fully-fledged international tourism events. There is also room for more forms of niche tourism to develop, including health tourism and film tourism beyond the Lord of the Rings franchise.

\subsection{Lack of Infrastructure}

\subsubsection{Statistics}

The tables below shows the position of New Zealand infrastructure in comparison with the rest of the world. These values are out of 141 , as this is how many countries were examined by the World Economic Forum.

Figure Nine: Air Transport Infrastructure

\begin{tabular}{|l|l|}
\hline Indicator & Rank (141) \\
\hline Overall & 14 \\
\hline Quality of air transport infrastructure & 14 \\
\hline Airline domestic seat kms per week & 28 \\
\hline Airline international seat kms per week & 34 \\
\hline Departures per 1,000 population & 6 \\
\hline Airport density per million population & 13 \\
\hline Number of operating airlines & 92 \\
\hline
\end{tabular}

Source: World Economic Forum. (2015). The Travel \& Tourism Competitiveness Report 2015.

Retrieved from

http://www3.weforum.org/docs/TT15/WEF Global Travel\&Tourism Report 2015.pdf 
Figure Ten: Ground and Port Infrastructure

\begin{tabular}{|l|l|}
\hline Indicator & Rank (141) \\
\hline Overall & 49 \\
\hline Quality of roads & 35 \\
\hline Quality of railroad infrastructure & 38 \\
\hline Quality of port infrastructure & 11 \\
\hline Quality of ground transport network & 45 \\
\hline Railroad density (km/surface area) & 46 \\
\hline Road density (km/surface area & 62 \\
\hline Paved road density (km/surface area) & 56 \\
\hline
\end{tabular}

Source: World Economic Forum. (2015). The Travel \& Tourism Competitiveness Report 2015.

Retrieved from

http://www3.weforum.org/docs/TT15/WEF Global Travel\&Tourism Report 2015.pdf

Figure Eleven: Tourist Service Infrastructure

\begin{tabular}{|l|l|}
\hline Indicator & Rank (/141) \\
\hline Overall & 18 \\
\hline Hotels rooms per 100 population & 9 \\
\hline Extension of business trips recommended & 1 \\
\hline Presence of major car rental companies & 59 \\
\hline ATMs accepting Visa cards per million population & 48 \\
\hline
\end{tabular}

Source: World Economic Forum. (2015). The Travel \& Tourism Competitiveness Report 2015.

Retrieved from

http://www3.weforum.org/docs/TT15/WEF Global Travel\&Tourism Report 2015.pdf

\subsubsection{Implications}

Currently there is an emerging problem with the lack of tourism infrastructure available in New Zealand, which is particularly concerning when considering the necessary changes to increase diversification needed. Tourism growth has created issues throughout the tourism supply chain in New Zealand at all levels and locations. High growth in visitor nights alongside high tourist satisfaction has led to an influx in tourism numbers of the last ten years. This growth has outpaced total spend on tourism-related infrastructure (e.g., transportation, toilets, carparks, sanitation and 
environmental protection). ${ }^{326}$ This is reflected in the study conducted by the World Economic Forum that shows New Zealand is starting to fall behind in terms of its infrastructure. ${ }^{327}$ While New Zealand does perform strongly in some areas (such the number of hotel rooms), the largest problem exists with transport facilities. There is a lack of rental cars, operating airlines, road density and ground transport network. There are also issues with New Zealand's mobile network (ranked 91), water level stress (ranked 62) and fuel prices (ranked 105). ${ }^{328}$ These scores reflect a system where there is not enough infrastructure to meet the current needs and demands of tourists or to make changes to develop diversification.

This inadequacy is even more pronounced during summer, considering that there are high concentrations of tourists in a few areas, which puts more pressure on infrastructure than before. MBIE is aware of the issues that the tourism industry is currently facing. In 2016, MBIE recommended a number of improvements that are needed to support New Zealand's tourism industry. ${ }^{329}$ Good signage, public toilets and dump stations, recycling and other local amenities were deemed essential. This is particularly important at the regional level to encourage regional diversification. ${ }^{330}$ There is often the perception of a decline in quality in rural and/or regional areas and quality and accessibility are crucial to ensuring these areas are viable tourism destinations. Infrastructure is an important means developing a sector as it provides the facilities to enables the production of commodities and increased infrastructural growth can be correlated with increased consumption. ${ }^{331}$ This increased consumption furthers growth and leads to a positive upward cycle. At the same time however, it is important to also consider the role of the private sector. Active engagement from the private sector will help to spur economic growth. ${ }^{332}$ There also needs to be

\footnotetext{
${ }^{326}$ Tourism Industry Aotearoa. (2016). Addressing New Zealand's most pressing local tourism infrastructure needs. Retrieved from https://tia.org.nz/assets/Uploads/4d868a4517/Tourism-Infrastructure-ExecutiveSummary4.pdf

${ }^{327}$ World Economic Forum. (2015). The Travel \& Tourism Competitiveness Report 2015. Retrieved from http://www3.weforum.org/docs/TT15/WEF_Global_Travel\&Tourism_Report 2015.pdf 328 Ibid.

${ }^{329}$ Ministry of Business, Innovation and Employment. (2016). Tourism and tourism infrastructure in New Zealand. Retrieved from https://www.mbie.govt.nz/assets/8fafb5e9a2/tourism-and-tourism-infrastructure-innew-zealand.pdf

${ }^{330}$ Petrova, M., Dekhtyar, N., Klok, O., \& Loseva, O. (2018). Regional tourism infrastructure development in the state strategies. Problems and Perspectives in Management, 16(4), 260.

${ }^{331}$ Agénor, P. R. (2010). A theory of infrastructure-led development. Journal of Economic Dynamics and Control, 34(5), 946.

332 Chatterjee, S., \& Morshed, A. M. (2011). Reprint to: Infrastructure provision and macroeconomic performance. Journal of Economic Dynamics and Control, 35(9), 1422.
} 
consideration in how to make sure that the development that occurs ensures environmental longevity. ${ }^{333}$

Overall, this section highlights some of the failings in New Zealand's tourism infrastructure, and argues that more investment in tourism is needed to cater to New Zealand's growing tourism market. One of the most effective methods of investment is through a mixture of public and private partnership (PPP) which public investment takes priority in meeting infrastructure requirements such as roads, electrification and water supply, particularly in regional areas where private participation is less likely. Private investment includes an integrated transport system, ports, airports, telecommunications, and power and energy. These are likely avenues for private investment because they benefit private entrepreneurs and there is the potential for profits and marketization. ${ }^{334}$ This can be supported through foreign direct investment (FDI), of which there is plenty in New Zealand. In 2019, the value of FDI was $\$ 113$ billion NZD. ${ }^{335}$ Overall, there is a need for improved infrastructure and a coordinated PPP strategy could help to ease this stress, if New Zealand was to launch a campaign to address these issues.

\subsubsection{Implications for Tourism}

The biggest question is what this means for the New Zealand tourism industry. Overall, this frames the movement of the New Zealand tourism industry towards an eco-friendly model that attempts to leverage on the currently existing tourism and advertisements relating to New Zealand's natural environment. The interest and concern for the planet is paramount and obvious from the directives outlined by the New Zealand government. From the focus on encouraging higher spending tourists, to developing spurring the growth of regional and seasonal tourism, it becomes apparent that the direction of tourism within New Zealand is focused on sustainability. Tourism New Zealand is striving to create a well-rounded tourism system that continues to promote high-yield, while minimising detrimental effects on the environment. This creates a system where Chinese tourists are increasingly valuable to New Zealand's tourism future. Chinese tourists are the second highest spenders per person (second only to German tourists) and the high spend per visitor per day. When comparing Chinese to German tourists, Chinese tourists spend an average of \$4091 NZD over a 9-

\footnotetext{
${ }^{333}$ Praticò, F. G., \& Vaiana, R. (2012). Improving infrastructure sustainability in suburban and urban areas: Is porous asphalt the right answer? And how?. WIT Transactions On The Built Environment, 128, 675.

${ }^{334}$ Joshi, G. S. (2010). Infrastructure development strategies for inclusive growth: India's Eleventh Plan. Leadership and Management in Engineering, 10(2), 66.

${ }^{335}$ Statistics New Zealand. (2019). Foreign direct investment in New Zealand continues to increase. Retrieved from https://www.stats.govt.nz/news/foreign-direct-investment-in-new-zealand-continues-to-increase
} 
day holiday, averaging around \$455 NZD a day. ${ }^{336}$ German tourists, by contrast, spend \$5580 over 44 days, which averages much lower at close to \$126 NZD. ${ }^{337}$ Because of their trending high spends, Chinese tourists are ideal to fill in the desired directions that New Zealand is aspiring towards. The growth of Chinese tourists can be seen to link alongside the interests of Tourism New Zealand. By concentrating efforts to encourage and increase visitation from Chinese tourists, New Zealand would be able to take effect steps towards reaching its directions in its tourism development model.

\subsection{Conclusion}

Again, Chinese outbound tourism has shaped New Zealand's political economy. There has been a shift from quantity to quality that has been spurred by the arrival of high spending Chinese tourists. This, alongside New Zealand's nature-based tourism model, has created an interest in the new tourism model that New Zealand is moving towards. TNZ is attempting to move towards a high value, lower volume tourism model that encourages conservation, which is reflected by the tourism attractions discussed in chapter two and the high spend of Chinese tourists in chapter three. To further the spend of tourists when they visit New Zealand, there are a few issues that need to be addressed. Regional and seasonal diversification pose a major challenge and New Zealand needs to consider its marketing to the Chinese tourism market to highlight their alternatives to Auckland in summer. There is also an infrastructure deficit that needs to be addressed, and this could stimulate the trading relationship between New Zealand and China, considering the value of Chinese equipment and machinery exports to New Zealand. ${ }^{338}$ Chinese tourism to New Zealand is not only shaping New Zealand's tourism industry, but it also influencing New Zealand's trading relationship with China and New Zealand is adjusting its image presentation in China.

\footnotetext{
${ }^{336}$ Tourism New Zealand (2018). Visitor Experience Infographic April 2018. Retrieved from https://www.tourismnewzealand.com/media/3423/visitor-experience-infographic-april-2018.pdf

337 Tourism New Zealand. (2018). Germany FY18 H2. Retrieved from https://www.tourismnewzealand.com/media/3645/germany-insights-h2-fy18.pdf

338 Trading Economics. (2019). New Zealand Imports from China. Retrieved from https://tradingeconomics.com/new-zealand/imports/china
} 


\section{CHAPTER FIVE: DISCUSSION AND CONCLUSION}

\subsection{Introduction}

This chapter summarises the findings of this thesis. It provides an overview of the key findings and discusses these findings within the context of the literature review. These findings and their discussions fall within two categories. The first section is tourism and IPE. The second section examines New Zealand's tourism development model. These two discussions reach three major conclusions, which highlights how New Zealand is changing and what more needs to be done to make the most of the Chinese tourism market. Firstly, New Zealand marketing strategies should consider the Chinese tourist gaze when targeting Chinese tourists and attention needs to be paid to the differences in interests based on cultural differences. Secondly, New Zealand is an expensive destination and therefore should target high value tourism to maximise yield. Thirdly, New Zealand needs to shift tourists to the shoulder seasons and regions. The thesis concludes with policy recommendations and a discussion of future research.

\subsection{Findings}

\subsubsection{Chapter Two}

Chinese tourism is changing New Zealand's political economy. This is visible in recent movements in the types of tourism offerings and marketing strategies. New Zealand tourist attractions generally place nature at the forefront. A focus on untamed nature is the major marketing attraction for New Zealand. Untamed nature like this is not always the most effective way at appealing to Chinese tourists on its own, because of their interest in culture. Confucian ideology highlights the important relationship between people and nature, and therefore many Chinese tourists are interested in the way that culture interacts with nature. Because of this, New Zealand is not maximising its potential as tourism destination in the eyes of Chinese tourists. Māori culture fills in this gap effectively, highlighting New Zealand's unique culture and history. Highlighting Māori tourism proves a meaningful way to appeal to Chinese tourists, though so far Rotorua is one of the only tourism sites in New Zealand that has been able to merge natural features and Māori culture into one location. More needs doing to cater to the Chinese tourism market if New Zealand wants to continue to profit from this market. Three other ideas related to attracting tourists to New Zealand were apparent in this case study. First, having an iconic status is important to Chinese tourists as they generally visit a nation's most famous attractions. The second idea is conservation, which is important to the ideas of the New Zealand story and experience. Highlighting the importance of nature is critical to the traditional Chinese tourist gaze. However, the relationship between nature and technology is an 
important consideration, as nature can also be enhanced with technology and/or infrastructure. This is not often done in New Zealand due to environmental considerations and concerns. Thirdly, challenges and risk are not appealing to the Chinese audience, as they generally do not want to challenge themselves while they are on holiday, especially not in New Zealand. Currently, Chinese tourism runs the risk of stagnating due to their needs not being fully met, and this has major ramifications for New Zealand's economy. Overall, this chapter suggests that New Zealand is not fully catering to Chinese tourists. New Zealand's tourism strategy is comprehensive, but it does not consider Chinese tourists' interests, which is creating the satisfaction issues reflected in studies by TNZ.

\subsubsection{Chapter Three}

The economic impact of Chinese tourism has been broadly positive for New Zealand but more can be done to leverage tourism. The economic effect of tourism is not only bound to tourist spending within the country. Through the development of stronger diplomatic ties, the growth of business tourism and the strengthening of trade relationships to develop facilities, there are many advantages to utilizing the links between tourism and trade. Through the initiation of e-commerce, spending enables economic growth once tourists return home. Strong links between tourism and trade continue to develop the New Zealand economy through the growth of revenue generated by tourism. Tourism can create strong links between the New Zealand brand and international tourists. There are risks to the current system however. New Zealand faces developing a negative reputation among Chinese tourists due to two reasons; (1) high costs and (2) the negative practices associated with shopping tours. Travelling to New Zealand is expensive, and so is the cost of visiting, with food, petrol and accommodation being costly compared with other popular destinations. This makes New Zealand less appealing as Chinese want value for money. High costs means high spending tourists should be targeted to maximise yield while shopping tours need to be dealt with through effective legislation. These problems create negative perceptions of New Zealand and the nation needs to ensure quality, in order to not develop a negative reputation and lose tourists. In the e-commerce sector, New Zealand underperforms through its limited presence and sole focus on agricultural products. E-commerce allows countries and companies to capitalize on tourism positivity and develops international presence. Therefore, creating a strong brand and developing both tourism and online shopping capabilities would help to more effectively market to Chinese tourists and would make New Zealand more memorable. This would help to protect the nation's economic interests and strengthen the economic earnings from a successful tourism relationship with China. 


\subsubsection{Chapter Four}

Chinese outbound tourism is changing the New Zealand political economy through highlighting the necessary changes the tourism industry need to make. Chapter four examined the future of New Zealand tourism and the strategy put in place by the New Zealand government to achieve this. By moving to high value tourism, with a focus on FIT travellers. TNZ plans to create an economically prosperous tourism industry, which is also environmentally sustainable. Chinese tourism has uncovered deficiencies in New Zealand's infrastructure and that the New Zealand government and tourist providers are working to try to resolve this, to varying degrees of success. A document-based investigation found that there were some issues relating to the ways in which tourist populations diversify when they come to New Zealand, though this is not a problem unique to the Chinese market. New Zealand currently has a fairly one dimensional tourism model with insufficient diversification among regional and seasonal tourism. This highlights a lack of diversification in New Zealand's tourism, and current infrastructural issues further highlights this. New Zealand's infrastructure deficit hinders the nation's ability to carry out necessary changes. Addressing this could stimulate the trading relationship between New Zealand and China, considering the value of Chinese equipment and machinery exports to New Zealand. ${ }^{339}$ New Zealand's national strategy has also continued to assist in the rise of the eco-tourism model that New Zealand has been working to establish, through promoting a move towards high value over high volume. This has been accompanied with renewed concerns over environmental sustainability and interest in promoting niche markets. Overall, Chinese outbound is changing the focus of the New Zealand tourism industry and is influencing discourse surrounding infrastructure and the environment. These strategies and issues need to be addressed to ensure New Zealand tourism does not stagnate.

\section{$\underline{5.3 \text { Discussion }}$}

\subsubsection{Tourism and the International Political Economy}

\subsubsection{Scope of Chinese Tourism}

The first discussion point is the relationship that Chinese tourism has with IPE. This section will argue that Chinese tourism is having a significant impact on IPE, as well as on the international tourism industry. Chinese tourists took an estimated 131 million international trips in 2017, and this accounted for 970 billion NZD in spending. ${ }^{340}$ The number and high spend of Chinese tourists means

\footnotetext{
339 Trading Economics. (2019). New Zealand Imports from China. Retrieved from https://tradingeconomics.com/new-zealand/imports/china

340 No Author. (2018). OUTBOUND CHINESE TOURISM AND CONSUMPTION TRENDS. Neilson. Retrieved from https://www.nielsen.com/content/dam/nielsenglobal/cn/docs/Outbound\%20Chinese\%20Tourism\%20and\%20 Consumption\%20Trends.pdf
} 
that those that can attract Chinese tourists will be able to make substantial profits. The sheer scope of Chinese tourism has had a massive impact on the tourism world, and has promoted many different countries to adjust their approach to tourism marketing. This combined with the close links that the CCP have with Chinese tourism patterns/behaviours means that Chinese tourism can easily be manipulated according to the interests of the CCP.

\subsubsection{Rise of China Debate}

This section returns to the original debate about how the rise of China is shaping the IPE. This economic growth (resulting in the growth of outbound tourism) is shaping New Zealand's own political economy as new debates, policies and offerings are created to attract this new market. Several key debates have emerged alongside the rise of Chinese outbound tourism and this is influencing the ways the Chinese market is being considered. The first major way is through environmental politics. The rise of international politics has occurred parallel to a rise in environmental movements, which have translated into an interest in eco-tourism. New Zealand is leveraging its long held nature-based tourism destination marketing plans to capitalise on this interest in eco-tourism. At the same time however, a primary interest in the Western understanding of nature-based tourism (i.e. untamed nature with a focus on ecological processes) remains the dominant discourse of New Zealand attractions. There continues to be a lack of implementation of tourism facilities to cater to the Chinese cultural variations. Chinese tourists are interested in a culturescape over the idea of untamed nature, and as Māori tourism is a heavily marketed feature of New Zealand's tourism there is room to develop this cultural space. Yet, as the case study demonstrated, this is currently underdeveloped.

A second consideration is the rise of e-commerce as a revenue outlet. E-commerce within China generates a lot of international attention from companies because of sales figures. Chinese ecommerce is changing the way the rest of the world thinks about China because of its scale and profitability. Chinese tourism has a major impact on the IPE, through the close relationship that the government has with both tourism and economics. Developments need to engage with and capitalise on the emerging e-commerce market. Chinese tourism is also creating the need for quality tourism standards. This has primarily been done through the Approved Guide Status implemented by the CTAB. Overall, there is genuine interest in engaging with the Chinese tourism market, particularly high-spending tourists, but not enough has yet been done to cater to their needs. While language and visa barriers have been mitigated, and there are new varieties of tours available for this market, differences that have arisen from cultural and historical reasons have not been 
accounted for. The Chinese tourism is having a marked impact on the IPE through the influence it is having on other nation's policy agendas and the way they consider Chinese tourism as a profit revenue.

\subsubsection{Political Affiliations in Tourism}

Outbound Chinese tourism has an enormous influence on IPE through the influence that tourism has had on political relationships, which has in turn affects economics. The literature review highlighted the relationship between tourism and politics in China. Politics has the potential to either spur or slow visitors and this was highlighted over 2018 and 2019 when tourism numbers to New Zealand declined following a series of tensions. These tensions include the debate over the use of Huawei telecommunications towers, an Air New Zealand flight bound for Shanghai being denied permission to land and public protests held in Auckland regarding human rights abuses and the freedom of expression to practice Falun Gong. ${ }^{341}$ This is not unique to the New Zealand situation, as similar case studies around the world suggest. Countries have little control over their image within China, because of the control of the media by the CCP. ${ }^{342}$ Therefore, negative political and/or economic relations with China can directly feed into tourism relationships. This was highlighted in this thesis through the case study of Japan, where tourism has been used to develop and hinder the Japanese economy depending on the relationship with China at the time. This was also seen in the case of the Dominican Republic. The Dominican Republic was granted ADS in 2014, and in 2018, it acknowledged China and pledged its support for the 'One China Policy' despite its historical relationship with Taiwan. ${ }^{343}$ Chinese State Councillor Wang Yi notes the positive impact that this decision has had on the Dominican Republic; "The Chinese developing economy and expanding market have brought real benefits to the Dominican Republic. ${ }^{34 \prime \prime}$ In 2012, China was the second largest source of import (10.04\%), and the third largest destination of export (5.4\%) for the Dominican Republic. ${ }^{345}$ ADS and increased trade are responsible for the Dominican Republic's

\footnotetext{
${ }^{341}$ Graham McLay, C. (2019). New Zealand Fears Fraying Ties With China, Its Biggest Customer. Retrieved from https://www.nytimes.com/2019/02/14/world/asia/new-zealand-china-huawei-tensions.html

342 Zhu, Y. (2013). Making sense of Canada's public image in China. Journal of American-East Asian Relations, 20(2-3), 284.

${ }^{343}$ Jiang, S. (2018). China snatches Dominican Republic from Taiwan in diplomatic blow. Retrieved from https://edition.cnn.com/2018/05/01/asia/china-taiwan-dominican-republican-int//index.html

344 Pineda, J. (2018). China opens embassy in Dominican Republic after break with Taiwan. Reuters. Retrieved from https://www.reuters.com/article/us-dominican-diplomacy-china/china-opens-embassy-in-dominicanrepublic-after-break-with-taiwan-idUSKCN1M12IF

345 Yuan, L. (2013). Dominican Republic and P.R. China: Exchange, Trade and Investment. 7. Retrieved from https://www.drfellowsprogram.org/reports/dr-china-exchange-eng.pdf
} 
newfound relationship with China. ${ }^{346}$ Chinese tourism to New Zealand is dependent on ongoing CCP approval. New Zealand needs to discuss how it wants to proceed with Chinese tourism and its relationship with the CCP.

The second way tourism is influencing political relationships is through the extra-judicial control over citizens, and the extension of Chinese laws outside of its sovereign jurisdiction. The examination into shopping tours demonstrated the Chinese government's authority occurring overseas. When the issue of zero-dollar tours was brought to the attention of the CCP, legislation was passed which would mean zero-dollar tour operators would have their licenses revoked. ${ }^{347}$ From all of these examples it is apparent that Chinese uses politics as a tool to push its own national agenda and interests. Chinese outbound tourism has had a massive impact on the international political stage and its plays a large role in dictating the future of both politics and tourism. Once again, New Zealand needs to discuss how it wants to respond to the rise of Chinese tourism and its growing intervention in the New Zealand market. Policy makers need to decide whether tourism is worth the growing influence of China in its jurisdiction, and how they want to respond to it. Overall, politics and tourism are closely related for the CCP, and this raises the issue of how New Zealand plans on responding.

\subsubsection{Economic Prowess and E-Commerce}

Chinese international outbound tourism has not only had a marked effect on the political system, but it has also had a significant effect on international economics. The most obvious way in which this occurs is through the growth of trade necessary to accommodate tourism. As discussed in chapter three, tourism plays a significant role in developing international trade. Tourists purchase food, transportation, accommodation, products and services while abroad, which stimulate the domestic economy, developing international trade relationships. ${ }^{348}$ This is particularly relevant when considering the relationship between New Zealand and China, as China is responsible for $15 \%$ of all New Zealand imports (total valued at over 6 billion NZD). ${ }^{349}$ Growth in trade can also stimulate tourism arrivals, because of a growth in interest in both the products from a country as well as

\footnotetext{
${ }^{346}$ Arita, S., La Croix, S., \& Mak, J. (2012). How China's Approved Destination Status Policy Spurs and Hinders Chinese Travel Abroad. Working papers of the Economic Research Organisation at the University of Hawaii.October 19, (2012-6), 20.

${ }^{347}$ Tourism New Zealand. (2020). Approved Destination Status. Retrieved from https://www.tourismnewzealand.com/media/3819/tour-guide-list-16-jan-2020.pdf 348 Ibid.

${ }^{349}$ Statistics New Zealand. (2011). New Zealand in Profile: 2011. Retrieved from http://archive.stats.govt.nz/browse for stats/snapshots-of-nz/nz-in-profile-2011/imports-exports.aspx
} 
interest in the country itself. ${ }^{350}$ This thesis has also established the links between tourism and trade through using e-commerce. This further serves to highlight the way Chinese outbound tourism has influenced the international economy.

E-commerce within China generates a lot of international attention from companies who want to invest in this lucrative market. Chinese e-commerce is largely untapped by Western markets at this current time. ${ }^{351}$ This was demonstrated by looking at the sites used by Chinese shoppers, where the vast majority of sales came from three different websites, all of which are specific to China. Some of these websites, such as AliExpress, have begun to gain traction outside of the Chinese market, but few sites have penetrated the Chinese market in the same way that the Alibaba Group has. ${ }^{352}$ Chinese e-commerce is changing the way the rest of the world thinks about China because of its scale and profitability. In 2016, the Alibaba Group overtook Walmart as the world's largest retailer and distributor. ${ }^{353}$ This all means that Chinese e-commerce is changing the way the world does business, and because of the close connections between commerce and politics in China (due to the influence of the CCP, which has already been discussed), this is also affecting political relationships. Overall, Chinese tourism is having a major impact on IPE, through the close relationship that the government has with both tourism and economics. This is undoubtedly changing the way the rest of the world interacts with China because of its growing influence and the impact that it is having on IPE.

\subsubsection{Contribution to New Zealand's Political Economy}

This thesis demonstrates that the Chinese outbound tourism market is shaping New Zealand's political economy in ways that people do not usually consider. Outside of the economic benefits of tourism, several other impacts are apparent. The first is how New Zealand is adjusting its international image. This has occurred in several different ways; including marketing strategies, development of niche markets/sectors and expanding on tourism and economic offerings. These changes are being made in line with Chinese preferences and with Chinese comforts in mind. Most important to consider in these adjustments is Confucianism as a guide for Chinese expectations and preferences. Confucian practices not only relate to cultural expectations already discussed, but also

\footnotetext{
${ }^{350}$ Katircioglu, S. (2009). Tourism, trade and growth: the case of Cyprus. Applied Economics, 41(21), 2747.

${ }^{351}$ No Author. (2014). More than half (63\%) of U.S. online shoppers are not familiar with Chinese e-commerce giant Alibaba.com. Chain Store Age, 90(7), 28.

352 Wei, H. (2019). Russian firms taking a shine to AliExpress. Retrieved from https://www.chinadaily.com.cn/a/201904/02/WS5ca2cf7aa3104842260b3e77.html

353 McLay, R. (2019). 10 Companies Owned by Alibaba. Retrieved from

https://www.investopedia.com/insights/10-companies-owned-alibaba/
} 
inform Chinese expectations from the service industry. This includes courtesy, moderation, kindness and consideration for others. ${ }^{354}$ The increased presence of Chinese tourists is causing the need for stronger engagement with Chinese cultural values and expectations, which shapes the New Zealand political economy to a significant degree.

The second impact Chinese tourism is having on the New Zealand political economy is through discourse surrounding sustainable tourism and eco-tourism. Within tourism development, economic growth comes at the cost of degradation to the environment. Infrastructure can lead to pollution, destruction of natural features and biodiversity loss. It is crucial to balance development with conservation. There has been a shift from quantity to quality tourism spurred by the arrival of high spending Chinese tourists. This, alongside New Zealand's nature-based tourism model, has renewed interest in eco-tourism. TNZ is attempting to move towards a high value, lower volume tourism model that encourages conservation, which is reflected by the tourism attractions discussed in chapter two and the high spend of Chinese tourists in chapter three. This shift maximises economic benefits while minimizing environmental damage. By encouraging FIT travel, discussion has moved towards diversifying New Zealand's offerings and expanding upon niche markets. This creates change in regional development plans, as tourism development is now linked with ideas of regional growth and market specialisation. The growth of Chinese tourism is encouraging diversification and development in New Zealand's market economy.

The third impact Chinese tourism has on the New Zealand political economy is in relation to infrastructure. The rise of Chinese tourism has highlighted that New Zealand is facing an infrastructure deficit, and this deficit influences sectors outside of tourism. Issues such as road density and quality, as well as railroad quality pose problems to the ongoing functionality of New Zealand as a whole. This infrastructure deficit runs parallel to issues in ICT preparedness, which was also highlighted by this thesis through the e-commerce discussion. According to the World Economic Forum, New Zealand has serious issues facing the accessibility of mobile coverage, ranking $91^{\text {st }}$ (out of 141). ${ }^{355}$ This raises concerns about the viability of increasing FIT travel to New Zealand, as they tend to go to regional areas (where low coverage is most prominent). This has prompted the need for more investment in ICT, to not only cope with rising numbers, but also to facilitate the a greater

\footnotetext{
${ }^{354}$ Hsu, C. H., \& Huang, S. S. (2016). Reconfiguring Chinese cultural values and their tourism implications. Tourism Management, 54, 235.

${ }^{355}$ World Economic Forum. (2015). The Travel \& Tourism Competitiveness Report 2015. Retrieved from http://www3.weforum.org/docs/TT15/WEF Global Travel\&Tourism Report 2015.pdf
} 
technological uptake to make practices such as e-commerce more practical for small to medium enterprises.

\subsubsection{New Zealand's Tourism Development}

\subsubsection{Effectiveness of Marketing Strategies}

This thesis also has a number of implications for New Zealand's tourism development model. Chapter two demonstrated that New Zealand's tourism was primarily interested in nature tourism, with cultural tourism as a secondary attraction. There is a large focus on messages about environmentally sustainable practices and educating the public about both the need to be environmentally conscious and how to do this. There is significant interest in highlighting New Zealand's unique flora and fauna and using this to spearhead the environmentally conscious message. The idea of placing nature at the forefront falls in line with the New Zealand government's plans to promote New Zealand's natural heritage and to move towards a more eco-friendly tourism model. This is further reflected in the move from high volume to high value. This shift will bring the greatest economic benefits with the lowest impact on the environment and on New Zealand's already strained tourism infrastructure.

This will provide a short-term solution to New Zealand's tourism infrastructure problem, but in the long term there will need to be an improvement in the facilities. The final way these sites are successful is because they encourage regional diversification. A major problem identified by both this research and TNZ was the lack of regional diversification. By having natural must-see attractions located outside of Auckland and Otago, nature-based tourism is encouraging tourist movements. An improvement of infrastructure could enable increased stay time and spend at these sites, which would further help to develop regional tourism facilities. Nature targeting tourists is most apparent at sites such as Milford Track where nature serves as the focal attraction and the number of visitors a year is restricted. This not only keeps down environmental degradation but it also helps to establish an environment that tourists find enjoyable, resulting in repeat visitation.

The second theme in New Zealand tourism was cultural tourism, in the form of Māori heritage. Māori tourism is unique to New Zealand so it is often utilized as a marketing device in New Zealand's destination image. This rarely discusses the history of contestation that has occurred across New Zealand, though it does provide an adequate amount of information about Māori culture and historical living. This is due in large part to the active involvement of some Māori iwi and hapū. This relates strongly to one of the desired outcomes set out by the New Zealand government of inclusive 
growth. ${ }^{356}$ Overall, the case studies fall within the goals outlined by the New Zealand government. The addition of Māori tourism at historical sites (such as Rotorua where there is a historical Māori village) helps to promote regional diversity, by encouraging tourists to travel outside of the main regions to see these attractions. As a whole, nature and Māori tourism are largely successful at achieving the goals the New Zealand government have established.

\subsubsection{E-Commerce and New Zealand}

The second consideration is the importance of e-commerce to New Zealand's tourism development. While specifically, the New Zealand government did not reference e-commerce itself; their strategies exhibited an interest in technology uptake. A lot of focus on the tourism experience focuses solely on their time within New Zealand, and does not consider post tourism. There is a large focus on building up the New Zealand brand/image. Following the introduction of the ' $100 \%$ Pure New Zealand' marketing campaign in 1999, developing this image for New Zealand has been the top priority for the government. Over the last 20 years, this has created an internationally recognisable image. The introduction of FernMark alongside this project has also created a quality assurance programme that highlights the best products that New Zealand has to offer.

However, the opportunities for growth made possible by innovations such as FernMark have yet to be utilized to their full potential, particularly in B2C transactions. FernMark as a product could be used much more widely to promote New Zealand products to help spur international trade and increase the nation's overall revenue. In B2B, FernMark is used as a selling point for New Zealand products, however, in B2C this has not yet happened. Highlighting the quality of New Zealand goods while tourists visit is great for sales, and by extending the opportunities for repeat purchasing once tourists return home, would increase overall revenue gained from tourism. TNZ has identified the role of business tourism and how this can be used to promote positive trading relationships with visitors and their families, friends and corporate networks. This thesis identified wine tourism and agritourism as two ways to promote further spending once tourists leave New Zealand. New Zealand wines is world-renowned and the industry's rapid growth makes wine tourism a smart decision for investment. Agritourism can provide a hands-on opportunity for New Zealand's world-renowned agriculture industry and this could stimulate growth through online purchases from a reputable source. Overall, New Zealand has worked on establishing a well-polished international tourism

\footnotetext{
356 Ministry of Business, Innovation and Employment. (n.d.). Aotearoa New Zealand Government Tourism Strategy. Retrieved from https://www.mbie.govt.nz/immigration-and-tourism/tourism/new-zealand-aotearoagovernment-tourism-strategy/
} 
image and has managed to associate themselves with some high quality products such as wine and dairy.

\subsubsection{China and New Zealand Tourism}

Overall, this thesis has examined the role of Chinese tourism in New Zealand as a means with which to evaluate the impact that the growth of Chinese tourism has had on IPE. Therefore, it makes sense to consider the position of Chinese tourism in New Zealand. First, it is important to address the distinctiveness of the Chinese tourism market compared with the rest of New Zealand's other major markets. Being the only major market to come from Asia, there are a number of cultural differences that have emerged between the Chinese market and the rest of New Zealand's other largest markets. A major reason behind this cultural difference is the influence of Confucianism, which operates in opposition to the US framework that is dominant in a lot of tourism research. Because of the significant differences between Chinese tourists to the rest of New Zealand's tourists, special consideration of how to effectively meet the needs of Chinese tourists should be a crucial part of the marketing strategy for TNZ. To some extent, there have been efforts to cater to the needs of Chinese tourists. Legislation to protect them while on shopping tours, the introduction of Chinese language facilities and the accessibility of police officers and doctors who speak Mandarin and Cantonese have all helped to make the tourism experience of Chinese tourists better. There has also been research conducted into how to more effectively market to the Chinese audience; through using Mandarin in advertising, using Chinese celebrities in advertising and adjusting the messages presented in destination campaigns. As the case studies demonstrated, attractions continue to be framed from a Western perspective and cultural differences are not adequately addressed in New Zealand tourism sites. The government has singled out the Chinese market as one to target for a number of reasons; including the large number of active considerers, high spend per visitor and the sustained growth since 2010. However, attention to cultural differences and different expectations arising from these differences have not adequately been addressed. New Zealand needs to investigate the needs and interests of this market and work towards creating a framework for attractions that they will be able to enjoy.

\subsubsection{Returning Post COVID-19}

One of the biggest issues with the ongoing relevance of this thesis is the obvious changes that have occurred as a result of COVID-19 and the effects this has had on international tourism. Inbound international tourism into New Zealand has all but stopped, with Chinese numbers declining drastically. As of June 2020, Chinese tourism numbers for the year were only 245,861 , down $41.6 \%$ 
on the same time during previous year. For the month of June there were only 239 visitors, which makes a $98.7 \%$ decline from June of 2019. ${ }^{357}$ While the numbers of have declined as a result of COVID-19, this does not mean that this needs to be a permanent change. However, once the threat of the pandemic has been mitigated, the challenge of encouraging Chinese tourists to return will present its own set of challenges. Because of the issues facing New Zealand tourism in appealing to the outbound Chinese tourism market that were highlighted within this thesis, it may prove difficult to attract Chinese tourists again once travel restrictions are lifted. This is due to several reasons, the first is because of the previously mentioned economic and time costs associated with travelling to a country as geographically distant from China as New Zealand. The second reason is the fact many places are not adequately equipped at catering to the interests of Chinese tourists, which has been highlighted throughout this thesis. If New Zealand wants to continue to benefit from the previous massive economic perks of appealing to the Chinese tourists (approximately $\$ 1.5$ billion NZD in 2018), New Zealand will need to make adjustments to cater to Chinese tourists more effectively, otherwise they will begin to travel elsewhere. Through considering some of the findings made in this thesis some changes could be made to improve New Zealand's ability to attract Chinese tourists. These include the introduction of culturescape, increasing access to quality tour programmes and strengthening the relationship between tourism and trade. Through implementing some of these ideas, New Zealand would be able to improve its tourism relationship with China and also could improve the recognition of Brand New Zealand abroad. Through the implementation of these ideas, tourism could spur more economic growth for New Zealand.

\subsection{Concluding Remarks}

\subsubsection{Policy Recommendations}

There are several policy recommendations that this thesis could make in order to aid New Zealand in making the most of inbound Chinese tourism. The first recommendation is the introduction of a system to incentivise employment in tourism and encouraging the industry as a viable career path. One of the biggest problems is tourism has a high turnover and are not considered career options. Highlighting higher skilled work, the opportunities for career progression and the variety of jobs available would serve to help create the perception of tourism as a more viable career path. There are many areas of study are useful to the tourism industry. This includes communications and marketing, statistics and accounting and history and political science. The second recommendation is

\footnotetext{
${ }^{357}$ Tourism New Zealand. (2020). China. Retrieved from https://www.tourismnewzealand.com/marketsstats/markets/china/
} 
the creation of a platform for New Zealand to launch a co-ordinated e-commerce campaign. A cooperative campaign highlighting FernMark to represent quality would enable New Zealand to develop its profit making potentials and expand its tourism marketing efforts. The third recommendation is to investigate the interests and behaviours of the Chinese inbound market more closely. Conducting this research would then need to be followed by an examination of how to effectively utilize these findings. Another policy recommendation involves the growth of shoulder seasonal visitation to New Zealand. This can be done through the creation of specialisation and niche-tourism. Chinese tourists have long been active in the field of film tourism and enjoy visiting film locations. ${ }^{358}$ Outside of Lord of the Rings, New Zealand has few films heavily marketed for film tourism. Embracing a large variety of films that showcase New Zealand and aiming to promote more films within the Chinese film scene could help to develop tourism and encourage off season travel. Food and health tourism are other niche markets that Chinese tourists are prominent participants in. ${ }^{359}$ The final policy recommendation is to invest more in high quality infrastructure to support the needs of tourists that are travelling to New Zealand.

Currently there are issues in New Zealand when it comes to the infrastructure and the total number of tourists is forecast to grow over the next five years. There needs to be a more effective infrastructure plan to mitigate not only the pressure placed on the tourism facilities, but also to protect the environment through environmentally conscious infrastructure. The quality will need to be high so that it will also appeal to the high value tourists New Zealand is hoping to attract. New Zealand needs a solid plan to develop its tourism infrastructure. There are a number of different things that New Zealand could do to promote itself and help develop its tourism facilities, not only within the context of the Chinese market, but with the whole world.

\subsubsection{Future Research}

There are a number of topics that would be useful as future research projects. The most prominent would be other country case studies using a similar model to the one employed in this thesis. By creating other case studies using this framework, the scope of literature related to how tourism relates to IPE would be expanded. These case studies would be to examine the way other nations react to the growth of Chinese outbound tourism. Case studies that would be particularly useful

\footnotetext{
358 Kim, S. (2012). A cross-cultural study of on-site film-tourism experiences among Chinese, Japanese, Taiwanese and Thai visitors to the Daejanggeum Theme Park, South Korea. Current Issues in Tourism, 15(8), 759-776.

${ }^{359}$ Islam, N. (2014). Chinese medicine as a product filling the wellness health tourism niche in China: Prospect and challenges. International Journal of Tourism Sciences, 14(1), 51-69.
} 
would be Thailand, the US, Australia and Canada. Thailand would make useful case studies for this field because it is the most popular destination for Chinese outbound tourists, so it is worth examining how they have been impacted by Chinese tourism and the close relationship that the CCP has with Chinese tourism behaviours. The US is the most popular English speaking destination for Chinese tourists. This would be useful in providing a metric for success in Chinese tourism and it would show how an economic superpower is influenced by the growing influence of China. Australia would be a useful case study because of its proximity to New Zealand and the often similar political and economic position New Zealand and Australia share would make for an interesting case comparison. Canada would be a useful case study because both New Zealand and Canada promote eco-tourism and natural phenomenon. ${ }^{360}$ This thesis has explored the relationship between tourism and IPE and there are many different ways for this field to be expanded on.

\section{$\underline{5.4 .3}$ Limitations}

A major limitation of this research is the fact that tourism and international relations are dynamic and never static. The information provided in this thesis is relevant at the time of writing; however should the relationship between New Zealand and China change significantly then the nature of tourism between the two countries could change. A possible consequence of significant changes could be a drastic decline in the number of Chinese tourists that come to New Zealand and reductions in Chinese purchasing New Zealand products. This is due to the heavy influence that the CCP has in managing Chinese citizens' perceptions of other nations through their control of the media and information dissemination. This research does not address sudden political changes and does not look to make a prediction for the future, but rather examines the current relationship as it stands as of February 2020. This also means that this research is unable to predict the future trends of tourism in New Zealand, as the political climate is so prone to change. This dramatic change has been highlighted by the events of COVID-19 which has shown to be highly disruptive to the status quo of not only Chinese tourism, but of all tourism to New Zealand. This research is only able to present a static image that is based on February 2019, as it rooted in a policy understanding.

\subsubsection{Conclusion}

This thesis has explored the relationship between tourism and IPE within the context of Chinese inbound tourism to New Zealand. It asks what the rise of China means for the growth of New Zealand tourism. The findings can be grouped into two sections; one covering IPE and the other

\footnotetext{
${ }^{360}$ Gössling, S., \& Hall, M. C. (2006). Tourism and global environmental change: Ecological, social, economic and political interrelationships (Vol. 4). Taylor \& Francis.
} 
covering New Zealand's current tourism situation considering Chinese tourists. The first section refers to the way Chinese tourism is shaping IPE, and concludes Chinese tourism is able to shape international politics in a number of ways. Currently, Chinese tourism runs the risk of stagnating due to their needs not being fully met, and this has major ramifications for New Zealand's economy. In response new types of tourism offerings and marketing strategies have emerged. The economic impact of Chinese tourism has been broadly positive for New Zealand but more could be done to leverage tourism. This economic effect is not only bound to tourist spending within the country. Through e-commerce and links between tourism and trade, the New Zealand economy is massively influenced by tourism. Chinese outbound tourism is also highlighting the necessary changes the tourism industry need to make. Chinese tourism has uncovered deficiencies in New Zealand's political economy and that the New Zealand government and tourist providers are working to try to resolve these. The large scale of Chinese tourism and the close relationship that both the tourism industry and the economy have with the CCP means that these impacts are also political in nature and they have to be considered in accordance with China's international ambitions. China is challenging the current set up of IPE by altering it through the use of tourism and economics tied to tourism.

The second section focuses on New Zealand tourism, and comes to three conclusions. Firstly, that New Zealand overall, has a competent tourism strategy that understands a number of problems that the industry faces such as seasonal and regional diversification that need to be addressed. Secondly, New Zealand is doing a good job of meeting the desired outcomes according to the tourism strategy. However, New Zealand focuses too much on its international image, and is not equipped to deal with the continued tourism growth. New Zealand faces a lack of skilled staff and infrastructure. Thirdly, this thesis has found that New Zealand could attract more revenue if it was to establish an ecommerce market to capitalise on the nation's brand. E-commerce spurs international trading as well as encourages shopping once tourists return to their home nation. Tourism can create positive brand associations with New Zealand. E-commerce can create capitalise on these positive brand perceptions and generate revenue potential. Overall, all these conclusions shed a lot of light on the current political situation. This thesis has demonstrated the rise of China's tourism system and the impact that it is having on New Zealand, as well as the rest of the world. There are a number of policy decision that have been advised for New Zealand government officials, but ultimately more research into this area needs to be done to fully determine the impact that Chinese tourism is having on the rest of the world. 


\section{Bibliography}

100\% Pure New Zealand. (n.d.). Events. Retrieved from https://www.newzealand.com/int/events/

100\% Pure New Zealand. (n.d.). Good Morning World. Retrieved from

https://www.newzealand.com/int/

Acharya, A. (2014). Power shift or paradigm shift? China's rise and Asia's emerging security order. International Studies Quarterly, 58(1), 158-173.

Agency China. (2019). 2019 China Tourism Trend Predictions. Retrieved from https://agencychina.com/blog/2019-china-tourism-trend-predictions/

Agénor, P. R. (2010). A theory of infrastructure-led development. Journal of Economic Dynamics and Control, 34(5), 932-950.

Alcohol Healthwatch. (2009). INFORMATION SHEET: TAX ON ALCOHOL. Retrieved from http://www.ahw.org.nz/Portals/5/Resources/Fact\%20Sheet/Info\%20Sheet\%20Alcohol\%20and\%20T ax\%20Final\%2009.pdf

Aljazeera. (2019). China to increase overseas military bases: Pentagon report. Retrieved from https://www.aljazeera.com/news/2019/05/china-increase-overseas-military-bases-pentagonreport-190503065146243.html

Almay. (n.d.). Mao Memorabilia souvenirs in Shaoshan village Hunan province China. Retrieved from https://www.alamy.com/stock-photo-mao-memorabilia-souvenirs-in-shaoshan-village-hunanprovince-china-59636962.html

Alonso, A. D. (2009). Are travellers interested in wine tourism in New Zealand?. International Journal of Culture, Tourism and Hospitality Research, 3(1), 13-24.

Alonso, A. D., Fraser, R. A., \& Cohen, D. A. (2008). Exploring wine tourism in New Zealand: the visitors' points of views. Tourism Analysis, 13(2), 171-180.

Amadeo, K. (2019). China's Economic Growth, Its Causes, Pros, Cons, and Future. The Balance. Retrieved from https://www.thebalance.com/china-s-economic-growth-cause-pros-cons-future$\underline{3305478}$

Anyebe, A. A. (2018). An Overview of Approaches to the Study of Public Policy. e-Bangi, 15(1).

Arcodia, C. (2003). Confucian values and their implications for the tourism industry. CAUTHE 2003: Riding the Wave of Tourism and Hospitality Research, 6. 
Arita, S., La Croix, S., \& Mak, J. (2012). How China's Approved Destination Status Policy Spurs and Hinders Chinese Travel Abroad. Working papers of the Economic Research Organisation at the University of Hawaii.-October 19, (2012-6).

Arita, S., La Croix, S., \& Edmonds, C. (2014). Effect of Approved Destination Status on Mainland Chinese Travel Abroad. Asian Economic Journal, 28(3), 217-237.

Arrell, R. (n.d.). Waitomo Caves, N.Z.: Waitomo Caves Museum Society.

Arroyo, C. G., Barbieri, C., \& Rich, S. R. (2013). Defining agritourism: A comparative study of stakeholders' perceptions in Missouri and North Carolina. Tourism Management, 37, 39-47.

Ashton, A. S. (2014). Tourist destination brand image development-an analysis based on stakeholders' perception: A case study from Southland, New Zealand. Journal of Vacation Marketing, 20(3), 279-292.

Ateljevic, I., \& Doorne, S. (2000). Local government and tourism development: Issues and constraints of public sector entrepreneurship. New Zealand Geographer, 56(2), 25-31.

Baird, M. F. (2013). 'The breath of the mountain is my heart': indigenous cultural landscapes and the politics of heritage. International Journal of Heritage Studies, 19(4), 327-340.

Baird, T., Hall, C. M., \& Castka, P. (2018). New Zealand winegrowers attitudes and behaviours towards wine tourism and sustainable winegrowing. Sustainability, 10(3), 797.

Barnett, S. (1997). Māori tourism. Tourism management, 18(7), 471-473.

Barrick, K. A. (2007). Geyser decline and extinction in New Zealand-energy development impacts and implications for environmental management. Environmental Management, 39(6), 783-805.

Baum, T., \& Lundtorp, S. (Eds.). (2001). Seasonality in tourism. Elsevier.

Becken, S. (2003). Chinese Tourism to New Zealand. Lincoln, New Zealand: Landcare Research.

Becken, S. (2005). The role of tourist icons for sustainable tourism. Journal of Vacation Marketing, 11(1), 21-30.

Berg, S. V., \& Horrall, J. (2008). Networks of regulatory agencies as regional public goods: Improving infrastructure performance. The Review of International Organizations, 3(2), 179-200.

Boase, J. P. (2000). Beyond government? The appeal of public - private partnerships. Canadian Public Administration, 43(1), 75-92. 
Bradley, G. (2019). Hotels.com figures show prices on the move - are you paying too much?. NZ Herald. Retrieved from

https://www.nzherald.co.nz/business/news/article.cfm?c id=3\&objectid=12229598

Bräutigam, D., \& Xiaoyang, T. (2012). Economic statecraft in China's new overseas special economic zones: soft power, business or resource security?. International Affairs, 88(4), 799-816.

Brooks, S. G., \& Wohlforth, W. C. (2016). The rise and fall of the great powers in the twenty-first century: China's rise and the fate of America's global position. International Security, 40(3), 7-53.

Buhalis, D., \& Wagner, R. (2013). E-destinations: Global best practice in tourism technologies and applications. In Information and communication technologies in tourism 2013. Springer, Berlin, Heidelberg. 119-130.

Burns, B., Ward, R., \& Downs, J. (2013). Trampling Impacts on Thermotolerant Vegetation of Geothermal Areas in New Zealand. Environmental Management, 52(6), 1463-1473.

Butler, R., \& Suntikul, W. (Eds.). (2017). Tourism and political change. Goodfellow Publishers Ltd.

Byers, A. (2005). Contemporary human impacts on Alpine ecosystems in the Sagarmatha (Mt. Everest) national park, Khumbu, Nepal. Annals of the association of American Geographers, 95(1), $112-140$

Cahn, R., \& Cahn, L. (1989). Reorganizing Conservation Efforts in New Zealand. Environment: Science and Policy for Sustainable Development, 31(3), 18-45.

Cao, X. (2015). Challenges and potential improvements in the policy and regulatory framework for sustainable tourism planning in China: The case of Shanxi Province. Journal of Sustainable Tourism, 23(3), 455-476.

Carr, A. (2004). Mountain places, cultural spaces: The interpretation of culturally significant landscapes. Journal of Sustainable Tourism, 12(5), 432-459.

Cave, D. (2019). Espionage and Interference? Australia Grapples With Its China Relationship. Retrieved from https://www.nytimes.com/2019/11/29/world/australia/china-espionageinterference.html

Cave, J., \& Dredge, D. (2018). Reworking tourism: Diverse economies in a changing world.

CBS. (2019). China hatches plan to keep vacationers in check. Retrieved from https://www.cbsnews.com/news/china-government-keep-records-chinese-tourists-inappropriateactions-abroad/

Chan, D. (2009). Sustainable tourism in New Zealand: The Chinese visitors' view. 
Chan, F., \& Lim, C. (2011). Spectral analysis of seasonality in tourism demand. Mathematics and Computers in Simulation, 81(7), 1409-1418.

Chang, D. (1988). China under Deng Xiaoping : political and economic reform. Basingstoke: Macmillan.

Chatterjee, S., \& Morshed, A. M. (2011). Reprint to: Infrastructure provision and macroeconomic performance. Journal of Economic Dynamics and Control, 35(9), 1405-1423.

Che, L. (2014). Understanding motivations to visit New Zealand: A quantitative study amongst young Chinese FITs (Doctoral dissertation, Auckland University of Technology).

Chen, C. Y. (2016). The impact of the Chinese tourism market on Taiwan residents' attitudes. Journal of Quality Assurance in Hospitality \& Tourism, 17(1), 1-23.

Chen, L. (2019). Rotorua tourist bus crash: Passengers tell of harrowing rescue. NZ Herald. Retrieved from https://www.nzherald.co.nz/nz/news/article.cfm?c id=1\&objectid=12265309

Chen, T., \& Pearce, P. L. (2012). Research note: Seasonality patterns in Asian tourism. Tourism Economics, 18(5), 1105-1115.

Chen, Y., Yan, X., \& Fan, W. (2015). Examining the effects of decomposed perceived risk on consumer's online shopping behavior: A field study in China. Inzineriné Ekonomika, 26(3), 315-326.

Cheng, K. M., Kim, H., \& Thompson, H. (2013). The exchange rate and US tourism trade, 1973-2007. Tourism Economics, 19(4), 883-896.

China - New Zealand Year of Tourism. (2019). Catering to Chinese visitors. Retrieved form https://www.cnzyot.govt.nz/assets/PDF-resources/c002499002/Catering-to-Chinese-visitors.pdf

China Travel Guide. (2018). 2018 China Tourism Facts \& Figures. Retrieved from https://www.travelchinaguide.com/tourism/2018statistics/

Christensen, J. (2014). Building an Environmental Ethics from the Confucian Concepts of Zhengming and Datong. Asian Philosophy, 24(3), 1-15.

Christian, H. (2019). New Zealand-China relationship: What's at stake for trade, tourism, students? Retrieved from https://www.stuff.co.nz/business/110664747/new-zealandchina-relationship-whatsat-stake-for-trade-tourism-students

Choo, H., \& Petrick, J. F. (2014). Social interactions and intentions to revisit for agritourism service encounters. Tourism Management, 40, 372-381 
Chung, H. F. (2003). International standardization strategies: The experiences of Australian and New Zealand firms operating in the greater China markets. Journal of International Marketing, 11(3), 4882.

Clarkson, D. (2016). Chinese tour drivers had no licences, police allege. Stuff. Retrieved from https://www.stuff.co.nz/national/crime/84044806/chinese-tour-drivers-had-no-licences-policeallege

Cole, J. (2017). Surveying the Digital Future. The 2017 Digital Future Report. Centre for the Digital Future.

Congressional Research Service. (2019) China's Economic Rise: History, Trends, Challenges, and Implications for the United States. Retrieved from https://fas.org/sgp/crs/row/RL33534.pdf

Corre, P. (2018). China's Rise as a Geoeconomic Influencer: Four European Case Studies. Retrieved from https://carnegieendowment.org/2018/10/15/china-s-rise-as-geoeconomic-influencer-foureuropean-case-studies-pub-77462

Correia, A., Kozak, M., \& Kim, S. (2018). Luxury shopping orientations of mainland Chinese tourists in Hong Kong: Their shopping destination. Tourism Economics, 24(1), 94.

Cropp, A. (2017). Tourism: a brilliant career or a job for dummies? Stuff. Retrieved from https://www.stuff.co.nz/business/93595748/tourism-a-brilliant-career-or-a-job-for-dummies?rm=m

Cropp, A. (2019). The tourism industry is twitchy about continued political chatter about China. Stuff. Retrieved from https://www.stuff.co.nz/business/110617012/tourism-worries-speculation-aboutchinese-political-interference-could-become-a-self-fulfilling-prophecy

Cropp, A. (2018). Tourism is embracing Te reo and visitors love it. Retrieved from https://www.stuff.co.nz/business/106907095/tourism-is-embracing-te-reo-and-visitors-love-it

Ctrip and China Tourism Academy. (2017). 2017 China Outbound Tourism Travel Report. China. Retrieved from https://www.chinatravelnews.com/images/201802/fc66f776a9111201.pdf

Cuccia, T., \& Rizzo, I. (2011). Tourism seasonality in cultural destinations: Empirical evidence from Sicily. Tourism Management, 32(3), 589-595.

Dann, L. (2019). NZ/China relationship: 'We have a big problem.' Retrieved from https://www.nzherald.co.nz/business/news/article.cfm?c id=3\&objectid=12203566

Department of Conservation. (2006). Geothermal systems. Retrieved from https://www.doc.govt.nz/Documents/about-doc/concessions-and-permits/conservationrevealed/geothermal-systems-lowres.pdf 
Department of Conservation. (2011). Exploring Visitor Experiences, crowing perceptions and coping strategies on the Milford Track, New Zealand. ISSN 1177-9241.

Department of Conservation. (2017). Aotearoa New Zealand Government Strategy: Summary. Retrieved from https://www.mbie.govt.nz/dmsdocument/1492-aotearoa-new-zealand-governmenttourism-strategy-summary-draft-pdf

Department of Conservation. (2018). Plan and Prepare Milford Track. Retrieved from https://www.doc.govt.nz/globalassets/documents/parks-and-recreation/tracks-andwalks/southland/milford-track-brochure.pdf

Department of Conservation. (n.d.). About Tongariro National Park. Retrieved from https://www.doc.govt.nz/parks-and-recreation/places-to-go/central-north-island/places/tongarironational-park/about-tongariro-national-park/

Department of Conservation. (n.d.). Flora and Fauna. Retrieved from https://www.doc.govt.nz/parks-and-recreation/places-to-go/central-north-island/places/tongarironational-park/about-tongariro-national-park/flora-and-fauna/

Department of Conservation (n.d.). Milford Track Winter Tramping. Retrieved from https://www.doc.govt.nz/globalassets/documents/parks-and-recreation/tracks-andwalks/southland/milford-track-winter-tramping.pdf

Department of Conservation. (n.d.). Waitomo and King Country Tracks. Retrieved from http://www.waitomo.govt.nz/PageFiles/597/waitomo-kingcountrywalks\%5B1\%5D.pdf?epslanguage $=$ en-NZ

Department of Conservation. (n.d.). Walks in and around Tongariro National Park. Retrieved from https://www.doc.govt.nz/globalassets/documents/parks-and-recreation/tracks-andwalks/tongariro-taupo/tongariro-national-park-walks.pdf

Destination Fiordland. (n.d.). Flora and Fauna. Retrieved from https://www.fiordland.org.nz/aboutfiordland/flora-and-fauna/

Devin, G. (Ed.). (2017). Resources and Applied Methods in International Relations. Springer.

Donaubauer, J., Meyer, B., \& Nunnenkamp, P. (2016). Aid, infrastructure, and FDI: Assessing the transmission channel with a new index of infrastructure. World Development, 78, 230-245.

Doorne, S. (2000). Caves, cultures and crowds: carrying capacity meets consumer sovereignty. Journal of Sustainable Tourism, 8(2), 116-130.

Doorne, S. M. (1999). Visitor experience at the Waitomo glowworm cave. Department of Conservation. 
Dowling, R. (2001). The First New Zealand Wine Tourism Conference, Tourism Recreation Research, 26:2, 89-91, DOI: 10.1080/02508281.2001.11081347

Downes, D. (2000). The New Zealand environmental movement and the politics of inclusion. Australian Journal of Political Science, 35(3), 471-491.

Eiraku, M. (2019). Foreign visitors to Japan hits record high. NHK World. Retrieved from https://www3.nhk.or.jp/nhkworld/en/news/backstories/347/

Eurostat. (2016). E-commerce statistics for Individuals. https://ec.europa.eu/eurostat/statisticsexplained/pdfscache/46776.pdf

Ezeuduji, I. O. (2015). Strategic event-based rural tourism development for sub-Saharan Africa. Current Issues in Tourism, 18(3), 212-228

Fagence, M. (1996). Regional tourism cooperation. Annals of Tourism Research, 3(23), 717-720.

Fairweather, J. R., \& Swaffield, S. R. (2002). Visitors' and locals' experiences of Rotorua, New Zealand: An interpretative study using photographs of landscapes and $Q$ method. International Journal of Tourism Research, 4(4), 283-297.

Farrar, L. (2012). China's E-Commerce Upswing. WWD, 203(75), 1

Farrell, H., \& Newman, A. L. (2010). Making global markets: Historical institutionalism in IPE. Review of International Political Economy, 17(4), 609-638.

Fayissa, B., Nsiah, C., \& Tadasse, B. (2008). Impact of tourism on economic growth and development in Africa. Tourism Economics, 14(4), 807-818.

Feng, D. (2013). National voice: A discourse analysis of China central television's news simulcast. Discourse \& Communication, 7(3), 255-273.

Fernmark. (n.d.). Promoting Provenance To Grow Export Success. Retrieved form https://www.fernmark.nzstory.govt.nz/info

Foley, D. (2011). From traditional carving to plastic Tiki: Māori struggles to balance commerce and culture within the global tourism marketplace, 1860-2010. Journal of Tourism History, 3(2), 177-199.

Fountain, J. (2018). The Wine Tourism Experience in New Zealand: An Investigation of Chinese Visitors' Interest and Engagement. Tourism Review International, 22(1), 67-79.

Fountain, J., Espiner, S., \& Xie, X. (2010). A cultural framing of nature: Chinese tourists' motivations for, expectations of, and satisfaction with, their New Zealand tourist experience. Tourism Review International, 14(2-3), 71-83. 
Fry, D., Saayman, A., \& Saayman, M. (2010). The relationship between tourism and trade in South Africa. South African Journal of Economics, 78(3), 287-306.

Gao, Y., \& Wu, X. (2010). A Cognitive Model Of Trust In E-Commerce: Evidence From A Field Study In China. Journal of Applied Business Research, 26(1), 37-44.

Gee, S. (2019). DOC investigating illegal guides operating in Abel Tasman National Park. Stuff. Retrieved from https://www.stuff.co.nz/environment/114687072/doc-investigating-illegal-guidesoperating-in-abel-tasman-national-park

Gong, W., Stump, R., \& Maddox, L. (2013). Factors influencing consumers' online shopping in China. Journal of Asia Business Studies, 7(3), 214-230.

Gössling, S., \& Hall, M. C. (2006). Tourism and global environmental change: Ecological, social, economic and political interrelationships (Vol. 4). Taylor \& Francis.

Gössling, S. (2009). Carbon neutral destinations: A conceptual analysis. Journal of Sustainable Tourism, 17(1), 17-37.

Graham McLay, C. (2019). New Zealand Fears Fraying Ties With China, Its Biggest Customer. Retrieved from https://www.nytimes.com/2019/02/14/world/asia/new-zealand-china-huaweitensions.html

Groot, R. (2003). The Tongariro National Park: Are We Loving it to Death?. New Zealand Journal of Geography, 115(1), 1-13.

Gu, J., Zhang, C., Vaz, A., \& Mukwereza, L. (2016). Chinese state capitalism? Rethinking the role of the state and business in Chinese development cooperation in Africa. World Development, 81, 2434.

Gupta, M. R., \& Barman, T. R. (2010). Health, infrastructure, environment and endogenous growth. Journal of Macroeconomics, 32(2), 657-673.

Hall, C. M., \& Higham, J. (Eds.). (2005). Tourism, recreation and climate change. Channel View Publications.

Hampton, L. (2017). Tongariro Crossing struggling to cope with hordes of tourists. Retrieved from https://www.newshub.co.nz/home/new-zealand/2017/02/tongariro-crossing-struggling-to-copewith-hordes-of-tourists.html

Harun, R., Chiciudean, G. O., Sirwan, K., Arion, F. H., \& Muresan, I. C. (2018). Attitudes and perceptions of the local community towards sustainable tourism development in Kurdistan regional government, Iraq. Sustainability, 10(9), 2991.

He, C. (2018). New Confucianism, Science and the Future of the Environment. 26(2), 368-380. 
Heimler, A. (1991). Linkages and vertical integration in the Chinese economy. The Review of Economics and Statistics, 73(2), 261-267

Heremia, J. (n.d.). Battle of the Mountains: The Māori Legend. Retrieved from https://destinationsmagazine.com/maori-mountain-legend/

Hikuroa, D. (2017). Mātauranga Māori-the ūkaipō of knowledge in New Zealand. Journal of the Royal Society of New Zealand, 47(1), 5-10.

Hjalager, A. M., Staunstrup, J. K., \& Ibsen, R. (2011). Trade and value developments in the Danish second-home sector: Implications for tourism policies. Tourism Economics, 17(3), 677-691.

Hoadley, S., \& Yang, J. (2007). China's cross-regional FTA initiatives: Towards comprehensive national power. Pacific Affairs, 80(2), 327-348.

Hsu, C. (2016). Reconfiguring Chinese cultural values and their tourism implications. Tourism Management, 54, 230-242

Hsu, C. H., \& Song, H. (2012). Projected images of major Chinese outbound destinations. Asia Pacific Journal of Tourism Research, 17(5), 577-593.

Huang, S., Keating, B. W., Kriz, A., \& Heung, V. (2015). Chinese outbound tourism: An epilogue. Journal of Travel \& Tourism Marketing, 32(1-2), 153-159

Hunter, William Cannon. (2013). China's Chairman Mao: A visual analysis of Hunan Province online destination image. Tourism Management, 34, 101-111.

Hwang, D., Stewart, W. P., \& Ko, D. W. (2012). Community behavior and sustainable rural tourism development. Journal of Travel research, 51(3), 328-341.

Internet World Statistics. (2019). Internet Users in the World by Regions. Retrieved from https://www.internetworldstats.com/stats.htm

Ioppolo, G., Saija, G., \& Salomone, R. (2013). From coastal management to environmental management: The sustainable eco-tourism program for the mid-western coast of Sardinia (Italy). Land Use Policy, 31, 460-471.

Islam, N. (2014). Chinese medicine as a product filling the wellness health tourism niche in China: Prospect and challenges. International Journal of Tourism Sciences, 14(1), 51-69.

Jainchill, J. (2016). Growth of Chinese tourism the talk of U.S. Travel show. (NEWS). Travel Weekly, 75(26). 
Jamieson, D. (2018). Queenstown short hundreds of workers during busiest time of year. Stuff. Retrieved from https://www.stuff.co.nz/business/industries/109420375/queenstown-shorthundreds-of-workers-during-busiest-time-of-year?rm=m

Jensen, J., Krishnan, V., Spittal, M., \& Sathiyandra, S. (2003). New Zealand living standards: their measurement and variation, with an application to policy. Social Policy Journal of New Zealand, 7297.

Jia, R. (2012). An Agenda for Promoting Cultural Exchanges and Cooperation. Policy Perspectives, $145-148$.

Jiang, S. (2018). China snatches Dominican Republic from Taiwan in diplomatic blow. Retrieved from https://edition.cnn.com/2018/05/01/asia/china-taiwan-dominican-republican-int//index.html

Jin, X. C., \& Sparks, B. (2017). Barriers to offering special interest tour products to the Chinese outbound group market. Tourism Management, 59, 205-215.

Jing Travel. (2018). The Number of Potential Chinese Outbound Tourists Could Double by 2020 to 240 Million. Retrieved from https://jingtravel.com/number-of-potential-chinese-outbound-touristsdouble-by-2020/

JNTO. (2018). 2017 Breakdown of the Length of Stay in Japan (Overall). Retrieved from https://statistics.jnto.go.jp/en/graph/\#graph--length--of--stay

Johnson, A. (2004). Tourists tempted by a touch of class. Dominion Post (Wellington, N.Z.).

Johnston, A. I. (2017). Is Chinese Nationalism Rising? Evidence from Beijing. International Security, 41(3).

Johnston, R. F. (2014). Confucianism and modern China. Cambridge University Press.

Jolly, G. E., Keys, H. J. R., Procter, J. N., \& Deligne, N. I. (2014). Overview of the co-ordinated riskbased approach to science and management response and recovery for the 2012 eruptions of Tongariro volcano, New Zealand. Journal of Volcanology and Geothermal Research, 286, 184-207.

Joshi, G. S. (2010). Infrastructure development strategies for inclusive growth: India's Eleventh Plan. Leadership and Management in Engineering, 10(2), 65-72.

Kaai, T. (n.d.). Mātauranga Māori. Auckland University of Technology. Retrieved from https://www.aut.ac.nz/study/study-options/maori-and-indigenous-development/research/researchexpertise/mataurangamaori\#: : :text=The\%20term\%20m\%C4\%81tauranga\%20M\%C4\%81ori\%20literally,them\%20to\%20Aot earoa\%2FNew\%20Zealand

Kastner, S. L. (2008). The Global Implications of China's Rise. 
Katircioglu, S. (2009). Tourism, trade and growth: the case of Cyprus. Applied Economics, 41(21), 2741-2750.

Kelly, R. (2019). DOC catches hundreds of illegal walking and tour guides operating in Fiordland. Stuff. Retrieved from https://www.stuff.co.nz/business/114058023/doc-catches-hundreds-of-illegalwalking-and-tour-guides-operating-in-fiordland

Kelly, R. (2019). DOC catches tourism operators operating illegally. Stuff. Retrieved from https://www.stuff.co.nz/business/industries/113554263/doc-catches-tourism-operators-operatingillegally? rm=a

Keum, K. (2011). International tourism and trade flows: A causality analysis using panel data. Tourism Economics, 17(5), 949-962.

Kim, H., \& Stepchenkova, S. (2015). Effect of tourist photographs on attitudes towards destination: Manifest and latent content. Tourism Management, 29-41.

Kim, S. (2012). A cross-cultural study of on-site film-tourism experiences among Chinese, Japanese, Taiwanese and Thai visitors to the Daejanggeum Theme Park, South Korea. Current Issues in Tourism, 15(8), 759-776.

King, B., Dwyer, L., \& Prideaux, B. (2006). An evaluation of unethical business practices in Australia's China inbound tourism market. International Journal of Tourism Research, 8(2), 127-142.

Kumoi, Y., \& Matsubayashi, N. (2014). Vertical integration with endogenous contract leadership: Stability and fair profit allocation. European Journal of Operational Research, 238(1), 221-232.

Kuo, L. (2019). China bans $23 \mathrm{~m}$ from buying travel tickets as part of 'social credit' system. Retrieved from https://www.theguardian.com/world/2019/mar/01/china-bans-23m-discredited-citizens-frombuying-travel-tickets-social-credit-system

Kwak, J., Y., \& Yu, J. (2019). Legitimacy building and e-commerce platform development in China: The experience of Alibaba. Technological Forecasting and Social Change, 139, 115-124.

Kwok, S. (2018). Alibaba tops e-commerce market share while facing fresh competition in China. Retrieved from https://www.marketing-interactive.com/alibaba-tops-e-commerce-market-sharewhile-facing-fresh-competition-in-china/

Lahiri, N., \& Narayanan, S. (2013). Vertical integration, innovation, and alliance portfolio size: Implications for firm performance. Strategic Management Journal, 34(9), 1042-1064.

Lamont, C. (2015). Research methods in international relations. Sage. 
Lejárraga, l., \& Walkenhorst, P. (2013). Economic policy, tourism trade and productive diversification. International Economics, 135, 1-12.

Li, S., Li, H., Song, H., Lundberg, C., \& Shen, S. (2017). The economic impact of on-screen tourism: The case of The Lord of the Rings and the Hobbit. Tourism Management, 60, 177-187.

Li, X. R., Lai, C., Harrill, R., Kline, S., \& Wang, L. (2011). When east meets west: An exploratory study on Chinese outbound tourists' travel expectations. Tourism Management, 32(4), 741-749.

Li, Xiang, Cheng, Chia-Kuen, Kim, Hyounggon, \& Li, Xiangping. (2015). Positioning Usa in the Chinese Outbound Travel Market. Journal of Hospitality \& Tourism Research, 39(1), 75-104.

Lin, L. (2017). Food souvenirs as gifts: tourist perspectives and their motivational basis in Chinese culture. Journal of Tourism and Cultural Change, 15(5), 439-454.

Liu, J., Nijkamp, P., \& Lin, D. (2017). Urban-rural imbalance and tourism-led growth in China. Annals of Tourism Research, 64, 24-36.

Lohmann, G \& Netto, P. (2017). Tourism theory concepts, models and systems. Boston. CAB International.

Mackay, M., Nelson, T., \& Perkins, H. C. (2019). Agritourism and the adaptive re-use of farm buildings in New Zealand. Open Agriculture, 4(1), 465-474.

Magole, L. I., \& Magole, L. (2011). Revisiting Botswana's high-value, low-volume tourism. Tourism Analysis, 16(2), 203-210.

Mandić, A., Mrnjavac, Ž., \& Kordić, L. (2018). Tourism infrastructure, recreational facilities and tourism development. Tourism and hospitality management, 24(1), 41-62.

March, R. (2008). Towards a Conceptualization of Unethical Marketing Practices in Tourism: a CaseStudy of Australia's Inbound Chinese Travel Market. Journal of Travel \& Tourism Marketing, 24(4), 285-296.

Martin, L. L., \& Frieden, J. (2003). International Political Economy: Global and Domestic Interactions. Political Science: The State of the Discipline, ed. I. Katznelson and HV Milner. New York: WW Norton. 118.

McCleave, J., Espiner, S., \& Booth, K. (2006). The New Zealand people-park relationship: An exploratory model. Society and natural Resources, 19(6), 547-561.

McIntosh, A. J., Hinch, T., \& Ingram, T. (2002). Cultural identity and tourism. International Journal of Arts Management, 39-49. 
Mckinsey and Company. (2018). Chinese tourists: Dispelling the myths. Retrieved from

https://www.mckinsey.com/ /media/McKinsey/Industries/Travel\%20Transport\%20and\%20Logistics

Our\%20Insights/Huanying\%20to\%20the\%20new\%20Chinese\%20traveler/Chinese-tourists-

Dispelling-the-myths.ashx

McLay, R. (2019). 10 Companies Owned by Alibaba. Retrieved from

https://www.investopedia.com/insights/10-companies-owned-alibaba/

McNally, C. A. (2012). Sino-capitalism: China's reemergence and the international political economy. World politics, 64(4), 741-776.

Mejia, C., Wei, W., Fu, X., Hua, N., \& Wang, Y. (2018). Hospitality and tourism experts' perspectives on Chinese independent tourists' U.S. service expectations through a mobilities lens. The International Journal of Tourism Research, 20(6), 726-737.

Mendi, P., Moner-Colonques, R., \& Sempere-Monerris, J. J. (2011). Vertical integration, collusion, and tariffs. SERIEs, 2(3), 359-378.

MFAT. (n.d.). China. Retrieved from https://www.mfat.govt.nz/en/countries-and-regions/northasia/china/

Middleton, J. (2001). Staff turnover 'way too high'. Retrieved from

https://www.nzherald.co.nz/employment/news/article.cfm?c id=11\&objectid=230298

Mihalič, T. (2000). Environmental management of a tourist destination: A factor of tourism competitiveness. Tourism management, 21(1), 65-78.

Milford Track. (2017). Milford Track Diary - One Tramper's Experience of the Milford Track. Retrieved from https://milfordtrack.net/milford-track-diary-one-trampers-experience-milford-track/

Miller, E., Van Megen, K., \& Buys, L. (2012). Diversification for sustainable development in rural and regional Australia: How local community leaders conceptualise the impacts and opportunities from agriculture, tourism and mining. Rural Society, 22(1), 2-16.

Ministry of Business Innovation and Employment. (2013). New Zealand tourism sector outlook. Retrieved from https://nzier.org.nz/static/media/filer public/84/bd/84bd02f2-13f3-4f4a-8e60fa5aa51de9ec/tourism-forecasts-2013-2019 mbie.pdf

Ministry of Business, Innovation and Employment. (2015). China FIT Visitor Market Research Report [PowerPoint Slides]. 28(3), 217-237.

Ministry of Business, Innovation and Employment. (2016). Tourism and tourism infrastructure in New Zealand. Retrieved from https://www.mbie.govt.nz/assets/8fafb5e9a2/tourism-and-tourisminfrastructure-in-new-zealand.pdf 
Ministry of Business, Innovation and Employment. (2018). New Zealand Tourism Forecasts 2018 2024. Retrieved from https://www.mbie.govt.nz/assets/5c05b7bfce/nz-tourism-forecasts-20182024-report.pdf

Ministry of Business, Innovation and Employment. (2019). New Zealand-Aotearoa Government Tourism Strategy. Retrieved from https://www.mbie.govt.nz/dmsdocument/5482-2019-newzealand-aotearoa-government-tourism-strategy-pdf

Ministry of Business, Innovation and Employment. (2019). New Zealand-Aotearoa Government Tourism Strategy Summary of consultation submissions. Retrieved from https://www.mbie.govt.nz/dmsdocument/5483-new-zealand-aotearoa-government-tourismstrategy-summary-of-consultation-submissions

Ministry of Business, Innovation and Employment. (n.d.). Aotearoa New Zealand Government Tourism Strategy. Retrieved from https://www.mbie.govt.nz/immigration-andtourism/tourism/new-zealand-aotearoa-government-tourism-strategy/

Mok, C., \& DeFranco, A. L. (2000). Chinese cultural values: Their implications for travel and tourism marketing. Journal of Travel \& Tourism Marketing, 8(2), 99-114.

Morton, R. (2014). Political economy experiments: introduction. The Economic Journal, 124(574), F129-F130.

Mosedale, J. (2011). Political economy of tourism: A critical perspective / edited by Jan Mosedale. (Contemporary geographies of leisure, tourism, and mobility). Milton Park, Abingdon, Oxon ; New York: Routledge.

National Priorities Projects. (2016). Military Spending by the United States. Retrieved from https://www.nationalpriorities.org/campaigns/military-spending-united-states/

Naughton, B., \& Tsai, K. S. (Eds.). (2015). State capitalism, institutional adaptation, and the Chinese miracle. Cambridge University Press.

New Zealand China Council. (2019). Statistics. Retrieved from https://nzchinacouncil.org.nz/statistics/

New Zealand Foreign Affairs and Trade. (n.d.). China. Retrieved from https://www.mfat.govt.nz/en/countries-and-regions/north-asia/china/

New Zealand Story. (2018). CHINA COUNTRY PERCEPTIONS RESEARCH PRESENTATION. Retrieved from https://toolkit.nzstory.govt.nz/assets/243584 
New Zealand Trade and Enterprise. (2017). The New Zealand Story Briefing for the Incoming Minister. Retrieved from https://www.nzte.govt.nz/-/media/NZTE/Downloads/About-us/Briefingsto-incoming-ministers/New-Zealand-Story-Briefing-to-Incoming-Ministers-Oct-2017.pdf

New Zealand Trade and Enterprise. (n.d.). New Zealand Story Group. Retrieved from https://www.nzte.govt.nz/tools-and-templates/new-zealand-story-group

Nicolas, F., \& Buchanan, D. (2016). China and the global economic order: A discreet yet undeniable contestation. China Perspectives, 106(2), 10-16.

No Author. (2010). Revised code aims to improve NZ experience for Chinese visitors. Xinhua Economic News. Retrieved from

https://go.gale.com/ps/i.do?p=ITOF\&u=vuw\&id=GALE\%7CA228314764\&v=2.1\&it=r

No Author. (2011). An internet with Chinese characteristics; Chinese internet companies. The Economist, 400(8744), 71-72

No Author. (2013). Thailand/China: China's new policy of regulating outbound zero-dollar tours will benefit Thai tourism industry in the long term. Asia News Monitor. Retrieved from http://search.proquest.com/docview/1438690090/

No Author. (2014). CHINESE TOURISTS ARE THE WORLD'S BIGGEST SPENDERS. Market to China. Retrieved from https://www.marketingtochina.com/chinese-tourists-worlds-biggest-spenders/

No Author. (2014). More than half (63\%) of U.S. online shoppers are not familiar with Chinese ecommerce giant Alibaba.com. Chain Store Age, 90(7), 28.

No Author. (2015). Chinese tourists turning off NZ package tours. NZ Herald. Retrieved from https://www.nzherald.co.nz/business/news/article.cfm?c id=3\&objectid=11451178

No Author. (2016). Renewable energy resources. EECA. Retrieved from https://www.eeca.govt.nz/energy-use-in-new-zealand/renewable-energy-resources/

No Author. (2016). Thailand: Govt to beef up campaign against zero-dollar tours. Asia News Monitor. Retrieved from http://search.proquest.com/docview/1825255682/

No Author. (2018). Agriculture. Environment Guide. Retrieved from http://www.environmentguide.org.nz/activities/agriculture/

No Author. (2018). OUTBOUND CHINESE TOURISM AND CONSUMPTION TRENDS. Neilson. Retrieved from

https://www.nielsen.com/content/dam/nielsenglobal/cn/docs/Outbound\%20Chinese\%20Tourism\% 20and\%20Consumption\%20Trends.pdf 
No Author. (2018). Plan and Prepare; Milford Track. Department of Conservation. Retrieved from https://www.doc.govt.nz/globalassets/documents/parks-and-recreation/tracks-andwalks/southland/milford-track-brochure.pdf

No Author. (2019). BuyNZ Online Market. Retrieved from http://www.buynzmarket.org.nz/

No Author. (2019). China to stop issuing individual travel permits to Taiwan. BBC. Retrieved from https://www.bbc.com/news/world-asia-49178314

No Author. (2019). Fishpond. Retrieved from https://www.fishpond.co.nz/

No Author. (2019). How much does it cost to travel to Australia?. Budget Your Travel. Retrieved from https://www.budgetyourtrip.com/australia

No Author. (2019). JD. Retrieved from https://www.jd.com/2017

No Author. (2019). Kiwi Corner Dairy. Retrieved from https://kiwicornerdairy.com/

No Author. (2019). Mightyape. Retrieved from https://www.mightyape.co.nz/

No Author. (2019). Taobao. Retrieved from https://world.taobao.com/

No Author. (2019). Tmall. Retrieved from https://www.tmall.com/

No Author. (n.d.). About Te Rito. Te Puia. Retrieved from https://www.nzmaci.com/schools/te-rito/

No Author. (n.d.). About Te Takapū. Retrieved from https://www.nzmaci.com/schools/te-takapu-orotowhio/

No Author. (n.d.). About Te Wānanga Whakairo. Retrieved from https://www.nzmaci.com/schools/te-wananga-whakairo-rakau-o-aotearoa/

No Author. (n.d.). Accommodation. Japan Guide.com. Retrieved from https://www.japanguide.com/e/e2025.html

No Author. (n.d.). Accommodation. Rough Guides. Retrieved from https://www.roughguides.com/destinations/north-america/canada/accommodation/

No Author. (n.d.) Big Mac Index - Prices Around The World. Retrieved from https://www.worldatlas.com/articles/the-world-s-most-expensive-countries-measured-by-the-bigmac-index.html

No Author. (n.d.). BRICS - Brazil, Russia, India, China, South Africa. Retrieved from http://www.itamaraty.gov.br/en/politica-externa/mecanismos-inter-regionais/7505-brics-brazilrussia-india-china-south-africa 
No Author. (n.d.). Cave World Waitomo. Retrieved from https://www.caveworld.co.nz/

No Author. (n.d.). Discover Rotorua. Retrieved from https://www.rotoruanz.com/visit/home.aspx

No Author (n.d.). Milford Track. Retrieved from https://milfordtrack.net/milford-blog/

No Author. (n.d.). Milford Track winter tramping. Department of Conservation. Retrieved from https://www.doc.govt.nz/globalassets/documents/parks-and-recreation/tracks-andwalks/southland/milford-track-winter-tramping.pdf

No Author. (n.d.). NZ Māori Arts. Te Puia. Retrieved from https://tepuia.com/new-zealand-maoriarts-and-crafts/

No Author. (n.d.) Plan and Prepare; Milford Track. Department of Conservation. Retrieved from https://www.doc.govt.nz/globalassets/documents/parks-and-recreation/tracks-andwalks/southland/milford-track-brochure.pdf

No Author. (n.d.). The geysers of Te Whakarewarewa Valley. Te Puia. Retrieved from https://tepuia.com/news/the-geysers-of-te-whakarewarewa-valley/

No Author. (n.d.). Tongariro National Park. Retrieved from https://www.nationalpark.co.nz/

No Author. (n.d.). Waitomo Caves Discovery Centre. Retrieved from

https://www.waitomocaves.com/

No Author. (n.d.). WHAT IS MATAURANGA MAORI? Manaaki Whenua Landcare Research. Retrieved from https://www.landcareresearch.co.nz/about/sustainability/voices/matauranga-maori/what-ismatauranga-maori

Numbeo. (2019). Cost of Living. Retrieved from https://www.numbeo.com/cost-ofliving/prices by country.jsp

Numbeo. (2019). Price by Country (NZD). Retrieved from https://www.numbeo.com/cost-ofliving/prices by country.jsp?displayCurrency=NZD\&itemld=8

NZ Story. (2018). CHINA COUNTRY PERCEPTIONS RESEARCH PRESENTATION. Retrieved form https://toolkit.nzstory.govt.nz/assets/243584?tags=Market\%20Insights,China\&utm source=eNews| etter\&utm medium=Email\&utm campaign=November\&utm content=China\%20Market\%20Researc h\%20-\%20Heading

NZ Story. (n.d.). Creative Imagery Tips. Retrieved from

https://toolkit.nzstory.govt.nz/assets/264335?tags=creative\%20imagery\%20tips 
Odinye, I. (2012). Western influence on Chinese and Nigerian cultures. OGIRISI: a New Journal of African Studies, 9(1), 108-115.

One News. (2015). Walker dies on Milford Track. Retrieved from https://www.tvnz.co.nz/onenews/new-zealand/walker-dies-on-milford-track-6249499

Ozturk, A. B., \& Van Niekerk, M. (2014). Volume or value: A policy decision for Turkey's tourism industry. Journal of Destination Marketing \& Management, 3(4), 193-197.

Pan, G., Scott, N., \& Laws, E. (2006). Understanding and Sharing Knowledge of New Tourism Markets. Journal of Quality Assurance in Hospitality \& Tourism, 7(1-2), 99-116.

Pavlovich, K. (2003). The evolution and transformation of a tourism destination network: the Waitomo Caves, New Zealand. Tourism Management, 24(2), 203-216.

Pearce, D., \& Schott, C. (2011). Domestic vs outbound booking and channel choice behavior: Evidence from New Zealand. International Journal of Culture, Tourism and Hospitality Research, 5(2), 112-127.

Pearce, P. L., Wu, M. Y., \& Osmond, A. (2013). Puzzles in understanding Chinese tourist behaviour: Towards a triple-C gaze. Tourism Recreation Research, 38(2), 145-157.

Pekkanen, S. M., Ravenhill, J., \& Foot, R. (Eds.). (2014). Oxford handbook of the international relations of Asia. Oxford University Press, USA.

Peltier, D. (2016). Online Travel Booking Grows in China, But Traditional Agents Still Dominate. Skift. Retrieved from https://skift.com/2016/05/20/online-travel-booking-grows-in-china-but-traditionalagents-still-dominate/

Peng, J., \& Xiao, H. (2018). How does smog influence domestic tourism in China? A case study of Beijing. Asia Pacific Journal of Tourism Research, 23(12), 1115-1128.

Petrova, M., Dekhtyar, N., Klok, O., \& Loseva, O. (2018). Regional tourism infrastructure development in the state strategies. Problems and Perspectives in Management, 16(4), 259-274.

Phillip, S., Hunter, C., \& Blackstock, K. (2010). A typology for defining agritourism. Tourism Management, 31(6), 754-758.

Pike, S. (2003). Seasonality in tourism. Tourism Management, 24(3), 346-347.

https://doi.org/10.1016/S0261-5177(02)00078-X

Pineda, J. (2018). China opens embassy in Dominican Republic after break with Taiwan. Reuters. Retrieved from https://www.reuters.com/article/us-dominican-diplomacy-china/china-opensembassy-in-dominican-republic-after-break-with-taiwan-idUSKCN1M12IF 
Poon, A. (1994). The 'new tourism' revolution. Tourism Management, 15(2), 91-92.

Praticò, F. G., \& Vaiana, R. (2012). Improving infrastructure sustainability in suburban and urban areas: Is porous asphalt the right answer? And how?. WIT Transactions On The Built Environment, $128,673-684$.

Puriri, A., \& McIntosh, A. (2019). A cultural framework for Māori tourism: values and processes of a Whānau tourism business development. Journal of the Royal Society of New Zealand, 49(sup1), 89103.

Regional Tourism New Zealand. (2016). Regional Tourism New Zealand. Retrieved from https://rtnz.org.nz/

Reis, A. C. (2012). Experiences of commodified nature: Performances and narratives of nature-based tourists on Stewart Island, New Zealand. Tourist Studies, 12(3), 305-324.

Richards, J. (1954). Waitomo Caves / by J.H. Richards. (2nd ed.). Wellington, N.Z.: Reed.

Richmond, O. P. (2017). The paradox of peace and power: Contamination or enablement?. International Politics, 54(5), 637-658

Ritchie, J. B., \& Crouch, G. I. (1993). Competitiveness in international tourism: A framework for understanding and analysis. World Tourism Education and Research Centre, University of Calgary.

Richter, L. K. (1983). Political implications of Chinese tourism policy. Annals of tourism Research, 10(3), 395-413.

Rosselló, J., \& Sansó, A. (2017). Yearly, monthly and weekly seasonality of tourism demand: A decomposition analysis. Tourism Management, 60, 379-389.

Roser, M. (2019). Tourism. Our World in Data. Retrieved from https://ourworldindata.org/tourism

Rotherham, F. (2015). Wooing China. Noted. Retrieved from https://www.noted.co.nz/money/investment/wooing-china/

Rutherford, H. (2019). Ardern's swift trip to China marks a new political reality in New Zealand. Newshub. Retrieved from https://www.stuff.co.nz/business/111562567/arderns-swift-trip-to-chinamarks-a-new-political-reality-in-new-zealand

Ryan, C. (n.d.). Delivering on our clean and green image. Bright (Wellington, N.Z.), Bright (Wellington, N.Z.). 
Ryan, C., Minghui, S., \& Xiaoyu, Z. (2013). Chinese Tourists and Souvenir Shopping in New Zealand. The China-New Zealand Tourism Research Centre Department of Tourism and Hospitality Management. The University of Waikato Management School.

Ryan, C., \& Pike, S. (2003). Māori-based Tourism in Rotorua: Perceptions of Place by Domestic Visitors. Journal of Sustainable Tourism, 11(4), 307-321.

Safford, T. G., \& Hamilton, L. C. (2012). Demographic change and shifting views about marine resources and the coastal environment in Downeast Maine. Population and Environment, 33(4), 284303.

Sánchez-Zamora, P., Gallardo-Cobos, R., \& Ceña-Delgado, F. (2014). Rural areas face the economic crisis: Analyzing the determinants of successful territorial dynamics. Journal of Rural Studies, 35, 1125.

Schmekal, A. A., \& de Freitas, C. R. (2001). Condensation in Glow-worm Cave, Waitomo, New Zealand. Department of Conservation Science Internal Series, 15, 5-12.

Scoones, I., Amanor, K., Favareto, A., \& Qi, G. (2016). A new politics of development cooperation? Chinese and Brazilian engagements in African agriculture. World Development, 81, 1-12.

Shambaugh, D. L. (2013). China goes global: The partial power (Vol. 111). Oxford: Oxford University Press.

Smith, L. T., Maxwell, T. K., Puke, H., \& Temara, P. (2016). Indigenous knowledge, methodology and mayhem: What is the role of methodology in producing Indigenous insights? A discussion from mātauranga Māori.

Song, H., \& Hsu, C. (2013). The Image of Taiwan as a Travel Destination: Perspectives from Mainland China. Journal of Travel \& Tourism Marketing, 30(3), 253-271.

Song, H., Liu, K. N., \& Huang, Y. T. (2016). Understanding Mainland Chinese tourists' motivation and constraints of visiting Taiwan. Journal of China Tourism Research, 12(3-4), 9.

Sparks, B., \& Pan, G. W. (2009). Chinese outbound tourists: Understanding their attitudes, constraints and use of information sources. Tourism Management, 30(4), 483-494.

Statistia. (2018). Average Hotel Rate in the US since 2005. Retrieved from https://www.statista.com/statistics/195704/average-hotel-room-rate-in-the-us-since-2005/

Statista. (2019). E Commerce in China. Retrieved from https://www.statista.com/study/11567/ecommerce-in-china-statista-dossier/

Statista. (2019). Global travel and tourism industry - Statistics \& Facts. Retrieved from https://www.statista.com/topics/962/global-tourism/ 
Statista. (2019). Internet usage in China - Statistics \& Facts. Retrieved

from https://www.statista.com/topics/1179/internet-usage-in-china/

Statistics New Zealand. (2011). New Zealand in Profile: 2011. Retrieved from

http://archive.stats.govt.nz/browse for stats/snapshots-of-nz/nz-in-profile-2011/imports-

exports.aspx

Statistics New Zealand. (2016). Trade with China nearly tripled in past decade. Retrieved from https://www.stats.govt.nz/reports/trade-with-china-nearly-tripled-in-past-decade

Statistics New Zealand. (2019). Foreign direct investment in New Zealand continues to increase. Retrieved from https://www.stats.govt.nz/news/foreign-direct-investment-in-new-zealandcontinues-to-increase

Stewart, C. (2006). Story: Hot springs, mud pools and geysers. Te Ara. Retrieved from https://teara.govt.nz/en/hot-springs-mud-pools-and-geysers

Sun, A. (2012). The revival of Confucian rites in contemporary China. In Confucianism and Spiritual Traditions in Modern China and Beyond (pp. 309-328). Brill.

Sun, M., Ryan, C., \& Pan, S. (2015). Using Chinese Travel Blogs to Examine Perceived Destination Image: The Case of New Zealand. Journal of Travel Research, 54(4), 543-555.

Sun, Zhang, \& Ryan. (2015). Perceiving tourist destination landscapes through Chinese eyes: The case of South Island, New Zealand. Tourism Management, 46, 582-595.

Sznajderska, A. (2019). The role of China in the world economy: evidence from a global VAR model. Applied Economics, 51(15), 1574-1587.

Tahana, N., \& Oppermann, M. (1998). Māori cultural performances and tourism. Tourism Recreation Research, 23(1), 23-30.

Tamney, J. B. (2012). The Resilience of Confucianism in Chinese Societies. In Confucianism and Spiritual Traditions in Modern China and Beyond (pp. 97-129). BRILL.

Tan L. (2012) Chinese star's wedding boon for tourism. Retrieved from https://www.nzherald.co.nz/nz/news/article.cfm?c id=1\&objectid=10848887

Tan, L. (2018). \$10 to visit Mission Bay: China tourists get fleeced instead of a bargain from rogue tour operators. NZ Herald. Retrieved from

https://www.nzherald.co.nz/nz/news/article.cfm?c id=1\&objectid=12095049

Tan, L. (2018). Local Chinese tour businesses wage war against unlicensed operators. NZ Herald. Retrieved from https://www.nzherald.co.nz/nz/news/article.cfm?c id=1\&objectid=12093802 
Tang, X. (2017). The historical evolution of China's tourism development policies (1949-2013)-A quantitative research approach. Tourism management, 58, 259-269.

Tang, Z. (2015). An integrated approach to evaluating the coupling coordination between tourism and the environment. Tourism Management, 46, 11-19.

TAANZ. (n.d.). TAANZ Code of Ethics \& Practice. Retrieved from https://taanz.org.nz/

Taylor, J. B. (2016). The role of the Chinese economy in the world economy: A US perspective. China Economic Review, 40, 281-chung285.

Te Ara. (n.d.). Story: Tourist industry. Retrieved from https://teara.govt.nz/en/tourist-industry

Tew, C., \& Barbieri, C. (2012). The perceived benefits of agritourism: The provider's perspective. Tourism Management, 33(1), 215-224.

Tianchen, L. (2003). Confucian ethics and the environment. Culture Mandala, 6(1), 5856.

Thailand/China: China's new policy of regulating outbound zero-dollar tours will benefit Thai tourism industry in the long term. (2013). Asia News Monitor, p. Asia News Monitor, Oct 3, 2013.

The Nordics. (2018). Chinese Market Segment: High Spending FITs May 2018 Opportunities and Challenges for Nordic Destinations. Retrieved from http://www.tourismstat.gl/resources/reports/en/r23/Chinese Market Opportunities and Challeng es 07082018.pdf

THL. (2010). Waitomo Glowworm Caves Visitor Centre rises from the ashes. Retrieved from https://www.explorecentralnorthislandnz.com/wpcontent/uploads/2012/02/Waitomo Glowworms.pdf

The World Bank. (2019). China Overview. Retrieved from https://www.worldbank.org/en/country/china/overview

Tongariro National Park Villages. (n.d.). Retrieved from https://www.nationalpark.co.nz/

Tourism Industry Aotearoa. (2016). Addressing New Zealand's most pressing local tourism infrastructure needs. Retrieved from https://tia.org.nz/assets/Uploads/4d868a4517/TourismInfrastructure-Executive-Summary4.pdf 
Tourism Industry Aotearoa. (n.d.). Quick Facts and Figures. Retrieved from https://tia.org.nz/aboutthe-industry/quick-facts-and-figures/

Tourism New Zealand. (2009). Pure As; Celebrating 10 years of $100 \%$ Pure New Zealand. Retrieved from https://www.tourismnewzealand.com/media/1544/pure-as-celebrating-10-years-of-100-pure$\underline{\text { new-zealand.pdf }}$

Tourism New Zealand (2017). Four Year Strategic Plan.

Tourism New Zealand. (2017). Special Interest. Retrieved from

https://www.tourismnewzealand.com/markets-stats/sectors/special-interest/skiing/

Tourism New Zealand. (2017). Tourism New Zealand Statement of Intent FY18 - FY21. Retrieved from https://www.tourismnewzealand.com/media/3260/statement-of-intent-fy18-fy21.pdf

Tourism New Zealand. (2017). Year ends on high for tourism numbers. Retrieved from https://www.tourismnewzealand.com/news/year-ends-on-high-for-tourism-numbers/

Tourism New Zealand. (2018) China, Market information about our Visitors and our Active Considerers. Retrieved from https://www.tourismnewzealand.com/media/3418/china-visitorinformation.pdf

Tourism New Zealand. (2018). China Market Snapshot. Retrieved from https://www.tourismnewzealand.com/media/2590/china-market-snapshot.pdf

Tourism New Zealand. (2018). Germany FY18 H2. Retrieved from

https://www.tourismnewzealand.com/media/3645/germany-insights-h2-fy18.pdf

Tourism New Zealand. (2018). United Kingdom FY18 H2. Retrieved from

https://www.tourismnewzealand.com/media/3647/uk-insights-h2-fy18.pdf

Tourism New Zealand. (2018). United States of America. Retrieved from

https://www.tourismnewzealand.com/media/3422/usa-visitor-information.pdf

Tourism New Zealand (2018). Visitor Experience Infographic April 2018. Retrieved from

https://www.tourismnewzealand.com/media/3423/visitor-experience-infographic-april-2018.pdf

Tourism New Zealand. (2019). About the tourism industry. Retrieved from

https://www.tourismnewzealand.com/about/about-the-tourism-industry/

Tourism New Zealand. (2019). About the Tourism New Zealand. Retrieved from

https://www.tourismnewzealand.com/about/about-the-tourism-

industry/\#targetText=Data\%20and\%20statistics\&targetText=Total\%20tourism\%20expenditure\%20w 
as $\% 20 \% 2439.1$,billion)\%20from\%20the\%20previous $\% 20$ year. \&targetText=216\%2C012\%20people\%2

Owere\%20directly\%20employed,percent $\% 20$ from\%20the\%20previous\%20year.

Tourism New Zealand. (2019). Approved Destination Status. Retrieved from

https://www.tourismnewzealand.com/tools-for-your-business/china-market-

development/approved-destination-status/

Tourism New Zealand. (2019). China. Retrieved from

https://www.tourismnewzealand.com/markets-stats/markets/china/

Tourism New Zealand. (2019). Markets \& Stats. Retrieved from

https://www.tourismnewzealand.com/markets-stats/

Tourism New Zealand. (2019). What We Do. Retrieved from

https://www.tourismnewzealand.com/about/what-we-do/campaign-and-activity/

Tourism New Zealand. (2020). Approved Destination Status. Retrieved from

https://www.tourismnewzealand.com/media/3819/tour-guide-list-16-jan-2020.pdf

Tourism New Zealand. (n.d.). Australia. Retrieved from

https://www.tourismnewzealand.com/media/3417/australia-visitor-information.pdf

Tourism New Zealand. (n.d.). China Visitor Information. Retrieved from

https://www.tourismnewzealand.com/media/3418/china-visitor-information.pdf

Tourism New Zealand. (n.d.). Japan. Retrieved from

https://www.tourismnewzealand.com/media/3420/japan-visitor-information.pdf

Tourism Strategy Group. (2010). New Zealand Tourism Strategy 2010. Retrieved from

http://gdsindexnz.org/wp-content/uploads/2019/04/102.-

New Zealand Tourism Strategy 2010.pdf

Tourism Queensland. (2013). Meeting the expectations of your Chinese visitors and making them feel welcome. Retrieved from https://cdn-

teq.queensland.com/ /media/15c4dcb13eb643f0b1eb0931a9cb3eae.ashx?la=en-

au\&vs $=1 \& d=20140515 T 115458$

Trading Economics. (2019). New Zealand Imports from China. Retrieved from

https://tradingeconomics.com/new-zealand/imports/china

Travel China Guide. (2018). 2017 China Tourism Facts \& Figures. Retrieved from

https://www.travelchinaguide.com/tourism/2017statistics/ 
Trivett, V. (2013). Rise of the Chinese Independent Traveller. Retrieved from https://skift.com/wpcontent/uploads/2013/09/skift-chinese-traveler.pdf

Tse, T. S. (2013). Chinese outbound tourism as a form of diplomacy. Tourism Planning \& Development, 10(2), 149-158.

Tsujimoto, N. (2017). The purchasing behaviour of Chinese tourists at popular visiting areas in Japan. Journal of Global Tourism Research, 2(2). 99-104.

Turk, M. (2015). Vertical Integration. Computing in Science \& Engineering, 17(1), 64-66.

https://doi.org/10.1109/MCSE.2015.27

UNWTO. (2014). Global Report on Shopping Tourism. Retrieved from

http://cf.cdn.unwto.org/sites/all/files/pdf/am9-shopping-report v2.pdf

Upton-McLaughlin, S. (2015). Baijiu: the Misunderstood Drink of China. Retrieved from https://chinaculturecorner.com/2015/01/12/drink-baijiu-and-do-business-in-china/

Usui, R., Wei, X., \& Funck, C. (2018). The power of social media in regional tourism development: a case study from Ōkunoshima Island in Hiroshima, Japan. Current Issues in Tourism, 21(18), 20522056.

Van Beynen, P. E., \& Bialkowska-Jelinska, E. (2012). Human disturbance of the Waitomo catchment, New Zealand. Journal of environmental management, 108, 130-140.

Valente, F., Dredge, D., \& Lohmann, G. (2015). Leadership and governance in regional tourism. Journal of Destination Marketing \& Management, 4(2), 127-136.

Vargas-Sánchez, A., Porras-Bueno, N., \& de los Ángeles Plaza-Mejía, M. (2014). Residents' attitude to tourism and seasonality. Journal of Travel Research, 53(5), 581-596.

Veset, M. (n.d.). What is International Political Economy?. Retrieved from http://www2.ups.edu/ipe/whatis.pdf

Wall, G., \& Zhao, N. R. (2017). China's red tourism: communist heritage, politics and identity in a party-state. International Journal of Tourism Cities, 3(3).

Walliss, J. (2014). Transformative Landscapes: Postcolonial Representations of Ulu r u-Kata Tju ta and Tongariro National Parks. Space and Culture, 17(3), 280-296.

Walt, S. M. (2018). Rising powers and the risks of war: A realist view of Sino-American relations. Will China's Rise Be Peaceful? Security, Stability, and Legitimacy.

Walter, L. (2019). Government raises interference concerns with China. Retrieved from https://www.stuff.co.nz/national/politics/114804860/govt-raises-interference-concerns-with-china 
Wang, D., \& Ap, J. (2013). Factors affecting tourism policy implementation: A conceptual framework and a case study in China. Tourism Management, 36, 221-233.

Wang, D., \& Chen, T. (2013). Temporal-spatial change and driving mechanism for regional difference of domestic tourism in China. Chinese Journal of Population Resources and Environment, 11(1), 6978.

Wang, X. (2012). Foreign direct investment and innovation in China's e-commerce sector. Journal of Asian Economics, 23(3), 288-301.

Wang, X., Huang, S., Zou, T., \& Yan, H. (2012). Effects of the high speed rail network on China's regional tourism development. Tourism Management Perspectives, 1, 34-38.

Wang, Y., Weaver, D. B., \& Kwek, A. (2016). Beyond the mass tourism stereotype: Power and empowerment in Chinese tour packages. Journal of Travel Research, 55(6), 724-737.

Wei, H. (2019). Russian firms taking a shine to AliExpress. Retrieved from https://www.chinadaily.com.cn/a/201904/02/WS5ca2cf7aa3104842260b3e77.html

Wilkinson, P. F. (1987). Tourism in small island nations: a fragile dependence. Leisure studies, 6(2), 127-146.

World Economic Forum. (2015). The Travel \& Tourism Competitiveness Report 2015. Retrieved from http://www3.weforum.org/docs/TT15/WEF Global Travel\&Tourism Report 2015.pdf

World Politics Review. (2020). How China's Rise Has Remade Global Politics. Retrieved from https://www.worldpoliticsreview.com/insights/27828/how-china-s-rise-has-remade-global-politics

Worth, O. (2013). Polanyi's magnum opus? Assessing the application of the counter-movement in international political economy. The International History Review, 35(4), 905-920.

Wyman, O. (2016). THE CHANGING FACE OF THE CHINESE TRAVELLER. Retrieved from https://www.oliverwyman.com/content/dam/oliver-wyman/global/en/2016/june/SIN-MKTCND01003 screen singlepagelNT secured.pdf

Wyman, O. (2019). DIGITAL MEDIA PLAYS INCREASING ROLE FOR CHINESE TRAVELERS. Retrieved from https://www.oliverwyman.com/content/dam/oliverwyman/v2/publications/2019/January/digital-media-plays-increasing-role-for-chinese-travelers2.pdf

Xiaoguang, K. (2012). A study of the renaissance of traditional Confucian culture in contemporary China. In Confucianism and spiritual traditions in modern China and beyond (pp. 31-73). Brill.

Yan, X. (2014). From keeping a low profile to striving for achievement. The Chinese Journal of International Politics, 7(2), 153-184. 
Yang, F., \& Tamney, J. (Eds.). (2011). Confucianism and spiritual traditions in modern China and beyond. Brill.

Yang, J. (2009). China in the South Pacific: hegemon on the horizon?. The Pacific Review, 22(2), 139158.

Yang, Y., \& Fik, T. (2014). Spatial effects in regional tourism growth. Annals of Tourism Research, 46, 144-162.

Ye, L., Bose, M., \& Pelton, L. (2012). Dispelling the collective myth of Chinese consumers: a new generation of brand-conscious individualists. Journal of Consumer Marketing, 29(3), 196.

Yu, X., KIm, N., Chen, C. C., \& Schwartz, Z. (2012). Are you a tourist? Tourism definition from the tourist perspective. Tourism Analysis, 17(4), 445-457.

Yuan, L. (2013). Dominican Republic and P.R. China: Exchange, Trade and Investment. 7. Retrieved from https://www.drfellowsprogram.org/reports/dr-china-exchange-eng.pdf

Zeppel, H. (2010). Managing cultural values in sustainable tourism: Conflicts in protected areas. Tourism and Hospitality Research, 10(2), 93-115.

Zhan, L., \& He, Y. (2012). Understanding luxury consumption in China: Consumer perceptions of best-known brands. Journal of Business Research, 65(10), 1458.

Zhang, H. Q., Chong, K., \& Ap, J. (1999). An analysis of tourism policy development in modern China. Tourism Management, 20(4), 477.

Zhang, T., \& Zou, H. F. (1998). Fiscal decentralization, public spending, and economic growth in China. Journal of public economics, 67(2), 221-240.

Zhang, Y., Bian, J., \& Zhu, W. (2013). Trust fraud: A crucial challenge for China's e-commerce market. Electronic Commerce Research and Applications, 12(5), 299-308.

Zheng, C. (2016). China debates the non-interference principle. The Chinese Journal of International Politics, 9(3), 349-374.

Zheng, T. (2018). A study of Chinese Free Independent travellers' motivations and their preferred accommodation types in New Zealand (Doctoral dissertation, Auckland University of Technology).

Zhou, K. Z., Su, C., \& Bao, Y. (2002). A paradox of price-quality and market efficiency: a comparative study of the US and China markets. International Journal of Research in marketing, 19(4), 349-365.

Zhou-Grundy, Y., \& Turner, L. W. (2014). The challenge of regional tourism demand forecasting: the case of China. Journal of travel research, 53(6), 747-759. 
Zhu, D., Xu, H., \& Jiang, L. (2015). Behind Buying: The Chinese Gaze on European Commodities. Asia Pacific Journal of Tourism Research, 21(3), 1-19.

Zhu, S., \& Chen, J. (2016). E-commerce use in urbanising China: The role of normative social influence. Behaviour \& Information Technology, 35(5), 1-11.

Zhu, T.,rutherford \& Pearson, M. (2013). Globalization and the role of the state: Reflections on Chinese international and comparative political economy scholarship. Review of International Political Economy, 20(6), 1215-1243.

Zhu, Y. (2013). Making sense of Canada's public image in China. Journal of American-East Asian Relations, 20(2-3), 269-285. 